\title{
STUDIES ON THE INTERACTION \\ OF DESOXYRIBONUCLEIC ACID \\ WITH ACRIFLAVINE
}

\section{DISSERTATION}

\section{Presented in Partial Fulfillment of the Requirements for the Degree Doctor of Philosophy in the Graduate school of the Ohio state University}

By

HARRIET GERLETZ HEILWEIL, B.A., M.S.

The Ohio State University

1954

Approved by:

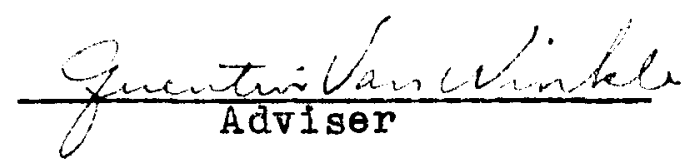




\section{ACKNOWLEDGNENT}

I wish to express my deepest appreciation to my adviser, Professor Quentin Van Winkle, for his unfailing kindness and his guldance throughout my years as a graduate student. I would like to thank the members and staff of the Department of Chemistry for their help and support and for giving me the opportunity to pursue my studies.

This work is dedicated to my husband, Israel, without whose encouragement and devotion it could not have been completed. 
TABLE OF CONTENTS

PAGE

I. INTRODUCTION . . . . . . . . . . . . 1

II. BACKGROUND . . . . . . . . . . . . . 3

A. Interaction studies. . . . . . 3

B. Structure and Properties of DNA. . . 10

C. DNA Interaction Siudies in

the Literature . . . . . . . .

III. THEORETICAL CONSIDERATIONS IN POLY-

PLECTROLYTH INTERACTION STUDIFS. • • . • . 24

A. Multiple Equilibria and the

Law of Mass Action... . . . .

25

B. The Method of Steiner for the

Determination of $k_{i} \cdot c^{*} \cdot \cdot \cdot \cdot \cdot \cdot$

27

C. The Method of Scatchard for the

Determination of $k_{i}$. . . . . 28

D. The Cases of one and Two Intrinsic

Association Constants. . . . . .

30

E. Proposed Relations Between Intrinsic Association Constant.s. . . . . .

F. Fluorescence Quenching: Upon Interaction ......... . . .

IV . EXPERIMENTAL PROCEDURES. . . . . . . . 41

A. Preparation and Properties of DNA. - 41

B. Puripication and Properties of Acriflavine. . . . . . . . .

C. Equilibrium Dialysis Procedure . . 50

D. The Procedure for Partition Analysis 54

E. The Measurement of Fluorescence Quenching............. 
V. EXPER IMENTAI RESUITS . . . . . . . . 64

A. Qualitative Results with Several Cationic Compounds....... . 64

B. The DNA-Acriflavine System: Partition Analysis Results . . . . 66

C. The DNA-Acriflavine: Fluorescence Quenching Results . . . . . . 86

VI. DISCUSSION • • • • . • • • • . • • . 97

VII. SUMMARY. . . . . . . . . . . . . 106 APPENDIX . . . . . . . . . . . . . . . . 109 


\section{INTRODUCTION}

An ever increasing proportion of the researches on polyelectrolytes appearing in the literature in recent years have been more or less quantitative studies of the interation of polyelectrolytes of many types with substances ranging from simple inorganic ions to other polyelectrolytes. The immediate object of the present investigation was to study the interaction of a highly polymerized preparation of the naturally occurring polyelectrolyte desoxyribonucleic acid (DNA) with a simple, we1l-defined, organic cation, employing techniques suitable for the system chosen. It was desired to obtain quantitative information as to the degree and strength of the binding of the cation by DNA and the thermodynamic constants of the reaction at several values of the experimental variables, ionic strength, pH, and temperature, preferably as a result of two or more independent experimental and theoretical approaches. After some searching, the fluorescent dye acriflavine, 3,6-diamino-10methyl-acridinium chloride, was selected as the cationic interactant, and its complexing with DNA isolated from calf thymus was studied as a function of component concentrations and environmental conditions both by means of the distribution of the unbound dye between the aqueous phase and an immiscible organic solvent and by means of the quenching 
of the fluorescence of the dye on its interaction with DNA. It is believed that a body of data on the interaction of desoxyribonucleic acids from various sources with a large variety of molecules would supplement physicochemical measurements on DNA alone and might yield valuable information concerning as yet unknown details of DNA structure and concerning its macromolecular configuration in solution and, particularly, in the nuclel of living cells. Further, from such accumulated data, taken under diverse experimental conditions, a great deal might be learned concerning the mode of interaction of DNA with proteins and other biological substances, the nature of the forces involved, the environmental conditions favoring interaction, and, ultimately, the role of DNA in cell metabolism and in mitosis and meiosis. 


\section{BACKGROUND}

\section{A. Interaction Studies}

By far the largest number of polyelectrolyte interaction studies are concerned with the interactions of proteins, and a great many of these have been thoroughly reviewed and evaluated by Klotz (1), by Goldstein (2), who dealt particularly with pharmacological interactions, and by Putnam, in articles on interactions with detergents (3) and on protein denaturation (4). Besides answering the specific questions at which they were directed, these studies, taken as a whole, have made significant contributions to research on the interactions of polyelectrolytes in general. First, quite a number of experimental methods have been developed for the detection of interaction with a macromolecule and its quantitative evaluation in various types of complexing systems. Second, theoretical treatments of binding by polyelectrolytes have appeared and

(1) I. M. Klotz, in The Proteins, Vol. I, Part B, eds. H. Neurath and K. Balley, Academic Press, New York, p. 727 (1953).

(2) A. Goldstein, J. Pharmacol. Exptl. Therap. 25, 102 (1949).

(3) F. W. Putnam, Advances in Protein Chem. 4, 79 (1948).

(4) F. W. Putnam, in The Proteins, Vol. I, Part B, eds. H. Neurath and K. Bailey, Academic Press, New York, p. 807 (1953). 
have been expanded and modifled so that increasingly complex types of interactions have been accounted for satisfactorily. Some of the concepts gleaned from the work on proteins, especially on relatively pure and well-characterized proteins, are of general applicability. While most of the interactions studied are basically electrostatic in nature, affinity is enhanced when the structure of the interactant molecule offers opportunities for secondary binding: Indeed, secondary forces alone are sometimes sufficient to permit the binding of neutral molecules by proteins (5). Whenever the interaction of a polyelectrolyte is under consideration, careful attention must be given to the factor of competition of other substances present in solution for the binding sites involved. The buffer ions, impurities, even the solvent itself may compete with the interactant under study to an extent dependent upon the relative affinities of the substances for the binding sites on the polyelectrolyte and the relative concentrations present. Studies of competitive bindinfs or of the binding of one substance by means of its displacement of another may be very instructive, except that, as Karush has pointed out (6), such studies are greatly complicated by the fact that two

(5) I. M. Klotz and J. Ayers, Disc. Far. Soc. 13, 189 (1953).

(6) F. Karush, J. Am. Chem. Soc. 12, 2714 (1950). 
interactants may have widely different affinities for particular sites on the polyelectrolyte. Although a great many opportunities remain unexploited, a good beginning has been made toward uncovering detailed structural features of proteins by studying their complexing properties. Data is being amassed on the relative affinities of proteins for organic molecules differing in size, nature of reactive group, substituent position, and so forth $(7,8,9)$. Hypotheses have been advanced to account for these differences in reactivity and, also, for the differences in the binding capacity of different proteins for the same substance in the reversible, non-specific sort of interaction which is emphasized in the reviews mentioned. Among these hypotheses we may note two which attempt to explain the remarkable affinity of serum albumins for a large number of unrelated anions: that of Klotz and his coworkers (10) suggesting that the low content of serum albumins in hydroxyl groups precludes internal hydrogen bonding with the amino and carboxy 1 groups needed for electrostatic binding; and that of Karush (11) proposing

(7) J. D. Teresi and J. M. Luck, J. Biol. Chem. 174, 653 (1948).

(8) I. M. Klotz, J. Am. Chem. Soc. 68, 2299 (1946).

(9) I. M. Klotz, R. K. Burkhard, and J. M. Urquhart, J. Phys. Chem. 56, 77 (1952).

(10) I. M. Klotz, Cold Spring Harbor Symp. Quant. Biol. 14, 97 (1950).

(I1) F. Karush, J. Am. Chem. Soc. 72, 2705 (1950). 
an unusual configurational adaptability for serum albumins that would permit them to accommodate interactant molecules of many sizes and shapes. In contrast, extensive study in the field of the extremely specific immunological reactions (12, 13) has yielded, In accordance with the general "lockand-key" concept, quite detailed ideas about specific and, presumably, very rigid configurations on the surfaces of individual proteins complementary to the structures of the particular haptens with which they interact (14). Similar structural information should arise from studies of the intermediate enzyme-substrate complexes, which likewise involve specific interactions. It is evident that the factors mentioned here, steric factors, degree of macromolecular flexibility, and requirements for special configurations In the neighborhood of binding sites will be as important in interpreting any polyelectrolyte interaction as they have been found to be in studying binding to proteins. Research on the interactions of natural polyelectrolytes other than proteins and of synthetic polyelectrolytes is still in the beginning stages. A review of some of the recent polyelectrolyte interaction studies is

(12) K. Landsteiner, The Specificity of Serological Reactions, Harvard University Press, Cambridge, Mass. (1945).

(13) W. C. Boyd, in The Proteins, Vol. II, Part B, eds. H. Neurath and K. Bailey, Academic Press, New York, p. $(1954)$.

(14) I. Pauling, Endeavor I, 43 (1943). 
included in the report from this laboratory on a light scattering investigation of the interaction between egg albumin and a synthetic cationic polyelectrolyte (15), and the relatively meager literature on binding by nucleic acids will be examined at the end of this section.

The equilibrium methods which have been developed for the study of reversible, non-specific associations giving rise to stable complexes can be divided into two groups $(1,2)$. One group depends upon alteration of the properties of a macromolecule: $\mathrm{pH}$ changes in the case of proteins and other polyampholytes, changes in spectra, refractive index, light scattering, or optical rotation, changes in osmotic pressure, viscosity, surface tension, sedimentation or electrophoretic properties, etc. The other group takes advantage of changes in the properties of a small interacting, molecule on interaction: increase In solubility of a slightly soluble substance, decrease in electrical mobility of an ion, decrease in diffusion current in polarographic reduction, or changes in diffusion properties, spectrum, or biological activity. In certain cases, It is possible to measure the concentration of unbound low molecular weight interactant, either by means of a suitable electromotive cell or by separating and analyzing a polymerfree portion of the solution. The separation is sometimes

(15) I. J. Heilweil, Doctoral Dissertation, The Ohio state Unive:rsity (1954). 
effected by ultrafiliration or ultracentrifugation, but, more usually, quantitative information is obtained by equilibrium dialysis or partition analysis.

In the equilibrium dialysis technique (16), the macromolecule is confined on one side of a membrane impermeable to it but fully permeable to the small interactant molecules. When equilibrium has been attained, the unbound low molecular weight interactant is distributed across the membrane in accordance with the Donnan equation, so that the total amount of unbound substance may be calculated if the polymer-free solution is analyzed and the volumes on both sides of the membrane are known. The amount bound is then easily obtained from the total amount of interactant present in the system. In most studies involving ionic interactants, the Donnan effect is made negligible by the adition of simple electrolytes, but it must be kept in mind that the results obtained for the thermodynamic constants of the reaction in such experiments are, because of competition for binding sites by the added ions, a function both of the foric strength of the medim and of the nature of the specific ions added. Quite often, the membrane takes up considerable amounts of the dialyzing component, so that control experiments must be run to determine a

(16) I. M. Klotz, F. M. Walker, and R. B. Pivan, J. Am. Chem. Soc. 68, 1486 (1946). 
correction for this adsorption. If the membrane uptake does not vary too greatly from membrane to membrane, the accuracy of the equilibrium dialysis technique depends only upon the accuracy of the method of analyzing for the interactant. Partition analysis, recently adapted for the study of the interactions of macromolecules by Karush (17), involves the distribution of one of the interactants between the aqueous phase and an 1mmiscible liquid in which the second interacting species, usually a polyelectrolyte, is insoluble. The concentration of the distributed species is determined in the organic phase, and the concentration of unbound substance in the aqueous phase is calculated by means of the separately determined partition coofficient. Inherent in the mothod is the assumption that the partition coefficient for the free interactant is not changed by the presence of the polyelectrolyte in the aqueous phase. Furthermore, if the organic phase is at all soluble in water, it may, in some cases, compete for binding sites on the polyelectrolyte or alter the binding properties of the polyelectrolyte in some way. Provided that a suitable organic phase can be found, the method offers several advantages. There are no restrictions upon the sizes of the molecules of the two interacting species. Membrane difficulties are avoided altogether, and, since the Donnan effect is absent,

(17) F. Karush, J. Am. Chem. Soc. 13, 1246 (1951). 
determinations may be made at zero or at very low ionic strength. Finally, the time required for equilibration is much shorter than in the equilibrium dialysis method, a factor which could be of considerable importance in working with molecules that are unstable. The details of the application of the se methods in the present work will be discussed in the section on experimental procedures (IV).

\section{B. Structure and Properties of DNA}

Desoxyribonucleic aciàs, along with associated proteins, are the major constituents of chromosomal material, the material believed responsible for the transmission of hereditary characteristics. They have been isolated for study from many tissues by several methods, some of which have recently been examined by Frick (18). Since the physico-chemical properties of DNA have been found to be very sensitive to factors in their preparation and storage, such as $\mathrm{pH}$, ionic strength, temperature, enzyme inhibition, stirring technique, and many others, the latest preparative procedures have been devised with the aim of producing DNA samples free of contamination, especially by protein and ribonucleic acid, and in a state of polymerization like that existing in vivo, as far as this state can be deduced.

(18) G. Frick, Biochim. Biophys. Acta 13, 374 (1954). 
With the exception of a few details, the chemical structure of DNA has been established by conventional techniques of organic and biochemistry, and the results are presented by Davidson (19) and in a monogreph on nucleic acids (20), both of which contain, as well, references to the vast earlier literature on DNA. A later discussion of some features of chemical structure may be found in a paper by Butier (21). Briefly, it may be said that the DNA chain has a backbone of alternate 2-desoxy-D-ribose and phosphate groups joined through phosphate diester linkages. Each sugar group has attached one of the five purine or pyrimidine bases which have been detected in DNA from many sources, adenine, quanine, thymine, cytosine, and 5-methyl-cytosine. The phosphate ester of the base-gugar glycoside is called a nucleotide, and several thousand nucleotides comprise a DNA molecule. Contrary to earlier opinion, the order of nucleotides is probably irregular, and the exact sequence is still the subject of much speculation. The careful paper chromatographic analyses of Chargaff and his colleagues (22) have revealed certain remarkable regularjities

(19) J. N. Davidson, The Biochemistry of the Nucleic Acids, Methuen and Co., Ltd., London (1950). .

(20) Symp. Soc. Exp. Biol. I (1947).

(21) G. Butler, Can. J. Med. Sci. 31, 222 (1953).

(22) E. Chargaff, C. F. Crampton, and R. Lipshitz, Nature 172, $289(1953)$. 
in the molar contents of the various purines and pyrimidines in DNA: while animal species differ slightly in the amounts of the several bases present in their nuclei, the various tissues from any individuals of the same species have a constant average composition; in every tissue studied, it has been found that the purine content equals the pyrimidine content, the cytosine plus adenine content equals the thymine plus guanine content, and the adenine to thymine and guanine to cytosine ratios are both unity.

In contrast, the macrostructure of DNA is being investigated by the many methods currently being developed for the study of the physico-chemical nature of polyelectrolytes and is still far from being completely elucldated, though congiderable progress has been made of late $(23,24$, 25). Investigations are made on the newer, less degraded preparations of DNA, or, more exactly in neutral solutions, of the sodium salt of DNA, in an effort to clarify such featureg as the amount of chain branching, the degree and manner of intemal hydrogen-bonding, a concept introduced by Gulland and his group in their series of physico-chemical studies (26), the degree and type of electrostatic

(23) Trans. Far. Soc. 50, 290 (1954).

(24) Proc. Nat. Acad. Sci. 40, 747 (1954).

(25) K. G. Stern, Bull. Soc. chim. biol. 34, 648 (1952).

(26) J. M. Gulland, et al., J. Chem. Soc. 1947, $1129 \mathrm{ff.;}$ 1949, $1406 \mathrm{ff}$. 
interaction between neighboring chains, the molecular weight, shape, and degree of chain flexibility, as functions of environmental conditions.

Although the results and interpretations of different workers sometimes seem to conflict, certain general trends of opinion in the recent research may be noted. Most viscosity studies (27) take into account the extraordinarily high structural viscosity of DNA and the consequent necessity for extrapolating to zero shear. Butler and his associates (28), working at very low DNA concentrations at several ionic strengths, present evidence that electrostatic interactions between DNA molecules exist at very low ionic strength. Moreover, sedimentation $(29,30)$ and diffusion (31) studies, also, indicate the existence of intermolecular interactions of some sort down to low DNA concentrations. Because of the high assymmetry of the DNA molecule, recent light scattering work $(32,33)$ has

(27) M. J. Callanan and W. R. Carroll, J. Poly. Sci. 1l, 53 (1953).

(28) J. A. V. Butler, B. E. Conway, and D. W. F. James, Trans. Far. Soc. 50, 612 (1954).

(29) K. G. Stem and S. M. Atlas, J. Biol. Chem. 203. 795 (1953).

(30) V. I. Koentg and J. D. Perrings, J. Coll. Sci. $\underline{8}$, 452 (1953).

(31) J.A. V. Butler and D. W. F. James, Nature 167, 844 (1951).

(32) J. W. Rowen, Biochim. Biophys. Acta 10, 391 (1953).

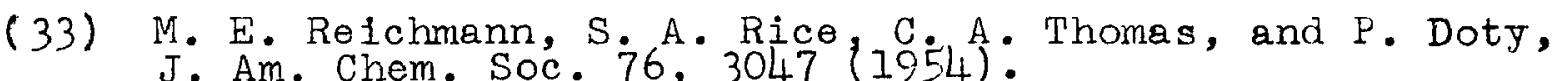


emphasized angular scattering measurements, and the general consensus of opinion appears to be that the molecular weight of highly polymerized samples of DNA are in the range of severalomillions, that the shape is that of a slightly flexible rod or a rather stiff chain even in solutions of a relatively high lonic strength, and that there is a high intermolecular attraction down to the lowest concentrations maasured. Electron microscopical examinations $(34,35)$ seem to confirm that the DNA macromolecule may exist as a long, thin, rather inflexible fiber, but little is as yet known of the effect on the apparent structure of the method of specimen preparation for electron microscopy. A number of $\mathrm{X}$-ray analyses of DNA samples prepared in various ways have yielded several very promising ideas about the structure of the DNA fiber and of concentrated DNA solutions $(36,37,38$, 39). In the most recent interpretations, there seems to be

(34) R. C. Williams, Biochim. Biophys. Acta 9, 237 (1952).

(35) H. Kahler and B. J. Lloyd, Biochim. Blophys. Acta 10, 355 (1953).

(36) W. T. Astbury, Symp. Soc. Exp. Biol. I, 66 (1947).

(37) D. P. Riley and G. Oster, Blochim. Biophys, Acta I, $526(1951)$.

(38) L. Pauling and R. B. Corey, Proc. Nat. Acad. Sci. $39,84(1953)$.

(39) R. E. Franklin and R. G. Gosling, Acta Cryst. $\underline{6}$, $673,678(1953)$. 
agrement that the molecular structure is helical in nature, and there is considerable evidence $(37,39)$ that the macromolecules aggregate, probably through their phosphate groups, to form more or less ordered systems depending upon the water content. Crick and Watson (40) have proposed an exceedingly attractive hypothetical macrostructure for DNA which, while it will no doubt require a good bit of modification and elaboration, appears to be in accord with the general features of the $\mathrm{X}$-ray evidence, the surprising analytical results of Chargaff and his collaborators (2?), and a large part of the reliable physlco-chemical data, including recent observations on infrared absorption (41). In addition, it suggests the outlines of a molecular mechanism, lone sought, for the role of a relatively simple substance Iike DNA in the transmission of a complex system of hereditary factors. The Watson and Crick proposal envisions two polynucleotide chains wound helj.cally about a common fiber axis and joined by hydrogen bonding between pairs of nitrogen bases, one from each chain, whose atoms lie in the same plane approximately perpendicular to the Liber axis. As a consequence of steric considorations, adenine may be faired only with thymine and guanine only with cytosine or

(40) F. H. C. Crick and J. D. Watson, Proc. Roy. Soc. A $223,80(1954)$.

(41) G. Frick and A. Rosenberg, Biochim. Biophys.Acta 13, 455 (1954). 
5-methyl-cytosine; thus, the sequence of nucleotides is determined for one chain by the sequence in the other, but any sequence is permissible on the first chain. It is noteworthy that the sugar phosphate backbone forms the outside of the helix in the proposed structure, so that the phosphate groups occur on the periphery of the helix and are therefore easily accessible for interchain interactions and binding of cations.

\section{DNA Interaction Studies in the Literature The expectation has already been expressed that} accumulated data on the interactions of DNA should ultimately yield information conceming features of macrostructure. This section is intended as a brief summary of some of the interaction studies already in the literature. As in the preceding section, emphasis is glven to investigations of the last few years, which, in turn, will serve as a guide to older researches.

Quantitative studies on the long-recognized association of inorganic cations with the negatively charged phosphate groups of the DNA backbone are just beginning to appear ( 1954 ) and will undoubtedly contribute significantly in the elucidation of the role of salts in intermolecular interactions, enzymatic degradation, competitive interactions, and other phenomena. The extent of binding of 
alkali ions per DNA phosphate group, roughly $0.5^{\circ}$ in neutral solutions, does not appear to depend upon the state of aggregation of DNA $(4.2,43)$. The binding of a series of divalent cations has been studied conductimetrically and by means of the effect of ionic association in lowering the absorption maximum of DNA at $260 \mathrm{mu}(44,45)$. Cavalieri (45) believes that magnesium ions interact both at the DNA phosphate groups and at the nucleotide amino groups. Using viscosity, light scattering, electrophoresis, and equilibrium dialysis techniques, Katz (46) investigated the rather unusual reaction of DNA with mercurlc lons, which is accompanied by aggregation without precipitation in mercuric chloride solutions. The compositions of several of the insoluble rare earth complexes of DNA have been determined (47). The experiments and commentary of Neuberg and Roberts (48) are

(42) J. Shack, R. J. Jenkins, and J. M. Thompsett, J. Biol. Chem. 198, 85 (1952).

(43) A. Veis, J. Phys. Chem. 57, 189 (1953).

(44) J. Shack, R. J. Jenkins, and J.M. Thompsett, J. Biol. Chem. 203, 373 (1953).

(45) I. F. Cavalieri, J. Am. Chem. Soc. 74, 1242 (1952).

(46) S. Katz, J.Am。Chem. Soc. 74, 2233 (1952).

(47) K. G. Stern and M. A. Steinberg, Biochim. Blophys. Acta 11, 553 (1953).

(48) C. Neuberg and I. S. Roberts, Arch. Biochem. 20, $185(1949)$. 
a good indication of the very numerous reactions of DNA with cations and the almost unlimited possibilities for studying them. It appears that Neuberg and Roberts did not consider competitive effects in their discussion of the solubility of water-insoluble DNA complexes in solutions containing relatively high concentrations of alkali ions.

Since the intergctions of DNA with proteins are generally belleved to be primarily electrostatic in nature, perhaps it would not be out of place to mention several such studies at this point. Attempts are often made to discover whether native nucleoproteins and reconstituted nucleoprotein complexes prepared from protein and DNA salts have the same properties at the same concentrations of simple salts: Alexander (49) studied the constitution and behavior of DNA-protamine complexes, and the reassociation of DNA and histone has recently received further attention (50). From their observation that the measured $X$-ray scattering curves of nucleoprotein samples agreed, essentially, with the curves obtained by summation of experimental scattering curves for the individual nucleates and proteinates, Riley and Arndt (51) concluded that the nucleoproteins they

(49) P. Alexander, Biochim. Biophys. Acta 10, 595 (1953). (50) C. F. Crampton, K. Lipshitz, and E. Chargaff, J. Biol. Chem. 206, 499 (1954).

(51) D. P. Riley and U. W. Arndt, Nature 172, 294 (1953). 
studied were addition complexes, linked electrostatically, for the most part, without major structural change in the components. The interaction between calf thymus DNA and bovine serum albumin below pH 5.5 has been studied electrophoretically by Goldwasser and Putnam (52) and by Geiduschek and Doty (53), who made use of recent theoret1cal derivations concerning the application of light scattering to multi-component systems. The indications are that the reaction is in good part electrostatic and that the nucleic acid undergoes little or no change in shape upon association with this protein. Steiner $(5 /)$ studied the interactions between DNA and the proteing serum albumin and lysozyme by means of fluorescence polarization.

In the last decade or two, reports have begun to appear rather frequently in the literature of researches especially designed for the investigation of the interactions in solution between DNA and dyes, drugs, and other small organic ions or molecules. Few general conclusions should as yet be drawn from these studies, not only because relatively few results are available and because the experimental conditions have not always been comparable, but also

(52) E. Goldwasser and F. W. Putnam, J. Phys. Coll. Chem. 54, $79(1950)$.

(53) E. P. Geiduschek and P. Doty, Biochim. Biophys. Acta 9, 609 (1952).

(54) R. F. Steiner, Arch. Biochem. Biophys. 46; 291 (1953). 
because the interactions are often found to depend markedly upon the state of aggregation of the DNA, and the DNA preparations used in the different studies have varied widely. Michaelis $(55,56)$ considered the interaction in solution of various nucleic acids with cationic dyes on the basis of the changes in the absorption spectra of the dyes and inferred that dye cations are bound at the DNA phosphate groups singly or in pairs but probably not as higher aggregates. From the difference in absorption properties of free "methyl green", ethyl hexamethyl para-rosaniline, and of methyl green in combination with DNA, Kurnick and Foster (57) were able to study the stoichiometry of DNA-methyl green complexing. They emphasize that methyl green does not seem to combine with depolymerized DNA (58). Cavalieri and his collaborators were probably the first workers to apply the equilibrium dialysis and partition analysis techniques to the study of reversible interactions of DNA. They studied the Interaction of a DNA sample prepared according to the method of Hammarsten with the dyes rosaniline hydrochloride, closely akin to methyl green, and trimethyl-

(55) L. Michaelis, Cold Spring Harbor Symp. Quant. Biol. 12, 131 (1947).

(56) L. Michaelis, J. Phys. Coll. Chem. 54, I (1950).

(57) N. B. Kurnick and M. Foster, J. Gen. Physiol. 34 , 147 (1950).

(58) N. B. Kurnick, J. Am. Chem: Soc. 16, 417 (1954). 
(p-(p-hydroxy-benzeneazo) -phenyl)-ammonium chloride (59, 60 ) under different conditions of $\mathrm{pH}$, ionic strength, and temperature, and they interpreted the results in terms of two groups of binding sites on DNA, presumably primary and secondary phosphate groups, with differing binding affinities. In several experiments $(60,45)$, the se workers attempted to determine whether magnesium Lons, bovine serum albumin, desoxyribonuclease, and others associate to any significant extent with DNA by measuring the degree of displacement of the dyes from DNA by these substances. As we have noted before, however, such results must be interpreted with a great deal of caution.

The equilibrium dialysis studies of Allenby and Collier (61) on the binding of uncharged thiazines to yeast nucleic acid and to nucleoprotein, while they do not directIy concem us here inasmuch as DNA was not investigated, are of interest because they indicate that binding may occur at sites other than the phosphate groups, sometimes by mechanisms other than coulombic attraction.

Several investigations have been reported of the strong interactions between DNA and quinoline and acridine

(59) L. F. Cavalieri and A. Angelos, J. Am. Chem. Soc. 72, $4686(1950)$.

(60) L. F. Cavalieri, A. Angelos, and M. E. Balis, J. Am. Chem. Soc. 13, 4902 (1951).

(6I) G. M. Allenby and H. B. Collier, Arch. Biochem. Biophys. 38, 147 (1952). 
derivatives. Interactions of this kind may, at least in part, account for the observed effectiveness of acridines in inhibiting, the growth of microorganisms (62), viruses, and even mouse tumors (63). In a comprehensive paper, Albert, et al. (62), analyzed the characteristics of molecular structure in acridine compounds which appear to enhance their antibacteriai activity, and the se observations should be of value in selecting specific compounds for quantitative interaction studies involving well-characterized nucleic acids. According to quantitative spectrophotometric and equilibrium dialysis results (64.65), doubly-charged cationic derivatives of 4-aminoquinoline and 9-aminoacridine, with the positive charges on the ring nitrogen and the diethylamino ritrogen of the rather compljcated aliphatic side chains, associate reversibly and to a considerable extent with highly polyrnerized DNA and nucleoprotein, the affinity being less for yeast nucleic acid. The acridine compound is bound more strongly than the quinoline derivative, and the side chains of these antimalarials are not

(62) A. Albert, S. D. Rubbo, R. J. Colaacre, M. E. Navey, and J. D. Stone, Brit. J. Expt. Path. 26, 160 (1.45).

(63) M. R. Lew1s and P. P. Goland, Am. J. Med. Sc. 215,

(64) F. S. Parker and J. L. Irvin, J. Biol. Chem. 199, 897 $(19,52)$.

(65) J. L. Irvin and E. M. Irvir, J. Biol. Chem. 206, 39 $(1954)$. 
necessary to the interactions. Some time ago, Oster and Grimmson (66) noted spectral shifts implying association of acriflavine and similar compounds with nucleic acids. Cster (67) examined the quenching of the fluorescence of acriflavine and of several other acridines by highly polymerized and commercial preparations of calf thymus DNA and attributed the strong quenching effect, greatest for the most highly polymerized sample, to interaction involving both electrostatic and secondary bonding. Acriflavine has been chosen as the cationic interactant in the quantitative work to be presented here, and fluorescence quenching data is used to derive the constants for the binding by a high molecular weight preparation of DNA according to a hypothesis somewhat different from that of oster. The results are corroborated by independent partition analysis experiments.

(66) G. Oster and H. Grimmson, Arch. Blochem. 24, 119 (1949).

(67) G. Oster, Trans. Far. Soc. 47, 660 (1951). 
III. THEORETICAL CONSIDERATIONS IN POLYELECTROLYTE INTERACTION STUDLES

Quite a few attempts have been made to account theoretically for binding by polyelectrolytes in terms of theories of solutions, theories of adsorption, molecular models, etc. Among the se we may note the application by Schellman (68) of the Bjerrum ion association theory to the binding of spherically symmetrical ions by proteins, with the assumption that the ion pair is shielded by the protein from the polar solvent so that the dielectric constant in the region of the binding site is reduced. Hill (69) has treated the binding in solution of ions or molecules by proteins, or, indeed, by any molecule capable of binding one or more molecules of another kind, on the basis of a recent quantum mechanical general theory of solutions involving all the forces operating in solution between molecules of any kind. From somewhat different considerations, Steiner (70) has derived equations which permit the calculation of the adsorption isotherm for binding by a one-

(68) J.A. Schellman, J. Phys. Chem. 57, 472 (1953).

(69) T. I. Hill, in Ion Transport Across Membranes, ed. H. T. Clarke, Academic Press, New York, p. 189 (1954). (70) R. F. Steiner, J. Chem. Phys. 22, 1458 (1954). 
dimensional array of sites, which could well be a nucleic acid or any other polyelectrolyte molecule, from measurements of the concentration of free adsorbate and estimates of the energies of interaction for first and second nearest neighbor palrs. Theoretical treatments such as these will no doubt be of great value in attempts to deduce a molecular mechanism for interaction in a given system for which experimental data is avaliable and to describe the forces involved. In this section, the discussion will be confined to the bases for the calculations of constants of binding which have been carried out in connection with the experiments to be described.

\section{A. Multiple Equilibria and the Law of Mass} Action (7Ia, 7Ib)

The equilibria involved in the reversible interaction of one molecule (or ion) of species $A$ with a number of molecules (or lons) of species $B$ may be described by the equations

$$
\begin{aligned}
& A+B \rightleftharpoons A B, \quad k_{1}=[A B] /[A]{ }_{0} c \\
& \mathrm{AB}+\mathrm{B} \rightleftharpoons \mathrm{AB}_{2}, \quad \mathrm{k}_{2}=\left[\mathrm{AB}_{2}^{\circ}\right] /[\mathrm{AB}] \mathrm{c} \\
& \vdots \quad=\left[\mathrm{AB}_{2}\right] / \mathrm{k}_{1}[\mathrm{~A}] \mathrm{c}^{2}
\end{aligned}
$$

(71a) J. Bjerrum, Metal Ammine Formation in Aqueous Solution, P. Haase and Son, Copenhagen (194I).

(71b) J. C. SuIlivan and J. C. Hindman, J. Am. Chem. Soc. 74, $6091(1952)$. 


$$
\begin{aligned}
{ }^{A B} B_{n-1}+B \rightleftharpoons A B_{n}, \quad k_{n} & =\left[A B_{n}\right]_{n} /\left[A B_{n-1}\right] c \\
& =\left[A B_{n}\right]_{n} /\left(k_{1} k_{2} \cdots k_{n-1}\right)[A] c^{n}
\end{aligned}
$$

where $n=$ maximum number of molecules of $B$ Bound to a single molecule of $\mathrm{A}$; $i . \theta$, maximum number of sites on $A$ available to $B$ under the conditions of the experiment

$$
\mathrm{k}_{1}=\begin{aligned}
& \text { equilibrium constant for the association } \\
& \mathrm{AB} \\
& i-1+\mathrm{B} \rightleftharpoons \mathrm{AB}_{1}
\end{aligned}
$$

$c=$ molar concentration of unbound $B$

$\left[\mathrm{AB}_{i}\right]=$ molar concentration of the $i^{\text {th }}$ complex, $\mathrm{AB}_{1}$.

Implicit in these equations is the assumption that the sites on $A$ act independently; that is, that the intrinsic affinity of any site for a molecule or ion of $B$ is not affected by the fact that other sites on A have reacted. As is generally the case in Mass Law treatments of multiple equilibria, the thermodynamic activity coefficients have been assumed to be constant at constant ionic strength.

If we define, as a measure of the extent of interaction of $B$ with $A$, the average number of $B$ molecules combined with one A molecule, $r$,

$$
r=\frac{\text { number of moles of bound } B}{\text { total number of moles of } A} \text {, }
$$

then we obtain directly from the Mass Law equations

$$
r=\frac{k_{1} c+2 k_{1} k_{2} c^{2}+\ldots+n\left(k_{1} k_{2} \ldots k_{n}\right) c^{n}}{1+k_{1} c+k_{1} k_{2} c^{2}+\cdots+\left(k_{1} k_{2} \cdots k_{n}\right) c^{n}}
$$

$\circ$ 
If $\mathrm{c}$ and $r$ are determined experimentally, by the equilibrium dialysis or partition analysis methods for example, the successive association constants $k_{1}$ may be calculated in a number of ways, several of which will be described below. Mention may be made here of the development by Steiner (72), from similar Mass Law considerations, of equations for the application of several of the ordinary physicochemical techniques, such as light scattering, electrophoresis, etc., to associating systems in which the macromolecule is polydisperse.

B. The Method of Steiner for the Determination of $k_{i}$

Without any assumption as to the value of $\mathrm{n}$ or as to the relationship between the successive association constants, $k_{1}$, the values of these constants may be obtained quite easily from a series of values of $r$ measured at several values of $c$. In the method devised by steiner (73), the denorinator in the definition of $r$ in equation [3] is set equal to $\lambda$ :

$$
\lambda=1+k_{1} c+k_{1} k_{2} c^{2}+\ldots+\left(k_{1} k_{2} \ldots k_{n}\right) c^{n}
$$

(72) R. F. Steiner, Naval Medical Research Institute Report Project NM 000018.06 .27 , 11, 799 (1953).

(73) R. F. Steiner, Arch. Biochem. Biophys. 47, 56 (1953). 
Then $r$ becomes

$$
r=\frac{c}{\lambda} \frac{d \lambda}{d c}
$$

so that

$$
\ln \lambda=\int_{0}^{c} \frac{r}{c} d c
$$

Values of $\lambda$ at different values of c may be obtained by graphical integration of a plot of $r / c$ versus $c$. The initial slope of a graph of these values of $\lambda$ plotted against $c$ is $k_{1}$, the equilibrixm constant for the binding of the first molecule of $B$,

$$
k_{1}=\left(\frac{d \lambda}{d c}\right)_{c=0}
$$

$k_{1}, k_{2}$, etc., may be obtained by successive differentiation, in accordance with the definition of $\lambda$, but, of course, the degree of accuracy decreases with each step. Much the same method was employed by Fronaeus (73a, 71b) in studying complex ions.

C. The Method of Scatchard for the Determination of $k_{i}$

In a paper by Edsall, et al. (74), on the tetra-coordinated imidazole complexes of zinc and copper, a method developed by scatchard is presented which, if $n$ is

(73a) S. Fronaeus, Acta Chem. Scand. 4, 72 (1950) 
known, allows the rapid determination of the first and last association constants and the estimation of intermediate association constants from data on $r$ and $c$. The method is generally applicable to any system where $n$ sites are available for binding, without regard to the relative values of the association constants.

The quantity $Q$ is defined:

$$
\begin{aligned}
Q= & \frac{r}{(n-r) c} \\
= & \frac{k_{1}+2 k_{1} k_{2} c+\ldots+i\left(k_{1} \ldots k_{1}\right) c^{i-1}+\ldots+\not 1}{n+(n-1) k_{1} c+\ldots+(n-1)\left(k_{1} \ldots k_{1}\right) c^{1}+\ldots+}-[7] \\
& -\frac{n\left(k_{1} \ldots k_{n}\right) c^{n-1}}{\left(k_{1} \cdots k_{n-1}\right) c^{n-1}}
\end{aligned}
$$

From this it follows directly that

$$
\lim _{c \rightarrow 0} Q=k_{I} / n
$$

and

$$
\lim _{\substack{c \rightarrow \infty \\ r \rightarrow n}} Q=n k_{n}
$$

so that, if the data are plotted as $\log Q$ against $r$, the intercepts at $r=0$ and at $r=n$ yield $k_{l}$ and $k_{n}$, respectively. Intermediate association constants are estimated from the limlting slopes of the curve.

The curve of $\log Q$ versus $r$ may have any shape, depending upon the relationships among the values of the $\circ$ association constants. When these are all equal, except 
for statistical factors which will be discussed in the succeeding section, equation [7] becomes $Q=k_{1} / n$ for all values of $c$, and the $\log Q$ plot is a horizontal straight Iine. In the case where the successive constants, after correction in accordance with statistical considerations, bear a constant ratio to one another, the curve is not quite linear and is symmetrical about $n / 2$. Regardless of the shape of the curve, however, the method is suitable whenever extrapolations can be made with sufficient accuracy.

The value of $n$, required for the calculation of Q, may, under favorable clrcumstances, be estimated from a graph of $r$ against $\log c$ (7Ia): Such a curve is asymptotic to $r=0$ at low values of $c$ and to $r=n$ at high values of $c$, and should be syminetrical about $\mathrm{n} / 2$. In many cases, however, measurements cannot be made at free concentrations high enough to determine the shape of the curve accurately. Another way to estimate $n$ will be given below, but this method, too, is inaccurate when data at high c are lacking. It 1 s fortunate that the value of $k_{1}$ obtained from the log Q plot is not very sensitive to the value chosen for $n$.

D. The Cases of One and Two Intrinsic Association Constants

Klotz (75), Scatchard (76), and others have

(75) I. M. Klotz, Arch. Biochem. , 109 (1946).

(76) G. Scatchard, Ann. N. Y. Acad. Sci. 51, 660 (1949). 
treatod the special case in which the intrinsic binding affinity of each site on A for a molecule or ion of $B$ is the same, and the sites are independent. Under these circumstances, the equilibrium constants $k_{1}$ are related to the intrinsic association constant, $K$, the equilibrium constant for the interaction of one molecule of $B$ with any one particular site available on $A$, through a statistical factor (71a):

$$
k_{i}=\frac{n-i+1}{1} k
$$

Thus, when the intrinsic affinities of all sites are equal, the likelihood of interaction decreases as more and more molecules of $B$ are complexed, only because the number of sites left available on the molecule of $A$ is decreased, and the number of possible dissociations is increased. Now, on replacing the constants $k_{i}$ in equation [3] for $r$ by their equivalents in terms of $K$, we obtain for $r$

$$
r=\frac{n K c}{1+K c}
$$

which may be rearranged to give

$$
\frac{r}{c}=n K-K r
$$

Equation [12] Indicates that a plot of $r / c$ against $r$ should be linear, with slope $-K$ and intercepts $n K$, or $k_{1}$ (equation [10]), on the $r / c$ axis, and $n$ on the $r$ axis. It is noteworthy that equation [1I] has the form of the Langmuir adsorption isotherm. 
$\circ$

0

If, for a given system, $r / c$ is not a linear function of $r$, then either the binding sites on $A$ do not act independently, or they differ sufficiently to have different intrinsic affinities for the molecule or ion B, or both of these factors operate. It cannot be emphasized enough that data must be obtained over as wide a range of $r$ as possible, - in order that deviations from linearity will show up signiflcantly. In the case of an ionic interactant B, the affinity of $A$ for a $B$ ion may be altered due to the electrostatic effect of the ions of $B$ already bound. This so-called electrostatic interaction, just one of the possible deviations from statistical binding at sites of equal intrinsic affinity, is often corrected for by the application of a method developed by Scatchard (76).

When the binding, sites on $A$ are independent but have different intrinsic affinities for $B$, equation [3] for $r$ in terms of the equilibrium constants $k_{i}$ is valid, as we have indicated. $r$ may be given, also, in terms of the intrinsic association constants, $K_{i}$

$$
r=\sum_{i=1}^{n} \frac{K_{1} c}{1+K_{1} c}
$$

equation [13] reducing to equation [11] when all the $K_{i}$ 's are equal. Examination of equations [3], [7], and [13] reveals that the intercepts of a plot of $r / c$ versus $r$ on the $y$ and $x$ axes yield, respectively, $k_{l}$ and $n$. In most 
cases, however, the extrapolations, especially the one necessary to obtain $n$, are uncertain because data cannot be obtained over a sufficiently wide range of $r$, and the curvature is often considerable at the ends of the curve. More reliable values of $k_{1}$ are frequently obtained by the methods of calculation of Steiner and scatchard already discussed.

Scatchard, et al. (77), and Karush (11) have been able to fit binding data on the assumption that the sites could be divided into groups, each with a single intrinsic association constant. Equation [13] becomes, for this case

$$
\frac{r}{c}=\frac{n_{1} K_{1}}{1+K_{1} c}+\frac{n_{2} K_{2}}{1+K_{2} c},
$$

and we have the relations

$$
\lim _{\frac{r}{c} \rightarrow 0} x=n=n_{1}+n_{2}
$$

and

$$
\lim _{r \rightarrow 0} \frac{r}{c}=n_{1}{ }_{1}+n_{2} K_{2}
$$

Using two sets of experimental values for $r$ and $c$, preferably taken near the ends of the range of $r$, in equation [14], and the best values for the intercepts $(r)_{r / c=0}$ and $(r / c)_{r=0}$

(77) G. Scatchard, J. H. Scheinberg, and S. H. Armstrong, Jr., J.Am. Chem. Soc. 72 , 540 (1950). 
that can be obtained by a visual fit of the data plotted as $r / c$ versus $r$, we may solve equations [14], [15], and [16] for the four constants of binding and then calculate a theoretical $\mathrm{r} / \mathrm{c}$ versus $\mathrm{r}$ curve. This curve may indicate a better choice of intercepts for a second calculation, and the procedure may have to be repeated several times in order to fit the theoretical curve to the data as closely as possible. Thus, if the two-constant hypothesis accounts for given binding data, the intercepts, and hence the values of $\mathrm{k}_{1}$ and $\mathrm{n}$, as well as the intrinsic binding constants and $\mathrm{n}_{1}$ and $\mathrm{n}_{2}$, are determined so as to be in agreement with all the data available.

\section{E. Proposed Relations Between Intrinsic Association Constants \\ It has been proposed by Karush and Sonenberg} $(78,11)$ that the intrinsic association constants, for some instances of interaction where these differ for the independent binding sites, may be related by a theoretical equation based upon the assumption of a Gaussian distribution of the free energies of binding. This equation involves the two parameters $K_{0}$, the average binding constant, and $\sigma$, a measure of the spread of the values of $K$, the equation reducing to equation [1I] for the one-constant case when

(78) F. Karush and M. Sonenberg, J. Am. Chem. Soc. II, 1369 (1949). 
$6=0$, and it contains an integral which must be evaluated numerically in order to determine a theoretical binding curve using the initially determined values of $\mathrm{K}_{0}$ and $\sigma$. Karush and sonenberg ( 78 ) were able to describe the data for the binding of alkyl sulfates by bovine serum albumin on the basis of this hypothesis. They pointed out that, since binding curves calculated even for high values of $\delta$ do not deviate far from linearity in certain ranges, data limited to such ranges might erroneously be interpreted in terms of a single intrinsic association constant.

Sips $(79,80)$ has derived binding isotherms for systems involving independent sites with differing intrinsic constants by considering several other distributions of the free energies of binding, one of which is very close to a Gaussian distribution. He has obtained expressions in which the integrals have been solved analytically and which have the form of Freundich adsorption isotherms:

$$
\begin{array}{ll}
\frac{r}{n}=\frac{k c^{a}}{1+\frac{k c^{a}}{a}} & (0<a \leqslant 1) \\
\frac{r}{n}=\left(\frac{c}{c+k}\right)^{a} &
\end{array}
$$

where a and $h$ are constants dependent upon temperature. It is evident that both these equations reduce to the Langmuir adsorption isotherm when $a=1$. For some systems, according

(79) R. Sips, J. Chem. Phys. 16, 490 (1948).

(80) R. Sips, J. Chem. Phys. 18, 1024 (1950). 
to Sips, the second equation may contain a sum of terms like that on the right, each with a different value for the constant a.

\section{F. Fluorescence Quenching Upon Interaction} The mechanism of diffusion controlled fluorescence quenching has received a great deal of attention in recent jears, but relatively little seems to have been written concerning the relation between the extent of interaction, in solution, of a fluorescent compound with another substance and the attendant alteration in intensity of fluorescence. On the other hand, protein binding studies have been carried out ( 81 ) utilizing changes in the polarization of fluorescence upon interaction, the phenomenon of fluorescence polarization having been considered from both theoretical and experimental viewpoints by weber (82) and appearing to offer many opportunities for further work. In the present investigation, a number of determinations of fluorescence intensity were made on the DNA-acriflavine system under a variety of experimental conditions, and we shall deal here with several rather simple relationships which have been of use in attempts to interpret these. measurements in terms of interaction constants.

(81) D. J. R. Laurence, Biochem. J. 51, 168 (1952).

(82) G. Weber, Biochem. J. 51, 145, 155 (1952). 
If the quantum yield of fluorescence of a fluorescent molecule in solution differs markedly from the quantum yield of the same molecule when it is bound to some complexing agent, and if the quantum yield per molecule is the same for all bound molecules and remains constant under the same conditions of $\mathrm{pH}$, ionic strength, temperature, etc., independent of the relative concentrations of the two interactants, it would be possible to determine the concentration of free and of bound fluorescent substance in any solution containing the interactants from a measurement of the intensity of the fluorescence of the solution. Under these circumstances, $r / c$ versus $c$ curves could be prepared from fluorescence intensity data alone, in accordance with the following development.

Equation [18] 1s often written to describe the quenching of a fluorescent substance; the particular form used here is taken from a study by Heintz (83) of the dependence of the quenching of the fluorescence of a dye by fractions of a certain synthetic polymer upon the molecular weights of the fractions.

$$
\frac{F_{0}}{F}=\frac{c_{0} \varnothing}{c_{\varnothing}+c_{b} \phi^{t}}=\frac{c_{0}}{c+p c_{b}}
$$

(83) E. Heintz, J. Phys. Radium 15, 219 (1954). 
0

Here, $\quad F_{0}=$ fluorescence intensity of the fluorescent compound at concentration $c_{0}$ when no quencher is present

$F=$ measured fluorescence intensity of the solution containing fluorescent compound at total concentration $c_{0}$ and quencher $\begin{aligned} c_{0}= & \text { initial or total molar concentration of } \\ & \text { fluorescent compound: }\end{aligned}$

$c=$ equilibrium molar concentration of free fluorescent compound

$c_{b}=$ equilibrium molar concentration of bound fluorescent compound

$\varnothing=$ quantum yield of fluorescence per mole of free fluorescent compound

$\phi I=$ quantum yield of fluorescence per mole of bound fluorescent compound

$\mathrm{p}=\phi 1 / \phi=$ ratio of quantum yields of bound and free fluorescent compound, assumed the same for all bound molecules.

Remembering that $c_{0}=c+c_{b}$, it follows that

$$
c=\frac{c_{0}\left(1-\frac{F_{O}}{F}\right)}{\frac{F_{O}}{F}(1-p)}
$$

When $c$ is negligible compared with $c_{b}$, equation [18] becomes

$$
\left(\frac{F Q}{F}\right)_{c=0}=\frac{1}{p} \text {, }
$$

so that $p$ may be determined by measuring $F$ in the presence of large amounts of quencher. Thus, provided $p$ is constant with concentration, then the value of $c$, and consequently of $r$, may be determined for a solution of a given $c_{0}$ and $[A]_{0}$, 
where [A] is the initial or total concentration of quencher, by measuring the fluorescence intensities of three solutions: the solution under consideration, a solution of the same $c_{0}$ but containing no quencher, and a solution at $c_{0}$ containing a large excess of quencher.

Oster (6 $\left.\mathbf{Q}^{7}\right)$ used his data on the quenching of the fluorescence of acriflavine by DNA to determine an equil1brium constant for the reaction

$$
\mathrm{A}+\mathrm{B} \rightleftharpoons \mathrm{AB} \text {, }
$$

where $A$ is DNA, the quencher, and $B$ is the fluorescent dye, acriflavine. If this were the reaction proceeding, $c_{b}$ would be equal to $[A B]$, the equilibrium concentration of complex. An equilibrium constant $K$ could then be written

$$
K=\frac{[A B]}{[A] c}
$$

and equation [18], written in the form

$$
\frac{F_{0}}{F}-1=\frac{(I-p)[A B]}{c+p[A B]} \text {, }
$$

would become, at exceedingly low ccncentrations of quencher when [AB] is insignificant in comparison with $c$,

$$
\left(\frac{F O}{F}-1\right)_{[A B] \rightarrow 0}=(I-p) K[A]
$$

Measurement of the fluorescence intensities of a series of solutions of constant dye concontration $c_{0}$ and quencher concentrations varying from zero to a concentration high enough 
to permit calculation of $p$ according to equation [20] would then give a curve of $\left(F_{0} / F-1\right)$ versus $[A]_{0}$ whose initial slope would yield $K$. The assumption is made that [A] is approximately equal to [A] at relatively low dye concentrations.

In the light of the discussion on the multiple equilibria involved in the binding of small molecules or ions by a macromolecule, it would seem unlikely that equation [21] is adequate to describe the equilibrium situation for the DNA-acriflavine system, except at exceedingly low concentrations of dye. The first complex, $A B$, would be expected to exist alone in equilibrium with free dye and free DNA, with no $A B_{2}, A B_{3}, \ldots, A_{n}$ present, only in solutions very dilute with respect to dye. It is easy to see, then how quenching data may be used to obtain $k_{1}$, the equilibrium constant for the formation of the first complex. Quenching curves, that is, graphs of $\left(F_{0} / F-I\right)$ against $[A]_{0}$, are obtained at several dye concentrations $c_{0}$, as low as is feagible. The inj.tial slopes divided by (1-p) are then plotted against $c_{0}$, the extrapolated value at $c_{0}=0$ being taken as $k_{1}$. At infinitely low dye concentration, toc, the assumption that $[A]=[A]_{0}$ becomes valid. 
IV. EXPERIMENTAL PROCEDURES

A. Preparation and Properties of DNA

The sample of calf thymus DNA, or, more accurately, the sodium salt of DNA, used in the studies to be described was prepared according to the procedure carefully detailed by Schwander and Signer (84). Several additional hints were taken from light scattering studies from Doty's laboratory $(85,86)$. It might be helpful to anyone undertaking the preparation to have a briet outline of the procedure which includes some of the detalls of application that seem worth mentioning.

The thymus glands were removed from the calves not more than twenty minutes after decapitation, immediately cut into small piecrs which were mixed with a large quantity of crushed dry ice, and transported to the laboratory in a tightly-covered Dewar. $450 \mathrm{~g}$. of the frozen tissue was run throngh an aluminum meat grinder, the remainder being stored in the deep-freeze at $-40^{\circ} \mathrm{C}$. for two weeks and used at that time in the preparation of a second batch. The extraction of nucleoprotein from the tissue with $1 \mathrm{M} N \mathrm{Nal}$, the three

(84) H. Schwander and R. Signer, Helv. Chim. Acta 33, 1521 (1950).

(85) P. Doty and B. H. Bunce, J. Am. Chem. Soc. 74, $5029(1952)$.

(86) B. H. Bunce, Doctoral Dissertation, Harvard University (1951). 
precipitations of the nucleoprotein by dilution to $0.14 \mathrm{M}$ NaCl, corresponding to the ionic strength of minimum solubility of nucleoprotein, and the dissociation, precipitation, and filtering of $f$ of the protein portion in saturated Nacl solution, were carried out essentially as described by Schwander and Signer. Since these steps require almost a month during which time it is essential to keep enzymatic degradation to a minfmum, great care was taken to insure that the temperature of the preparation never rose about $0^{\circ} \mathrm{C}$. All the work was carried out in a cold room regulated at $4^{\circ} \mathrm{C}$. The mincing of the still-frozen ground tissue was carried out in a pre-cooled Waring, blendor, each portion of tissue being mixed with partially frozen $1 \mathrm{M} \mathrm{NaCl}$ solution and run for no longer than half a minute (35), so that the blending did not heat the solutions sufficiently to melt all the ice. All solutions used through the final filtration to remove protein were $0.01 \mathrm{M}$ in sodium citrate, the desoxyribonuclease inhibitor recommended by schwander and signer, and all solutions and liqulds were pre-cooled to below $0^{\circ} \mathrm{C}$. before use. At every stage, the glass vessels containing the preparation were kept in ice baths and stirred efficiently to maintain temperature equilibrium, and frozen cubes of saturated $\mathrm{NaCl}$ solution were kept in the $8^{\prime \prime}$ Buchner funnels during the vacuum filtrations to remove protein. For the extensive stirring of large volumes of solutions required throughout the procedure, a Plexiglas 
paddle with two vanes about $5^{\prime \prime} \times 1^{\prime \prime}$ was constructed and used in connection with a variable-speed motor powerful enough to keep the viscous liquids well stirred. The speed of stirring was never greater than 100 revolutions per minute. Alcohol precipitation of the nucleate from the filtered saturated $\mathrm{NaCl}$ solution was facilitated (85) by diluting the nucleate solution $1: 1$ with water before pouring one volume into $11 / 2$ volumes of grain alcohol through a narrow-stemmed funnel. By this method, fine nucleate fibers were formed, and wound about the wooden dowel stirrer rod so that they could be separated from the supernatant very easily. Difficulty was experienced in carrying out the next precipitation of the nucleate redissolved in distilled water by adding one volume of the water solution to two of 95\% alcohol as recommended by Schwander and Signer; analysis of the supernatant of a trial portion treated in this way revealed that over $90 \%$ of the nucleate had remained in solution. Almost complete precipitation was achieved, however, by pouring one volume of the water solution into four of alcohol saturated with $\mathrm{NaCl}$.

The nucleate fibers, after the preliminary drying with absolute alcohol and anhydrous ether, were dried and stored somewhat differently than described by the other authors. In order to avold contamination by desiccants, the preparations were dried in a vacuum desiccator at $4^{\circ} \mathrm{C}$. 
for about a week, using no drying agent. It was felt that the preparations would be best preserved if kept as dry as possible, and so they were stored in covered glass containers at $4^{\circ} \mathrm{C}$. In a desiccator over $\mathrm{P}_{2} \mathrm{O}_{5}$. The $\mathrm{P}_{2} \mathrm{O}_{5}$ was kept in a dish tightly covered with lens paper and was left to settle several hours before each change, so that the dust would not contaminate the nucleate.

The product was in the form of very white, tangled fibrous masses, which were conveniently torn apart for sampling by means of glass needles. In the first preparation, the yield from $450 \mathrm{~g}$. of thymus was $4.0 \mathrm{~g}$. , while, in the second, the same amount of starting material yielded $8.6 \mathrm{~g}$. of dry nucleate, probably because the precipitates were bettor separated from the supernatants the second time when the nature of the substances and the pirocedure were familiar. Schwander and Signer (84) estimated the protein content of their preparations to be well below $1 \%$, and they found the viscosities at several intermediate rates of shear to be higher than those for any of the other preparations studied. Light scattering, studies $(85,33,87)$ indicate, too, that DNA samples prepared according to the schwander and signer procedure are somewhat less degraded than samples prepared by earlier methods. The molecular weight of the first

(87) M. E. Reichmann, R. Varin, and P. Doty, J. Am. Chem. Soc. 74, 3203 (1952). 
sample whose preparation is described above was determined by I. J. Heilweil of this laboratory from angular light scattering measurements made in $0.2 \mathrm{M} \mathrm{NaCl}$. Using his measured refractive index increment of 0.160 , he obtained a molecular weight of $10 \times 10^{6}$.

The Beckman Model DU spectrophotometer with watercooled lamp housing was used in making absorption measurements in the visible and ultraviolet. The extinction coefficients for DNA in doubly distilled water at $259 \mathrm{~m} \mu$, the wavelength of maximum absorption in the ultraviolet, were found to be 248 and $238(100 \mathrm{ml} / \mathrm{g} \cdot \mathrm{cm}$.) at a slit width of $1 \mathrm{~mm}$. for the first and second preparations, respectively. All extinction coefficients are given here in terms of grams of solute per $100 \mathrm{ml}$. of solution. The average deviation of three separate determinations of each value was well under 1\%. Although these values are somewhat higher than earlier ones given in the literature for DNA, recent determinations (33) on simllarly prepared DNA samples have tended to be in agreement with the values reported here. It was determined that Beer's Law is obeyed at $259 \mathrm{~m} \mu$ to concentrations at least as high as 0.005 g./100 $\mathrm{ml}$. At $231 \mathrm{~m} \mu$, the wavelength at which a minimum in the ultraviolet absorption occurs, the extinction coefficients were determined to be 92.8 and 89.4 , the ratio

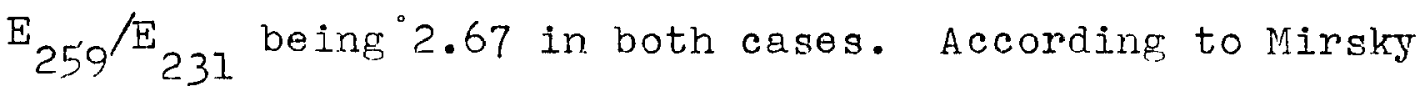


and Pollister $(88)$, a ratio as high as this indicates low protein content. The extinction coefficient in $0.2 \mathrm{M} \mathrm{NaCl}$ was found to be 204 for the first sample, the ratio of the coefficient in water to that in $0.2 \mathrm{M} \mathrm{NaCl}$ being 1.22 , which may be compared with the value of 1.21 obtained by other workers (33).

The extinction coefficients were based upon dry weight of DNA, determined by two independent methods which gave results agreelng within 1\%. One small sample was dried to constant weight in a vacuum oven at $100^{\circ} \mathrm{C}$. for eight days. A second sample of almost two grams was dried at $4^{\circ} \mathrm{C}$. in a vacuum desiccator for about a month and weighed every few days under the same conditions. A drying curve of sample weight versus the reciprocal of dryine time was prepared, so that the dry weight of any sample of DNA could be determined by comparison of its weight with the weight of the reference sample measured under the same conditions of humidity.

DNA solutions used in the studies reported here were prepared from the fibrous solid in the following way: Dissolution in pre-cooled distilled water was achieved by means of magnetic stirring at moderate speeds, for eight to twelve hours in the case of dilute solutions. After the

(88) A. E. Mirsky and A. W. Pollister, J. Gen. Physiol. 30, $117(1946)$. 
concentration of the water solution was determined from duplicate measurements of the absorption at $259 \mathrm{~m} \mu$, appropriate volumes of this DNA solution and of stock buffer solution were diluted with distilled water in a volumetric flask to yield a solution of the desired DNA concentration, $\mathrm{pH}$, and ionic strength. DNA solutions older than one week were discarded; indeed, all major experiments were set up using freshly dissolved DNA.

B. Purification and Properties of Acriflavine Acriflavine, also called euflavine, trypaflavine, and neutral acriflavine, is meant here to refer to 3,6-diamino-10-methyl-acridinium chloride,

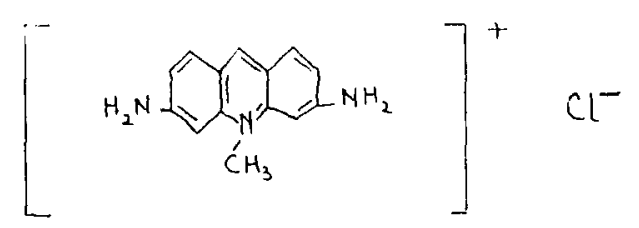

Commercial preparations of acriflavine contain about one third by weight of proflavine hydrochloride, the corresponding unmethylated compound. Since it, was desired to study the binding of a pure compound whose degree of ionization is independent of $\mathrm{pH}$, purification was undertaken according to the method given by Albert (89). Because acriflavine undergoes photooxidation rather rapidly, especially

(89) A. Albert, The Acridines, Edward Arnold \& Co., London, p. 197 (1951). 
in dilute solution, solutions were kept in the dark as much of the time as possible. A total of $45 \mathrm{~g}$. of commercial acriflavine were dissolved in two liters of distilled water, $25 \mathrm{~g}$. of a product of National Aniline and $20 \mathrm{~g}$. from the Abbott Laboratories. Molst silver oxide precipitate was stirred into the solution, the mixture was allowed to stand at $4^{\circ} \mathrm{C}$. in the dark for 24 hours, and the silver precipitate was removed by vacuur filtration at $4^{\circ} \mathrm{C}$. The $\mathrm{pH}$ of the filtrate was adjusted to 7.0 with about $30 \mathrm{ml}$. of $2 \mathrm{~N} \mathrm{HCl}$, and then the solution was concentrated to about $200 \mathrm{ml}$. by vacuum dehydration and, finally, lyophilized to dryness. The dried material was recrystallized twice from bolline methyl alcohol and once from boiling water, and the water was removed by vacuum desiccation at room temperature for two days. The yield was $14.4 \mathrm{~g}$.

In an attempt to determine the efficacy of the purification procedure, paper electrophoresis of the original commercial sample and of the purified material was carried out in $0.1 \mathrm{~N} \mathrm{HCl}$ as described by Lederer (90). Proflavine and acriflavirie should be separated in several hours, the acriflavine moving ahead of the proflavine, but separation could not be detected, either in the original or in the purified samples, although the electrophoresis was allowed to proceed for about 24 hours. The spot

(90) M. Lederer, Anal. Chim. Acta 6, 267 (1952). 
corresponding to the purified sample, however, moved somewhat faster than the one for untreated dye, indicating a higher acriflavine content in the pure material.

Analysis for chlorine, carried out by Miss Mary Renoll of this laboratory, gave $13.52 \%$ chlorine in the purified preparation, which may be compared with $13.65 \%$ calculated for $\mathrm{C}_{14} \mathrm{H}_{14} \mathrm{~N}_{3} \mathrm{Cl}$.

Absorption curves were determined for the purified sample in water and in n-hexanol, the organic phase used in the partition analysis experiments. For these measurements, and for all absorption measurements made on acriflavine solutions, a filter was mounted between the sample and the phototube compartments on the Beckman Du spectrophotometer in the filter holder provided with the attachment for the measurement of fluorescence. This filter had high transmissions in the ultraviolet and blue ranges where acriflavine absorbs but did not transmit the green wavelengths of the flizorescence spectrum. In water, maxima were observed at $263 \mathrm{~m} \mu$ and at $452 \mathrm{~m} \mu$, the extinction coefficients being 1960 and $1640(100 \mathrm{ml} . / \mathrm{g} \cdot \mathrm{cm}$.$) , respectively, the latter measured at$ a slit width of $0.1 \mathrm{~mm}$. These values are based on dry weight of purified acriflavine, obtained by heating the powdered dye to constant weight at $105^{\circ} \mathrm{C}$, and represent the average of several separate determinations which agreed within $1 \%$. The extinction coefficients at $452 \mathrm{~m} \mu$ in buffered solutions 
differ somewhat from the value in distilled water, and these coefficients are given in the appendix with the experimental data for the partition analyses. It was found that the extinction coefficient at $452 \mathrm{~m} \mu$ does not change upon saturating an aqueous solution with n-hexanol. At $452 \mathrm{~m} \mu$, deviations from Beer's Law become significant at concentrations higher than approximately $1 \times 10^{-3} \mathrm{~g} . / 100 \mathrm{ml}$. In $\mathrm{n}$-hexanol, equilibrated against the various buffer solutions used at $25^{\circ} \mathrm{C}$, the absorption maximum for acriflavine occurs at $470 \mathrm{~m} \mu$ in the visible range, and the extinction coefficient was found to be $2340(100 \mathrm{ml} / \mathrm{g}$. cm.) independent of the saturating buffer. In dry $n$-hexanol, the extinction coefficient is roughly 10\% higher. Beer's Law is obeyed for concentrations at least as high as $5 \times 10^{-4} \mathrm{e} / 100 \mathrm{ml}$. in n-hexanol; it was not found necessary to measure soluticns of higher concentration.

\section{Equilibrium Dialysis Procedure} Equilibrium dialysis experiments were run not only to confirm the partition analysis results for the binding of acriflavine by DNA, but also to find out whether other substances interact with DNA to any appreciable extent. A number of techniques were devised to make it possible to determine the concentration of interactants after equilibration spectrophotometrically in the near ultraviolet with 
negligible errors due to traces of DNA and contaminants from various sources.

A known volume of buffered DNA solution of the desired concentration, usually $3-5 \mathrm{ml}$., was confined within a dialysis sack made of Visking cellophane sausage casing, $3 / 4 "$ in extended diameter. Equal lengths of casing were always measured off carefully for each experiment, so that the amount of adsorption on each sack would depend only upon the concentration of dialyzing substance and inherent variations in adsorption properties along the length of the casing as it is manufactured. Because it was found that impurities absorbing quite considerably in the ultraviolet come off the casing and contaminate the solution, and that the contamination is greater at higher ionje strengths, the lengths of casing, were washed before use: several hours in running distilled water, an hour or so in each of three or four changes of buffer ten times as concentrated as that to be used in the experiment, and about an hour in each of three or four changes of the buffer at the concentration to be used. The washing, in buffer was accomplished by mechanical shaking of the casings with an appropriate volume of buffer in a glass-stoppered bottle. It was found that boiling the casing to remove diffusible ultraviolet-absorbing substances often caused the membrane to pass DNA, but the washing procedure described left them impermeable to DNA and resulted in negligible ultraviolet absorption in 
blank dialysis experiments containing only buffer on both sides of the membrane. Rubber gloves were worn in handling the casings, once they were washed. In filling the sacks, precautions were taken that DNA should not be present on the outer surface, and, to remove any traces of DNA that might have spilled over in knotting the casing end, as well as to remove any dialyzable components in the DNA solution, the filled sacks were shaken at $4^{\circ} \mathrm{C}$. With several changes of pre-cooled buffer in a glass-stoppered bottle, usual.ly overnight.

The sacks of DNA solution were then placed in cylindrical, glass pharmaceutical bottles of 30 or $40 \mathrm{ml}$. capacity, each containing a known volume of buffered solution of the interactant under invostigation at a desired concentration. Care was taken to tuck the sacks well under the surface of the liquid so that the whole length of casing would adsorb uniformly. The bottles used had almost leakproof snap-on caps of polyethylene, which was found not to adsorb any of the substances studied nor to give off any objectionable contaminants. Because the cellophane membrane carries an unknown arnount of imbibed and adherent liquid, the total volume of solution in the system was determined by weighing the "bottled" setup, subtracting the weight of the bottle and the average weight of the bottle caps and overdried casing length, and correcting for the presence of buffer salts. 
Controls were set up in the same manner, several bottles containing DNA solution inside the dialysis bag and buffer outside, as checks for possible leakage of DNA into the outer solution, and several containing buffer inside and interactant solution outside, these to be analyzed for equal distribution on both sides of the membrane. In cases where the interactant was adsorbed by the casing to any appreciable extent, blanks of the second kind were prepared so as to cover the entire range of free interactant concentrations, c, to be studied. The amount of interactant adsorbed was plotted versus free interactant concentration so that binding data at any c could be corrected for the loss due to membrane adsorption.

The bottles were shaken lengthwise in a horizontal plane on a mechanical shaker at a speed of about 60 cycles per minute, either in the cold room at $4 \pm 1^{\circ} \mathrm{C}$. or in a constant temperature room at $25 \pm I^{\circ} \mathrm{C}$. The time required for equilibration was determined for each system and was usually about 2.4 hours at $4^{\circ} \mathrm{C}$. Measurable degradation of DNA to dialyzable fractions was not found to occur during this period at the low temperature.

Since the ionj.c strength was at least 0.1 in all runs, so that the Donnan correction was negligible, spectrophotometric analysis of the outer solutions at the appropriate wavelength yielded $r$ in accordance with the equation 


$$
r=\frac{c_{0} V_{0}-c V t-c}{[N A]_{0} V_{1}} \text {, }
$$

where

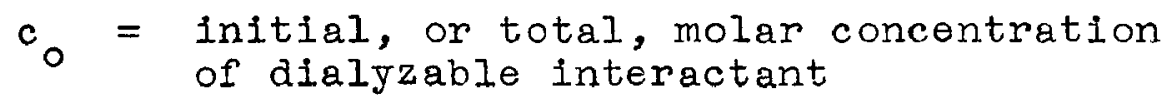

$$
\begin{aligned}
& c=\underset{\substack{\text { equilibrium concentration of free } \\
\text { interactant }}}{c} \\
& {[N A]_{0}=\text { initial, or total, concentration of DNA }} \\
& V_{0}=\begin{aligned}
\text { initial volume of the solution of inter- } & \text { actant placed outside the sack }
\end{aligned} \\
& \mathrm{V}_{1}=\begin{array}{l}
\text { volume of DNA solution placed inside } \\
\text { the sack }
\end{array} \\
& v_{t}=\begin{array}{l}
\text { total volume of solution in the system } \\
\text { determined by weiching }
\end{array} \\
& \mathrm{C}=\text { amount of interactant taken up by the }
\end{aligned}
$$

D. The Procedure for Partition Analysis $N$-hexanol was selected as the organic solvent for the partition analysis study of the DNA-acriflavine system. It was discovered that different batches of Technical Grade n-hexanol, even batches obtained from the same company at the same time, often extracted different amounts of acriflavine from an aqueous solution. As Karush pointed out (17), the indications are that organic acid impurities are responsible for this: a Carbide and Carbon product that yielded a much higher partition coefficient than an Eastman Kodak sample became almost identical with the Eastman sample after it was washed with $\mathrm{NaOH}$; and a much higher 
partition coefficient could be obtained with the Eastman n-hexenol by adding a very small amount of lauric acid. In view of these observations, several batches of Fastman Kodak Technical Grade n-hexanol were combined to give an ample amount for all the experiments reported. A quantity sufficient for all the work planned in a given buffer solution was treated in portions in a separatory funnel as follows, the portions being thoroughiy mixed before any was used: About $200 \mathrm{ml}$. of the commeroial n-hexanol was washed three times with roughly equal volumes of $0.01 \mathrm{~N} \mathrm{NaOH}$, three times with distilled water, and three times with approximately $200 \mathrm{ml}$. portions of the bufrer. A milliliter or two of buffer was added to the combined portions, and the sol-

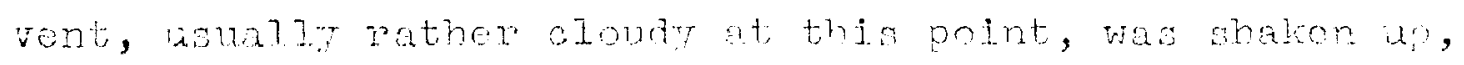
cooled almost to $\mathrm{O}^{\circ} \mathrm{C}$., and then stored at the temperature to be used in the experiment, vecoming clear as j.t warmed. Potassturn phosphate buffers were used exclusively In this investigation, and the concentrations of the salts necessary in a solidion of desired $\mathrm{pH}$ and ionic strenth we calculated according to the data publisher by cxeen (1). A stook solution ten tires as concentrated was then prepared and diluted 1:10 as required. pH measurements were made usuing, the Beckman ModeI G pt meter standardized against Beckman pH 7.00 standard buffer.

(91) A. A. Green, J. Am. Chem. Soc: 55, 2331 (1933). 
Partition analysis equilibrations were carried out in the same polyethylene-capped bottles as were used in the equilibrium dialysis experiments, the caps being unaffected by the n-hexanol and giving very little trouble with respect to leakage. Five milliliters of DNA solution of twice the desired final aqueous concentration and five milliliters of a solution of acriflavine, also at twice the desired aqueous concentration, both in the same buffer, were carefully pipetted into each bottlo. In almost all the experiments, the final DNA concentration was $0.005 \mathrm{~g} . / 100 \mathrm{ml}$., a few determinations at $0.01 \mathrm{E} / 100 \mathrm{ml}$. being made to check the effect of varying the DNA concentration. Since dilute acriflavine solutions were found to decrease in concentration with time, thouk stowly solutions were made up fresh on the day a particular equilibration was to start, and tieir exact concentrations were determined spectrophotometrically either that day or the next. The ranfe of acriflavine concentrations was chosen, for each set of experimental conditions, so that the lowest free dye concentration in the organic phase was measurable with an averace deviation of less than three per cent by the method to be described and the highest concentration was below that which would precipitate the DMA in the aqueous layer. A stock solution of acriflavine was prepared just before use by dissolving an approximately weighed amount of the soljd dye in a known volume of buffer, and this was 
diluted to yield a series of acriflavine solutions at concentrations near those selected so as to give an even spread of $r$ values. To the aqueous phase in the bottle, ten m1]liliters of washed n-hexanol, saturated with buffer at the temperature of the experiment, was added from a buret, slowly so that the liquid would drain.

A series of blanks containing no DNA was prepared in much the same way for the determination of the partition coefpicients of acrifiavine between the two phases. For each dye concentration, ten milliliters of buffer-saturated n-hexanol was added to ten milliliters of acriflavine solution in the buffer under consideration. The acriflavine concentrations were chosen so that the range of concentrations in the oremic lays after equilibration would be about the same as the range in the partition analysis experiments at the same ionic strength, pir, and temperature.

The bottles, carefully capped so as to make a dry seal, were shaken for four hours at $4 \pm 1^{\circ} \mathrm{C}$. or at $25 \pm 1^{\circ} \mathrm{C}$. just as in the equilibrium dialysis runs, except that the bottle rack was coverei to make it light tight.

Benaluse it was necessary to ineasure dye concentrations much lower than could be determined accurately from the absorption at $452 \mathrm{~m} \mu$ or at $470 \mathrm{~m} \mu$, even with absorption cells five centimeters in length, which require rather large volumes of test solutions, analyses were carried out in two ways: spectrophotometrically in $1 \mathrm{cin}$. absorption 
cells for the more concentrated solutions, and by the measurement of the fluorescence intensities of the very dilute ones. The fluorescence measurements were made on an Aminco high sensitivity photometer, American Instrument Company, Silvert Spring, Md., designed by Oster (92), In order that volumes less than $10 \mathrm{ml}$. could be measured, a small cylindrical cell, about $1 \mathrm{~cm}$. in diameter, was cemented to a square base of lucite which just fit into the square recess of the photometer. The cell was fitted with a snug glass cap to hinder evaporation and was painted black over its back surface to minimize reflection and givo a small solvent correction when used with the largest incident and receiver slits available. Instead of standardizing the instrunent arginst a standard fluorescent solution, all fluorescence measurements were made relative to a reading arbitrarily selected for one of the neutral density filters at an anele of $0^{\circ}$ with respect to the transinitted beam: the galvanometer needle was adjusted to read this value with the sample cell removed, the neutral density filter in position, and the phototube at $0^{\circ}$; and then the filled sample cell was set in place, a yellow-ereen exit filter was substituted for the neutral density filter, and the phototube was rotated to the $90^{\circ}$ position for the fluorescence determination. All the fluorescence work was

(92) G. Oster, Anal. Chem. 25, 1165 (1953). 
carried out at about $27^{\circ} \mathrm{C}$. using incident light of wavelength $436 \mathrm{~m}_{\mu}$.

For each buffer studied, two curves were prepared of fluorescence, in arbitrary photometer scale units, versus spectrophotometric extinction values for acriflavine solutions in buffer and in buffer-saturated $n$-hexanol. The series of solutions in each solvent was made up by dilution of a stock solution whose extinction had been carefully determined, the concentration range covered encompassing all the concentrations which would have to be deternined from fluorescence measurements.

Partition coefficients were calculated from concentration determinations in both layers of the series of blanis. It was convenient to expeess the concentrations in terms of extinction values, E, either measured directly or read off from the fluorescence-extinction curves after measuring the fluorescence, and to plot the ratio of the extinction in the n-hexanol layer to that in the aqueous layer, $E_{\text {org. }} / E_{\text {aq. }}$, against the extinction in the organic phase, $E_{o r g} \cdot$ Then, for any partition experiment run under the same environmental conditions, the extinction value corrosponding to the equilibrium concentration of unhound acriflavine in the aqueous layer containing DNA, $E_{\text {aq. }}$ could be obtained from the curve if $E_{\text {org. Were }}$ measured. 
In the case of the experiments at $4^{\circ} \mathrm{C}$., the layers were carefully separated at that temperature and then allowed to wam to room temperature before they were analyzed. The organic layer remained clear on warming, water being more soluble in n-hexanol at higher temperatures, but the aqueous layer clouded quickly as dissolved n-hexanol came out of solution. After standing several hours at room temperature, however, the aqueous layers of the blank experiments had. cleared and could be analyzed, but troublesome clouding, requiring further waiting, occurred if the solution temperature rose even slightly, for example, as the result of handling the small cells and bottles excessively.

The basic equation for the calculation of $r$, the number of moles of acriflavine bound to one mole of TNA, from partition analysis data may be written as

$$
r=\frac{c_{0} V-c V-c_{\text {org }} \cdot V_{\text {org }} \cdot}{[N A]_{0} V}
$$

where

$$
\begin{aligned}
& c_{0}=\text { initial molar concentration ô } \\
& \text { acriflavine in the aqueous layer } \\
& \text { c = equilibrium molar concentration of } \\
& \text { unbound acriflavine in the aqueous } \\
& \text { layer } \\
& c_{\text {org. }}=\text { equiliblirfum molar concentration of } \\
& \text { free acriflavine in the organic layer } \\
& \begin{aligned}
& {[N A]_{0}=} \text { initial, or total, concentration of } \\
& \text { DNA in the aqueous layer }
\end{aligned} \\
& \mathrm{V}=\text { volume of the aqueous phase } \\
& v_{\text {org. }}=\text { volume of the organic phase }
\end{aligned}
$$


In terms of the quantitias measured in the procedure as described, since $V=V_{\text {org. }}, r$ is given by

$$
\boldsymbol{r}=\frac{\left[E_{0}-\frac{k_{a q} \cdot}{K_{o r g} \cdot} E_{o r g}-E_{a q .}\right]}{k_{a q} \cdot{ }^{d} \frac{M}{10} \times[N A]_{0}}
$$

where $\quad E_{0}=$ extinction value corresponding to $c_{0}$; i.e., one half the measured extinction of the original dye solution before adding the DNA solution

$$
\begin{aligned}
& E_{\text {org }}= \text { extinction of the organic layer, measured } \\
& \text { directly, or determined from the fluores- } \\
& \text { cence-extinction calibration curve } \\
& E_{a q}=\text { extinction corresponding to c, determined } \\
& \text { from Eorg. and the partition coefficient } \\
& \text { at } E_{\text {org. }}
\end{aligned}
$$
$E_{a q}=$ extinction corresponding to $c$, determined from $E_{o r g}$, and the partition coefficient at $E_{\text {org. }}$.

$\mathrm{k}_{\mathrm{aq}}, \mathrm{k}_{\mathrm{org}}$. $=$ proper extinction coefficients

$d=$ length of absorption cell (om.)

$M=$ molecular weight of acriflavine $=260$

E. The Neasiarement of Fluorescence Quenching: The photometer, standardization procedure, incident wavelength, and yellow-green exit filter used for the measurements of fluorescence intensities in solutions containing no DNA, as described in section D. were cmployed, also, for the fluorescence measurements involved in the study of the quenching of the fluorescence of acriflavine by DNA. Since quenching measurements are made on systems at equilibrium, however, the instrument was transferred to the constant temperature room or to the cold room, 
according as measurements of binding were desired at $25^{\circ} \mathrm{C}$. or at $4^{\circ} \mathrm{C}$. Care was taken that the temperature of the photometer chamber was within $1^{\circ}$ of the desired temperature. In the early work, the small cylindrical cell was used to measure, one at a time, a series of solutions having the same buffer and dye concentrations but varying with respect to DHA concentration from zero to a value high enough to permit estimation of $p$, as discussed in section III. F. It was found, however, that points necessary to detemine the shape of the quenching curves, $\left(\mathrm{F}_{\mathrm{O}} / \mathrm{F}-1\right)$ versus [NA] , were often lacking in the first run and that dilution errors In preparing the individual solutions were considerable, so a titration procedure was substituted which was more accur-

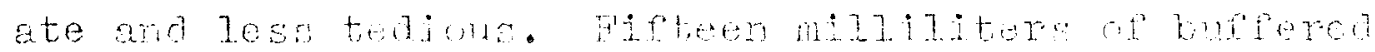
acriflavine solution were pipetted into the clean, dry square cell provicied with the Aminco photometer. This volume was just sufficient for the determination of $F_{0}$. A solution at the same buffer and dye concentrations but containing DNA at a suitable concentration as well was then added from a $10 \mathrm{ml}$. buret eraduated to $0.02 \mathrm{mI}$. A small elass-coverec ragnetic atirer in the bottom of the cell was used in mixing, the solutions well after each addition, before the measurement of $F$ was made, and the cell was kept covered with a square of plate glass as much of the time as possible. By this technique, up to ten milliliters of 
DNA solution could be added in such increments as were necessary to define the quenching curve. The dye concentrations used in the quenching experiments fell on the essentially straightiline portion of the fluorescence-concentration curve. 
o

V. Experimental Results

A Qualitative Results with Several Cationic Compounds

In the search for a compound which would interact reversibly with Dif to form soluble complexes to a measurable extent, even at relatively high ionic strengths, several cationic substances were investigated qualitatively by means of two or three methods for the detection of interaction. The rosults are indicated very briefly here, for they may be considered as clues to the type of interaction which DivA undergoes. The equilibrium dialysis technique (section IV. C.), using only three or four interactant concentrations, was applied in several cases to determine whether binding occurs at ionic strength 0.1 . Ihuch quicker, although theoretically not as valid, the following ultracentrifugation procedure was used in a few preliminary tests. 'l'wo tubes, one containing a buffer solution of DNA and the test compound, and the other containing the test compound only at the same concentration, were centrifuged at top speed in a spinco model L preparative ultracentrifuge for at least ten hours, a time found sufficient to centrifuge down completely DiA at a concentration of about $0.1 \%$. The supernatants were drawn off, very carefully, and analyzed spectrophotometrically for the test compound. If no difference in concentration was detected 
for the two tubes, it was concluded that binding did not take place under the conditions of the expeximent, but, if the supernatant concentration for the mixture was less than that for the blank, it was considered that complexing was indicated but not proved. A number of spectrophotometric titrations were run, too, on the assumption that a change in the spectrum of either the DNA or the test compound or both would probably, but not necessarily, accompany interaction between the two. In most of these titrations, absorption measurements had to be made at wavelengths at which both DNA and the test compound absorbed, so that the experimental extinctions were compared with the sum of the predicted extinctions for the constituents, which had been shown to obey Beer's Law individually. Since inorganic cations are known to lower the absorption maximum of Dis even in very low concentrations, theospectrophotometric titrations were carried out at zero ionic strength. It was not found l'easible to demonstrate interaction by means of paper electrophoresis, for the high molecular weight Diy A prenaration could not be made to move on the pavers ordinarily used in such work

Several alkyl pyridinium bromides were prepared, purified by recrystallization, and investigated in the expectation that these qualernary salts would combine with DwA. The ethyl and butyl derivatives, however, were 
not found to interact at 0.1 ionic strength at $\mathrm{pH} 7$ or at $\mathrm{pH} 5.5$ in equilibrium dialysis experiments covering a wide range of concentrations. horeover, spectrophotometric titration with ethyl pyridinium bromide in the absence of buffer revealed no spectral changes at four wavelengths in the near ultraviolet. The lauryl and cetyl derivatives, on the other hand, were bound on ultracentrifugation and on equilibrium dialysis, but the range of concentrations between the lowest tiat could bo determined spectrophotometrically and the critical nicelle concentration of the pyridinium salts in the buffer used was quite narrow. The doubly charged ethylene, tetramethylene, and decamethylene bis-quaternary pyridinium bromides, propared and very generously donalod by Dr. J. L. Hartwell (93) of the U. S. Public Health service, all caused spectral changes in the ultraviolet on being adced to DNA, and equiljbrium dialysis experiments, as well, indicated interaction in the case of the ethylene salt. Benzidine di-hydrochloride, howevor, did not interact under the same conditions of concentration and ionic strength.

B. The DivA-Acriflavine System: Partition Analysis Results

(93) J. L. Hartwell and H. A. Pogorelskin, J. Am. Chem. joc. 72,2040 (1950). 
- Partition analysis experiments on the DivA-acriflavine system were carried out under the following conditions of ionic strength $(\mu), \mathrm{pH}$, and temperature $(\mathrm{T})$ : .

$$
\begin{array}{ll}
\text { 1) } \mu=0.002, & \mathrm{pH}=6.92, \mathrm{~T}-25^{\circ} \mathrm{C} . \\
\text { 2) } \mu=0.1, & \mathrm{pH}=7.04, \mathrm{~T}=25^{\circ} \mathrm{C} . \\
\text { 3) } \mu=0.3, & \mathrm{pH}-6.88, \mathrm{~T}=25^{\circ} \mathrm{C} . \\
\text { 4) } \mu=0.1, & \mathrm{pH}=5.57, \mathrm{~T}=25^{\circ} \mathrm{C} . \\
\text { 5) } \mu=0.1, & \mathrm{pH}=7.04, \mathrm{~T}=44^{\circ} \mathrm{C} .
\end{array}
$$

since the interaction depends very little unon $\mathrm{oH}$, it is considered that the pH for series 1), 2),3) and 5) is the same and will, for practical purposes, be called pH 7 in the succeeding. A pH near 5.5 was chosen for the run Intended to indicate the effect of $\mathrm{pH}$ upon the interaction so that comparison misht be made with the study of Cavalieri (59) on rasaniline binding and so that extensive degradation of the DNA would be avoided $(26,94)$. ivo equilibrations were carried out in the absence of added salts, because it was desired to study the effect of varying ionic strength at a regulated and approximately constant $\mathrm{gH}$. The nucleic acid solution used in the experiments at the lowest ionic strencth, 0.002 , was dialyzed overnight against large volumes of buffer to remove any $\mathrm{NaCl}$ remaining from the preparative procedure, and it was determined that the $\mathrm{pH}$ of the DNA solution at

(94) W. E. Reichmann, B. H. Eunce, and P. Doty, J. Polymer 3ci. 10, 109 (1953). 
this low buffer concentration stayed constant in the presence of acriflavine and dissolved n-hexanol.

The data used in preparing the fluorescenceextinction curves for the aqueous and organic layers for the four buffers studied is given in the appendix. All fluorescence intensities, $F$, are given in photometer scale units and are corrected for the reading due to the solvent. Whenever possible, measurements for particular solutions were nade on the photometer ranges where the scale readings were greater than 20 and less than 80 . As we have noted, $\Xi_{\text {aq. }}$. was determined at $452 \mathrm{~m} \mu$, and $\mathrm{E}_{\text {org }}$. at $470 \mathrm{~m} \mu$. For the organic layer, the results fall on the same curve independent of the saturation buffer, but the curves for the aqueous layers at pH $7, \mu=0.002$ and at $\mathrm{pH} 5.5, \mu=$ 0.1 differ from that at pH $7, \mu=0.1$ or $\mu=0.3$. The curves are not quite linear, the slopes decreasing slowly as the concentration increases.

The partition coefficient curves, Eorg./Eaq. versus Eors., for all five sets of experimental conditions are shown in figures 1 and 2 , and the corresponding data are given in the appendix. The coefficients are seen to depend markedly upon $\mathrm{pH}, \mu$, and $\mathrm{T}$, but they vary with concentration in the same general way under constant conditlons: they decrease from the value at zero Porg., rather rapidly at first, and then much more slowly. The values of the experimentally determined 
Partition Coefficient vs. EORG at Given Values of $\mu$, $\mathrm{pH}$, and

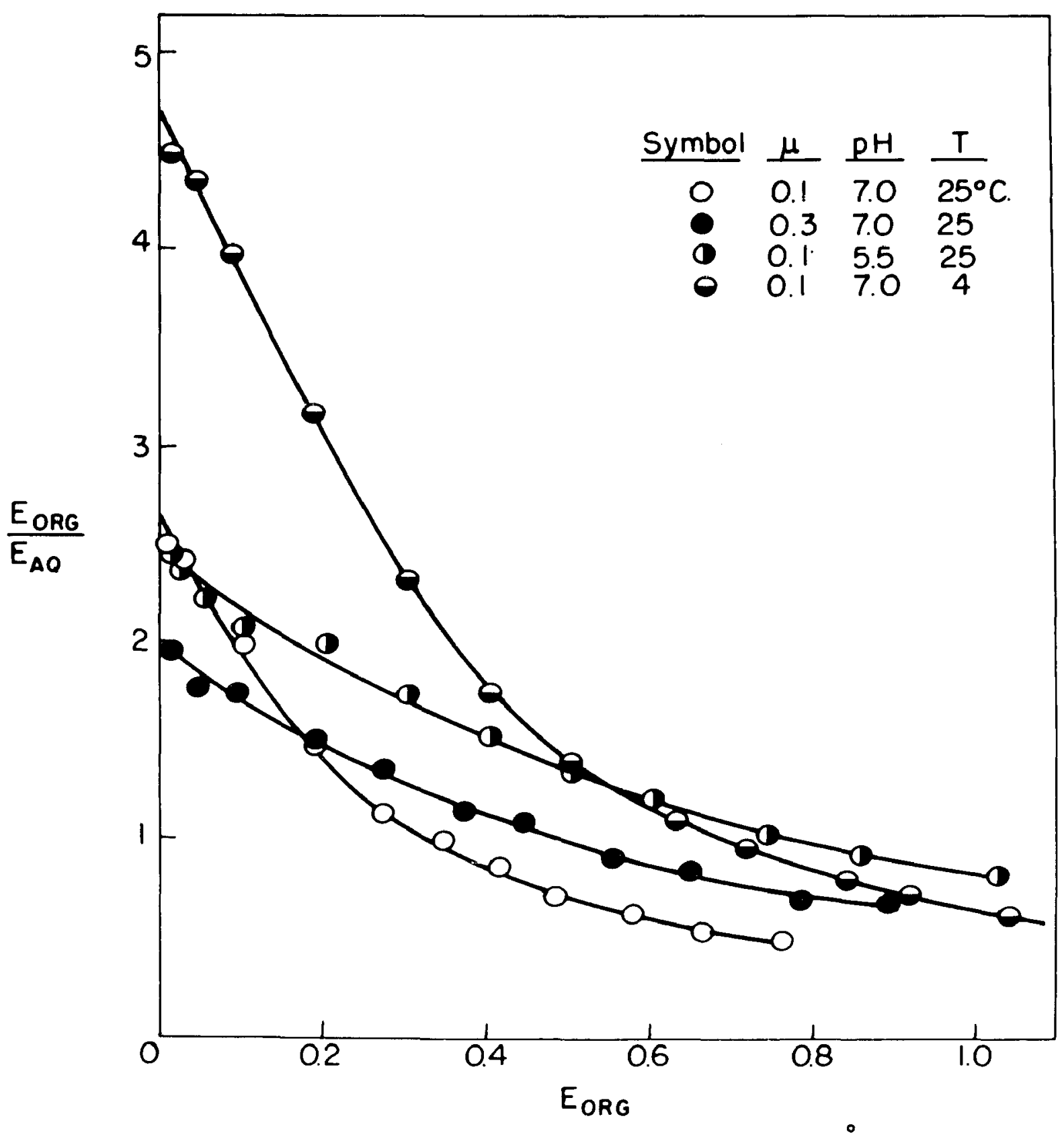

FIGURE I 
。

70

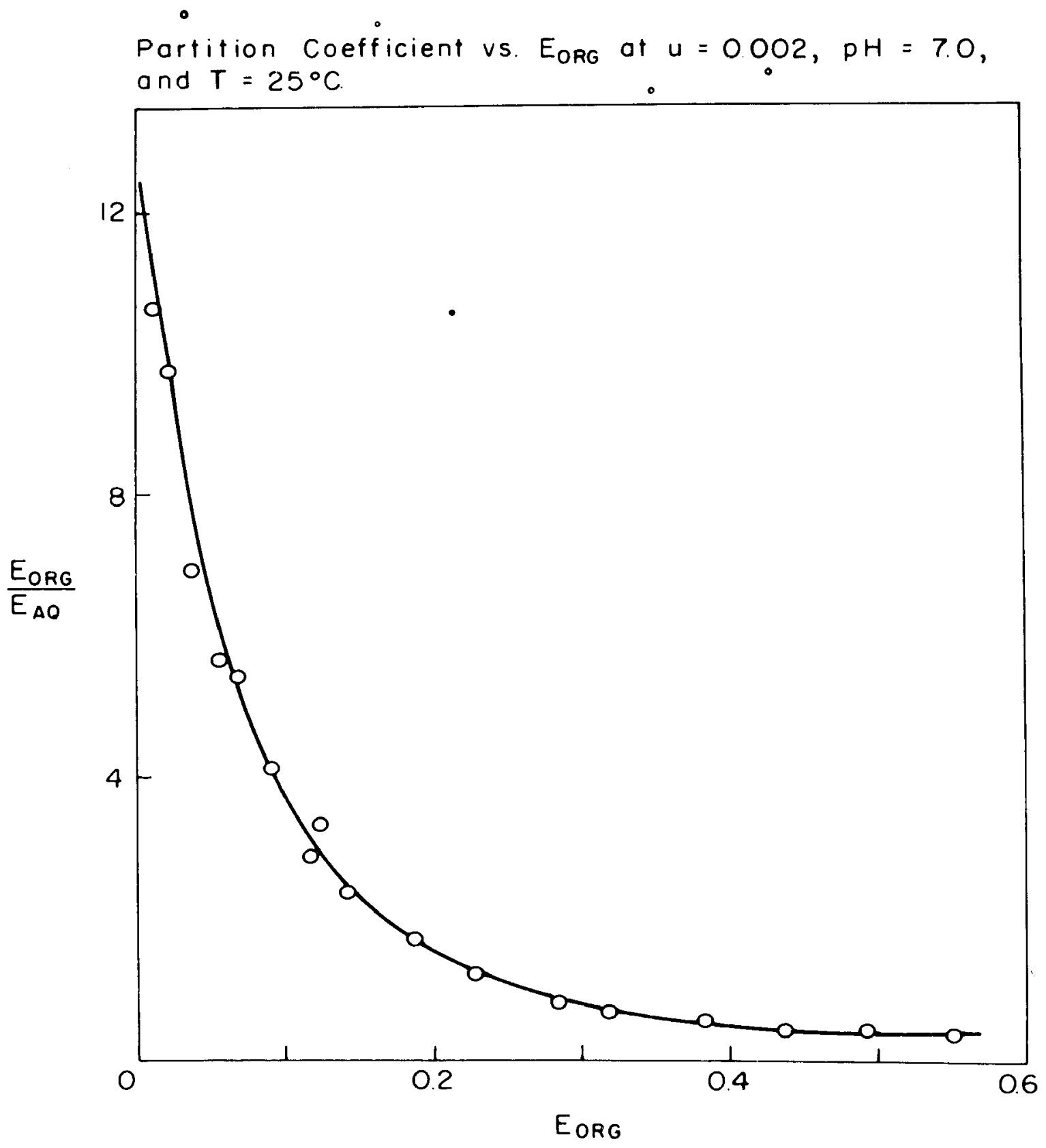

FIGURE? 
quantities, $E_{O}$, Forg., and $E_{0}$ org., in the partition analysis experiments are tabulated in the appendix for each set of experimental conditions, together with the corresponding values of $r$, calculated according to equation [27], and $r / c$. The value for $k_{a q}$. is given for each buffer, and $\mathrm{d}$ is, in all cases, $1.01 \mathrm{~cm}$. Although the DiNA concentration is given in $8 . / 100 \mathrm{ml}$. for reference, the value used in the calculations of $r$ has the units moles of phosphate groups per liter, calculated using the value 331 as the average weight of a Diva nucleotide. Thus, the necessity for assuming a value for the molecular weight of DiA js avoiced, and the estimated values of $\mathrm{n}$ indicate the fraction of the Diva phosphate groups present in the solution which a re avalable for binding under given conditions.

In Figures 3 through 7 , the data are plotted, for the different experimental conditions, as $r / c$ versus $r$. Several experiments at $0.01 \mathrm{~g} . / 100 \mathrm{ml}$. of DiA are specially indicated in ficure 7 and are seen to fall in with the data at $0.005 \mathrm{~g} . / 100 \mathrm{ml}$. of D A. In Figure 7, too, there appear the results of some prelininary partition analyses employing an 80:20 n-hexanol n-heptane mixture by volume as the organic phase. This solvent was abandoned because it gave low partition coefficients, but $^{\text {it }}$ is of interest that the results are in arreement with those from the experiments with n-hexanol alone. Finally, 
o

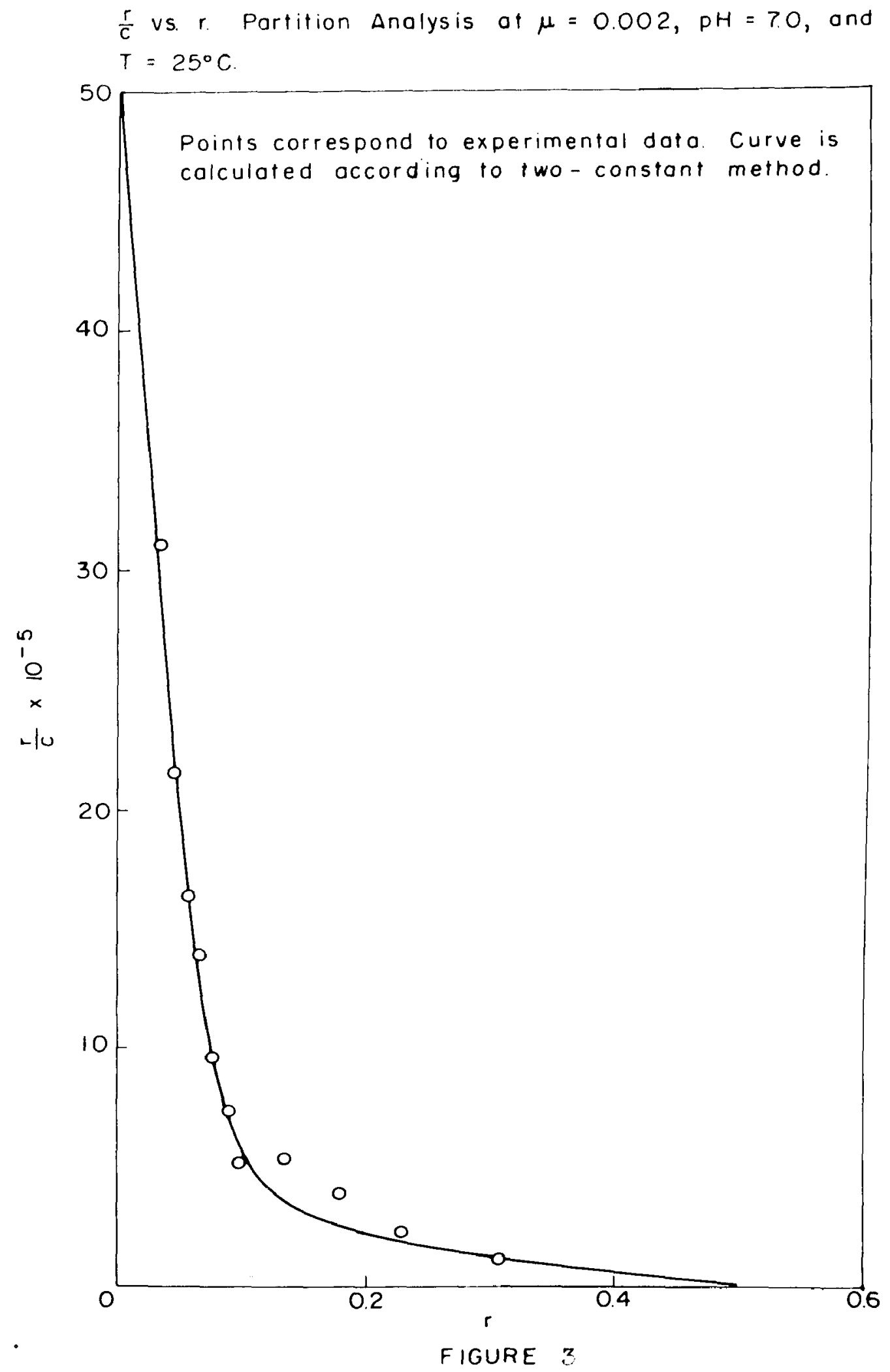


$\frac{r}{c}$ vs. $r$. Partition Analysis at $\mu=0.1, p H=7.0$, and $T=25^{\circ} \mathrm{C}$.

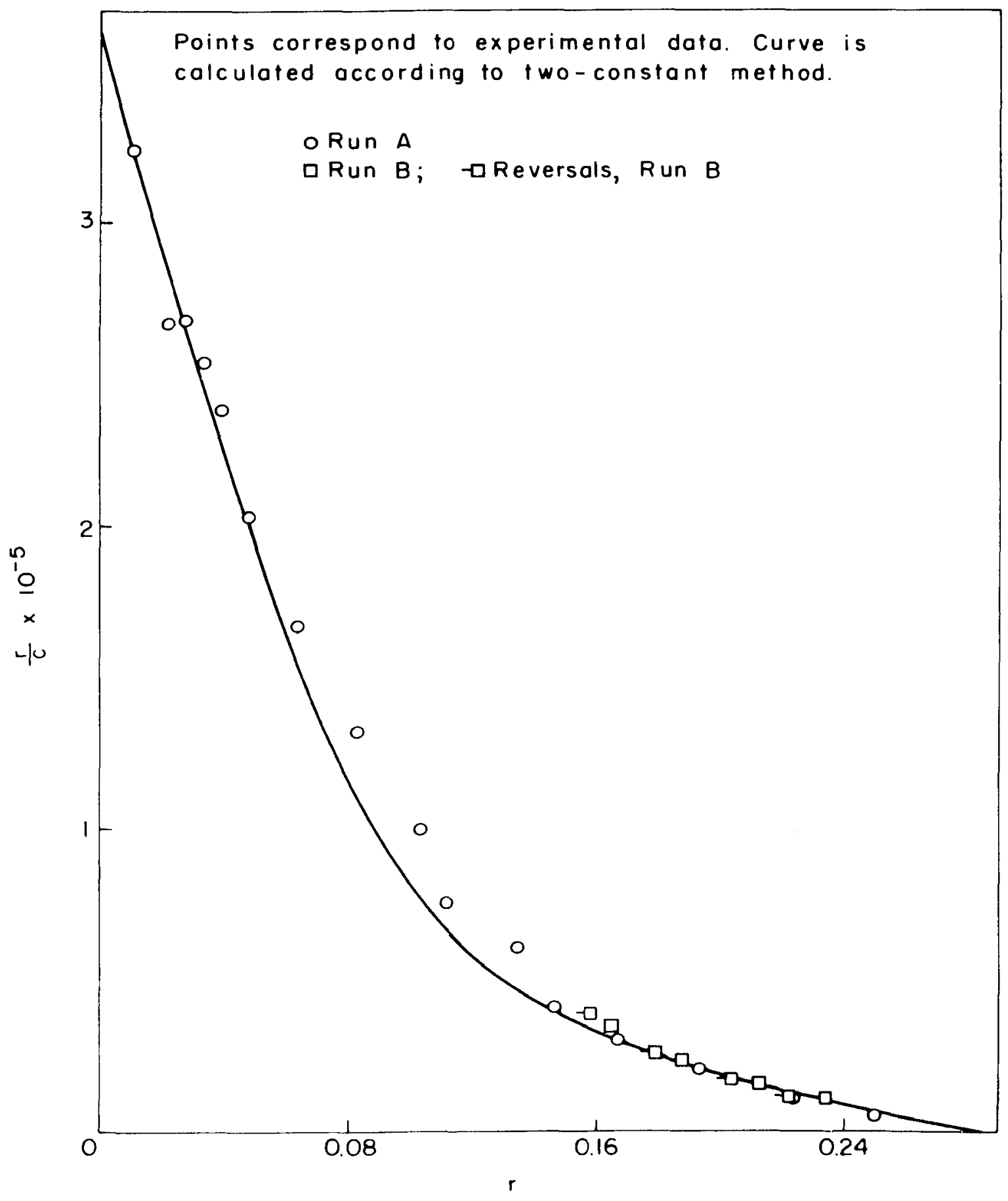

FIGURE 4 
$\frac{r}{c}$ vs. r. Partition Analysis of $\mu=0.3, \mathrm{pH}=7.0$, and $T=25^{\circ} \mathrm{C}$.

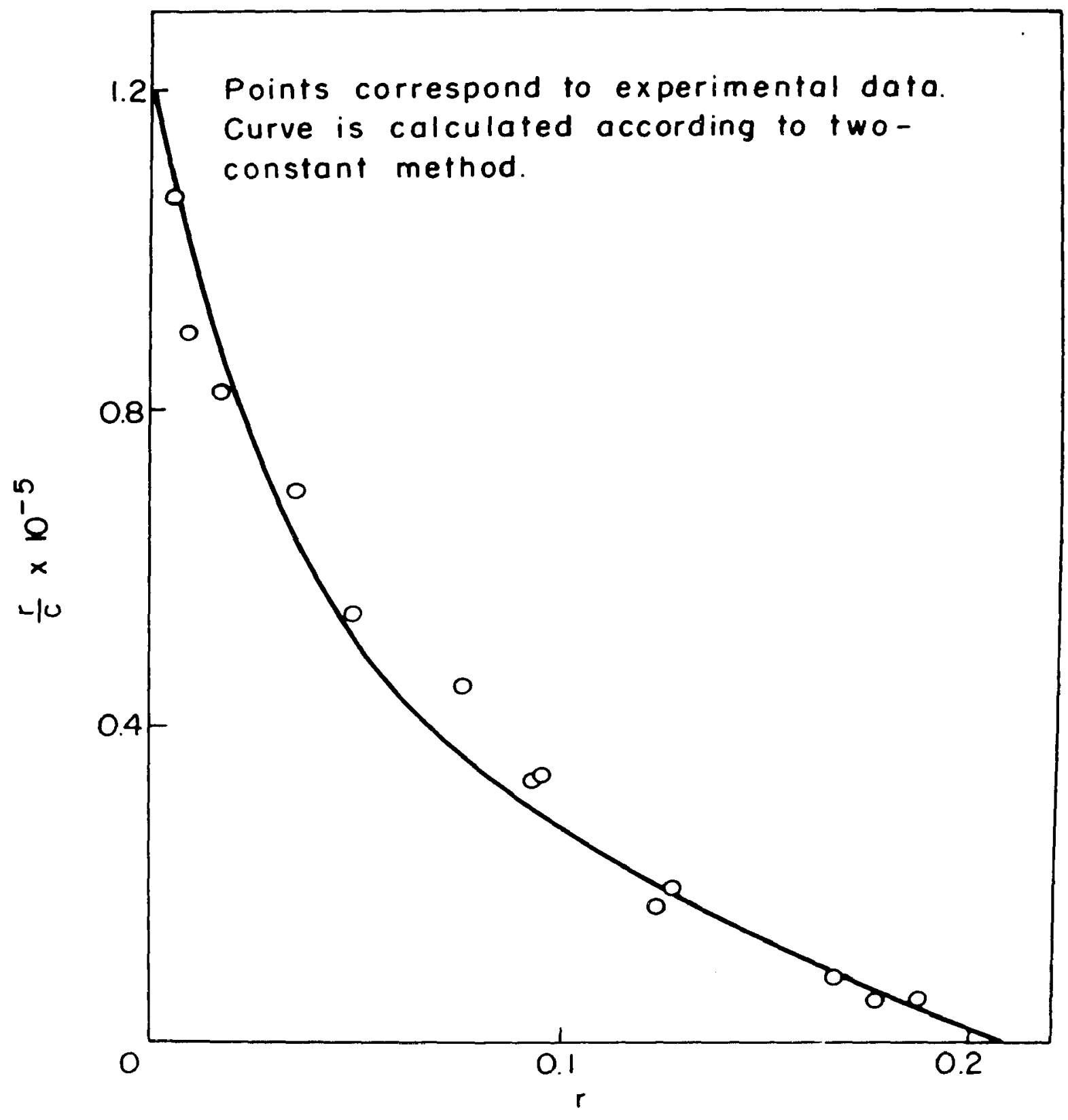

FIGURE 5 
o

0

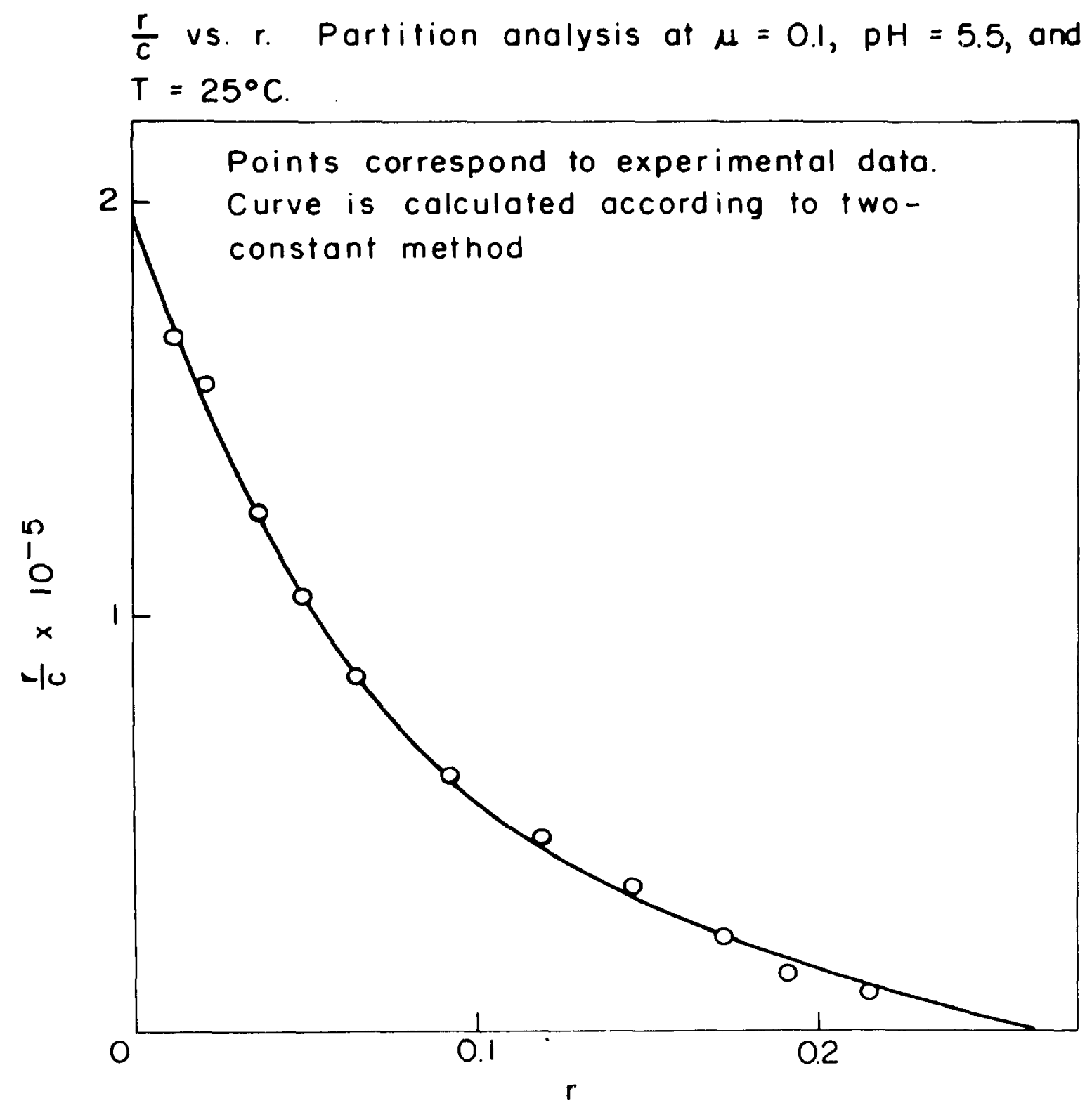

FIGURE 6 
0

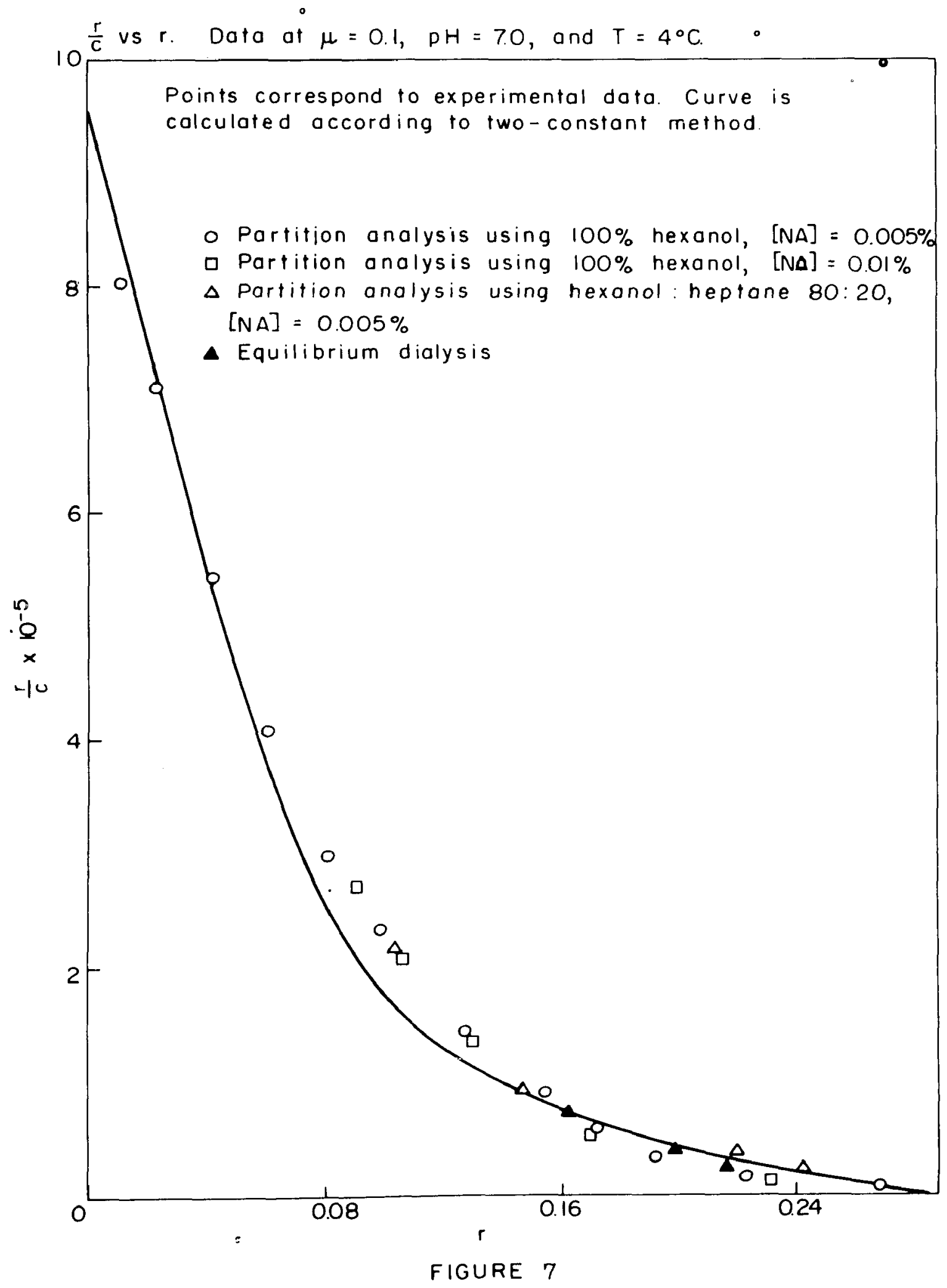

- 0 
Figure 7 includes several points obtained by the equilibrium dialysis technique. Although the dialysis method, at least using cellophane casing as the membrane, is not accurate enough for the quantitative study of acriflavine because the membrane takes up exceedingly large amounts of the dye, indeed, several times the amount of free dye, the results agree quite well with the partition analysis values. Evidence that the acriflavine-Div interaction is reversible is presented in pigure L. In an early partition analysis run, reversal experiments were carried out by removing, as exactly as possible, five milli-liters of the organic layers or several bottles after equilibration in the usual manner. Five milliliters of Presh buffer-saturated n-hexanol were then added, and the bottles were shaken an additional four hours to reequilibrate the system. Eorg. was determined for both equilibrations, and values of $r$ were calculated. It is $\operatorname{scen}$ (icure l!) that the results for the reversal experiments fall in with those for the first equilibrations.

\section{The curves drawn in Finges 3 through 7 were} calculated according to the method described in seation III. D., equations $[14],[15]$, and [16], for the case of two groups of sites, each with a single intrinsic assoclation constant. Although the intercepts might be chosen within rather wide limits, the theoretical curves 
fit the experimental points fairly satisfactorily for any choice of intercepts that appears reasonable, except that they are a little low in the central, curving region. The values for $K_{1}, K_{2}, n_{1}$, and $n_{2}$ calculated on the basis of the two-constant assumption are given in Table I at the end of section $V$. The values for $k_{1}$ and $n$ obtained from the intercepts of the theoretical curves are listed in Table $I$, also, the results for $k_{1}$ are in quite good arreement with those obtained by the other nethods of calculation. As is usually the case in binding studies, the extrapolation which determines $\mathrm{n}$ is less certain, and the effect on the theoretical curve of a considerable variation in the value of $n$ selected is relatively small, so that the values reported for $n$ are estimates only. An attempt was made to use the adsorption isotherms of equation $[17]$, section III. E., derived by Sips (79, 30) for two distributions of binding energies, to construct a theoretical curve wrich would fit the data. It was found that both equations yield curves which come down far too rapidly at low values of $r$, the second equation Siving worse results than the first.

The method of Scatchard (74), section III. C., was easily applied to the results for all the experimental conditions excepting those at $\mu=0.002$. Figure 8 shows the plots of $\log \ddot{q}$ versus $r$ obtained for the other four cases by using, to calculate $Q$, the same values of $n$ selected 


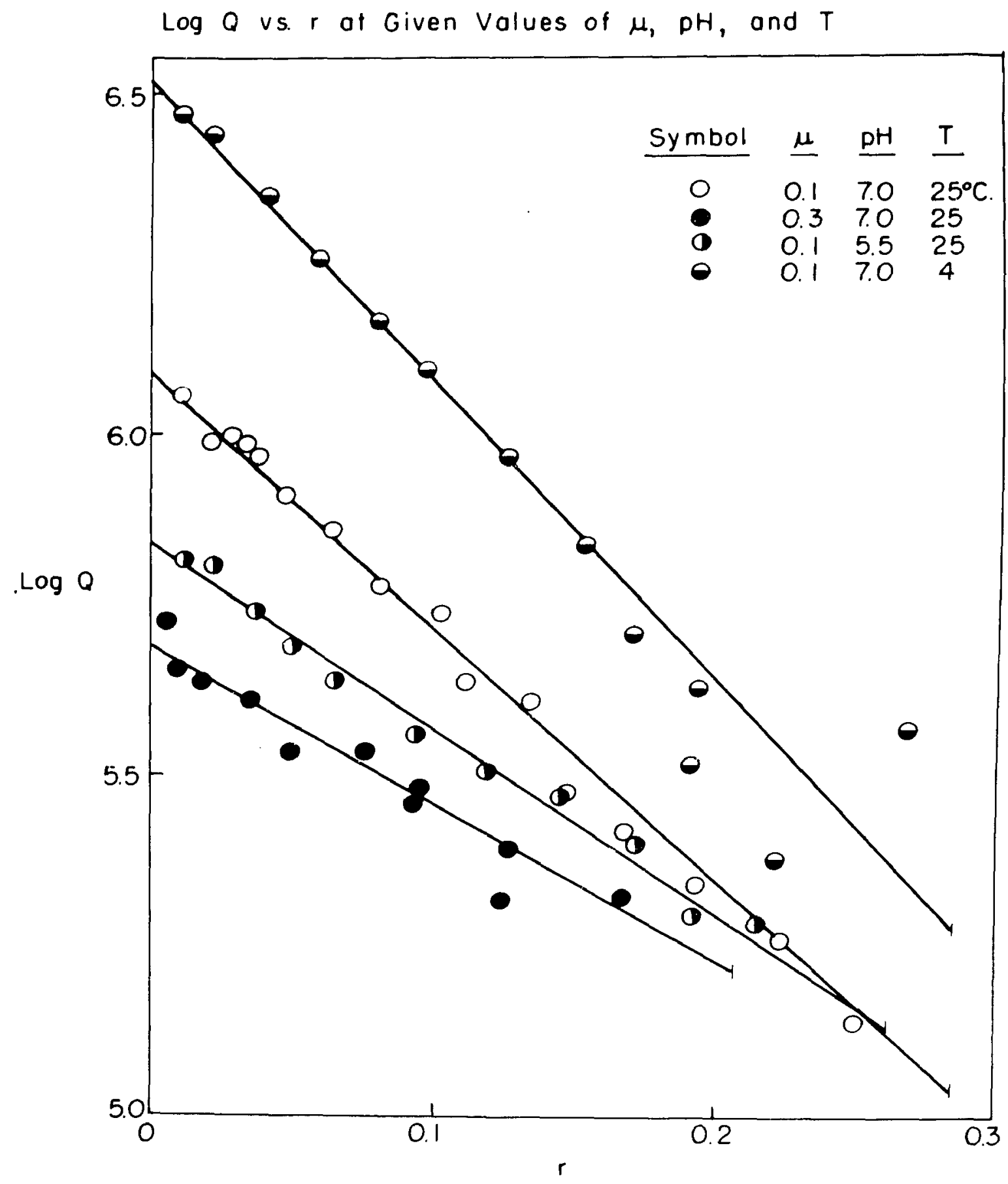

FIGURE 8 
in the application of the two-constant method. These plots, within experimental error, are straight lines and are extrapolated to $r=0$ without too much uncertainty to obtain values for $k_{l}$, listed in Table $I$, which agree quite well with the values ubtained in other ways. In the case of the data at low ionic strength, the $\log Q$ versus $r$ plot, not shown, appears to consist of two linear portions, neither of which extrapolates to a satisfactory value for $k_{1}$. It is difficult to say whether experimental error, which shows up very markedly in these plots, causes the curve to deviate from linearity, in which case an average straight line might be drawn through the points, or whether there is a theoretical reason for the shane of the curve. The $n^{\text {th }}$ intrinsic association constant, $k_{n}$, is not listed in Table $I$, because of the greater uncertainty in the extrapolation to $r=n$. It should be noted, in this connection, that $\left(c_{n}\right)_{n}$ when divided by $n$ yields a value for $k_{n}$ less than that for $k_{1}$; this is a consequence of the fractional units chosen for $\mathrm{n}$. In an attempt to obtain o more reliable estimate of $n$, erans of $r$ versus $l o g$ o were constructed, but the data do not reach values of $c$ high enough to determine center of symmetry of the curve (at $\mathrm{n} / 2$ ) with accuracy. Figure 9 , for the ${ }^{\circ}$ run at $\mathrm{pH} 5.5$ shows the easiest of these curves to interpret; the value of $n$ obtained happens to be the same as is estimated by 
extrapolating the $r / c$ versus $r$ curve to $r / c=0$.

Finally, the values of $k_{1}$ calculated from the partition analysis data by the method of steiner (73), section III. B., are included in Table $I$ and are seen to fall in with the other results satisfactorily. There was no difficulty in applying the method to any of the runs, and the manner in which the procedure works out is illustrated in Firures 10 through 12 for the data at $\mu$ $=0.1$, pis 7 , and $4^{\circ} \mathrm{C}$. In Figure $10, \mathrm{r} / \mathrm{c}$ is plotted against $c$ for the lowest values of $c$, the areas measured being marked off by the vertical lines. I'igure 11 shows the results for $\lambda$ as a function of $c$ for all the runs and Indicates clearl how the initial slopes vary under the various experimental conditions; if the curve for $\mu=$ 0.002 were plotted on the same c scale, it would, of course, have by far the himest initial slope. The socalled chord-area method for rraphical differentiation, used to determine $\left(\frac{d x}{d c}\right) c=0$, is jliustrated in ligure 12 . Estimates of $k_{2}, k_{3}$, etc., might be obtaired by successive differentiation, but it should be remembered that the shane of the $\lambda$ versus c curve deoends upon the units chosen for $r$, and the units chosen in the calculations presented here happen to result in negative values for the association constants $k_{i}$, where $1<i<n$. 'l'he $k_{i}$ 's become positive, of course, if the units are chosen so that $n$ is greater than 1 . 


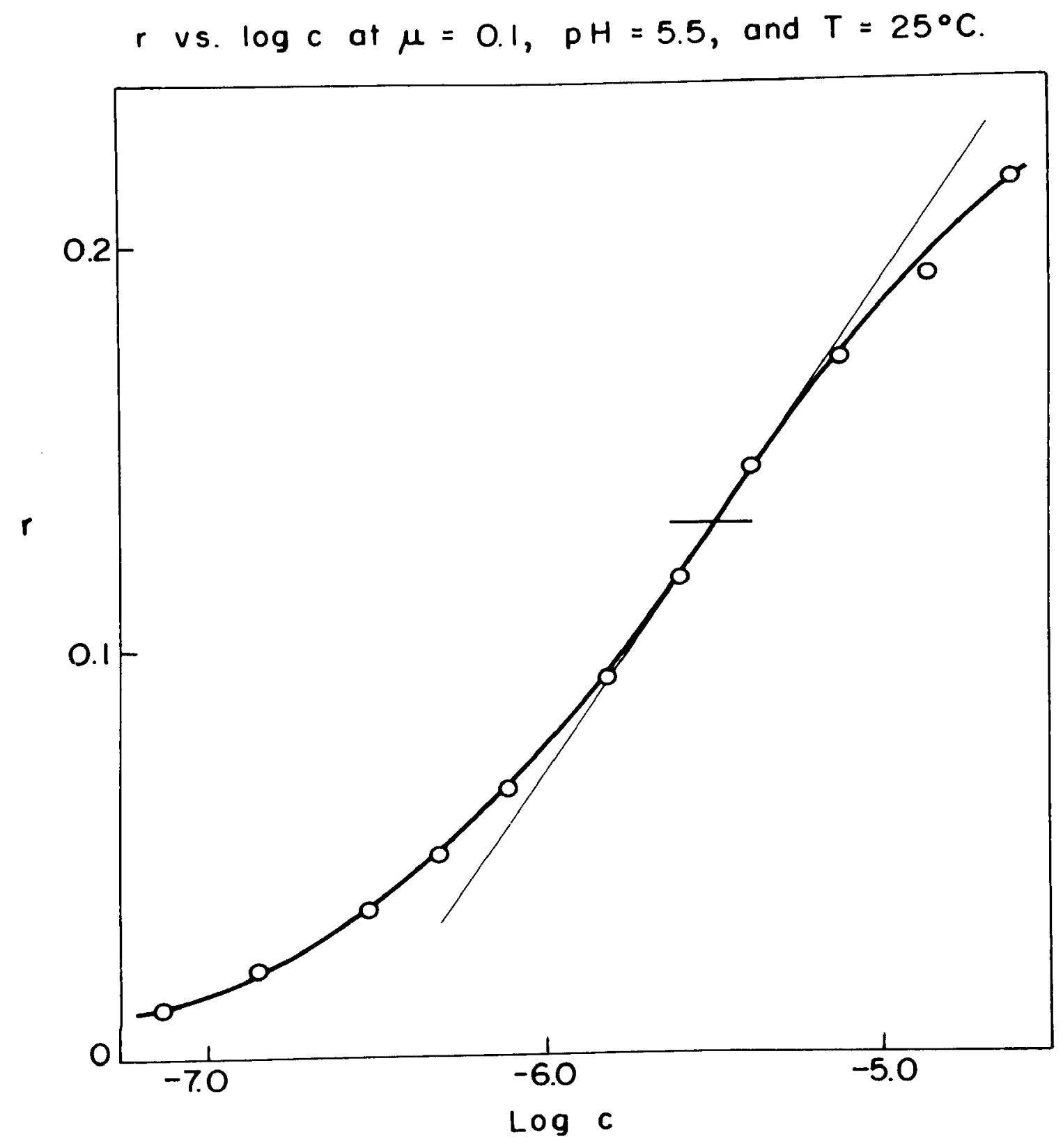

FIGURE 9 


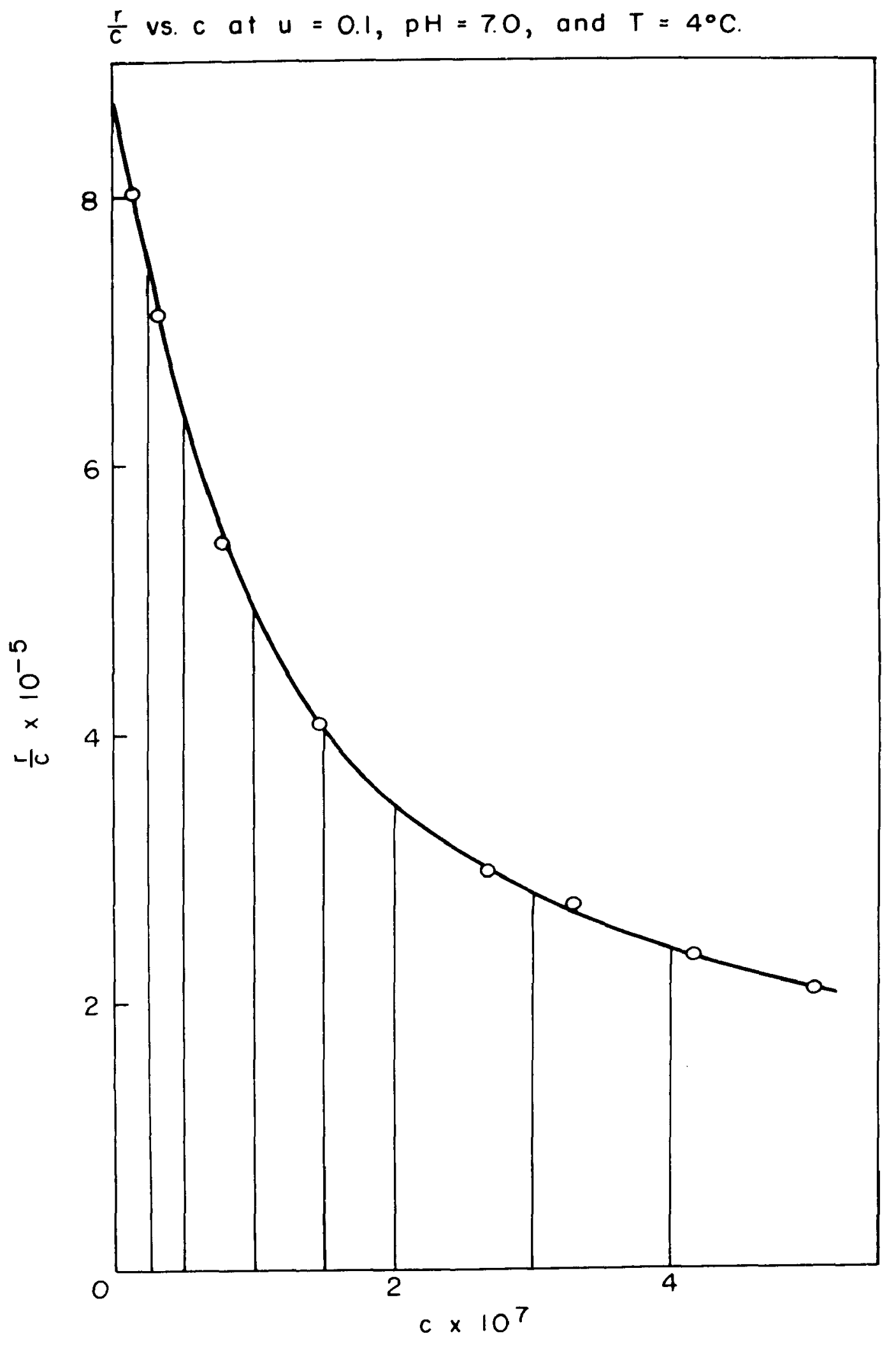

FIGURE 10 
$h$ vs. $c$ of Given values of $\mu, P H$, and $T$

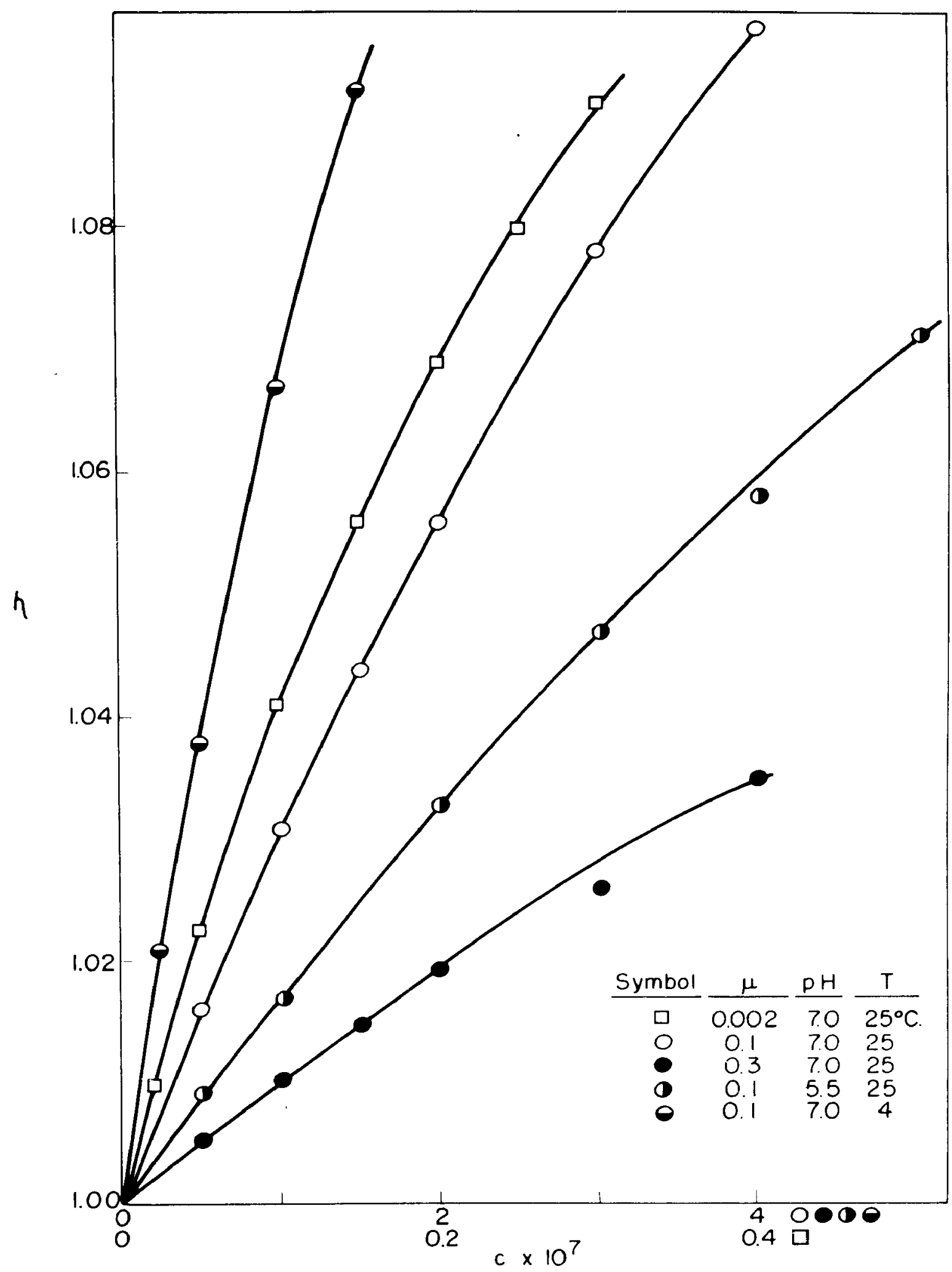

FIGURE II 


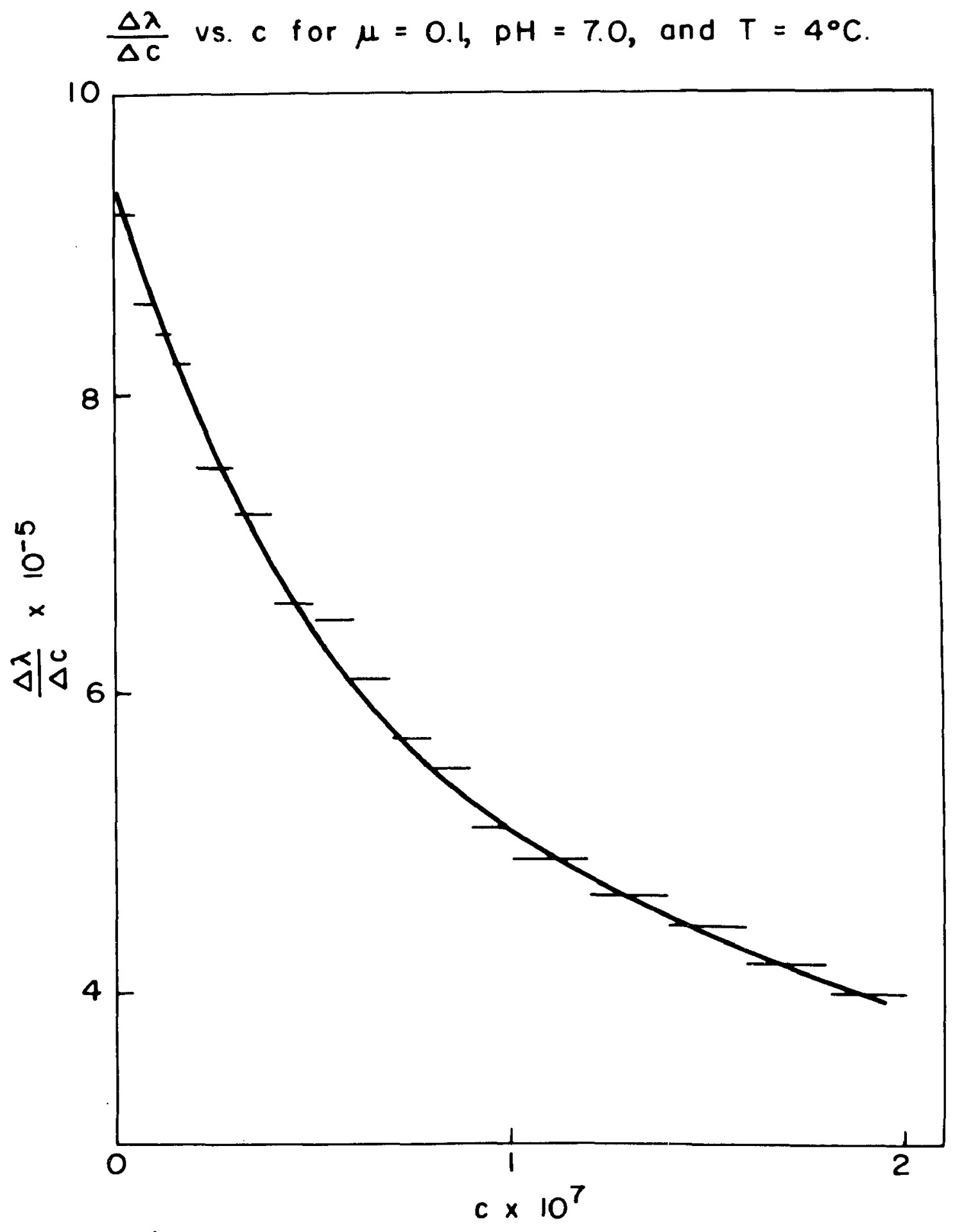

FIGURE I? 
C. The DNA-Acriflavine System: Fluorescence quenching Results

F'luorescence quenching curves were obtained both at $25^{\circ} \mathrm{C}$. and at $4{ }^{\circ} \mathrm{C}$. for pH 7 at $\mu=0.002,0.01,0.05$, 0.1 , and 0.3 , and for $\mathrm{pH} 5.5$ at $\mu=0.1$. Runs at two or three acriflavine concentrations were made under the experimental conditions that had been studied by partition analysis; a curve at a single dye concentration was deternined for each of the additional cases. All the data are tabulated in the appendix. As a further check on the reversibility of the system, solutions at several different concentrations of acriflavine and of DilA and in several different buffers were measured at $25^{\circ} \mathrm{C}$, then at $4{ }^{\circ} \mathrm{C}$., where more acriflevine is bound, ond then at $25^{\circ} \mathrm{C}$. ggair. The results at $25^{\circ} \mathrm{C}$. checked, and so did those at $4^{\circ} \mathrm{C}$, with measurements made on solutions prepared from DivA and dye stocks which were at $4^{\circ} \mathrm{C}$. before nixing.

The shapes of the quenching curves varied gradually betweon two extreme types, according to the extent of binding occurring under the experimental conditions being investigated. ligure 13 shows the curves obtained at throe dye concentrations for $\mu=0.1$, pll 7 , and $25^{\circ} \mathrm{C}$, conditions under which the amount of binding is relatively low. ( $\left.F_{0} / F-1\right)$ increases linearly with $[N A]_{0}$ at first and then the slope of the curve decraases as [NA] increases further. In Figure 14, we have examples of the types of 


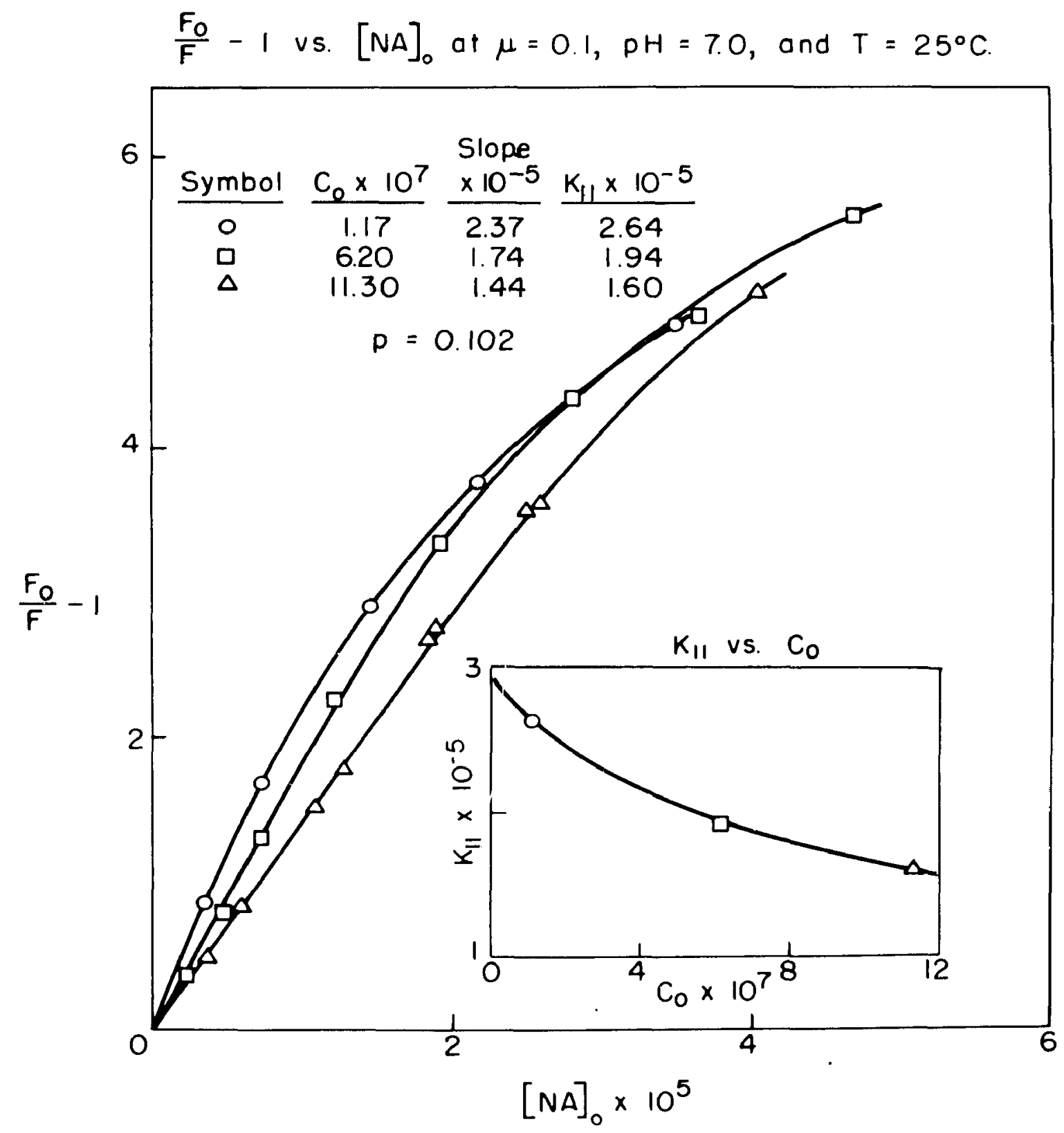

FIGURE I* 


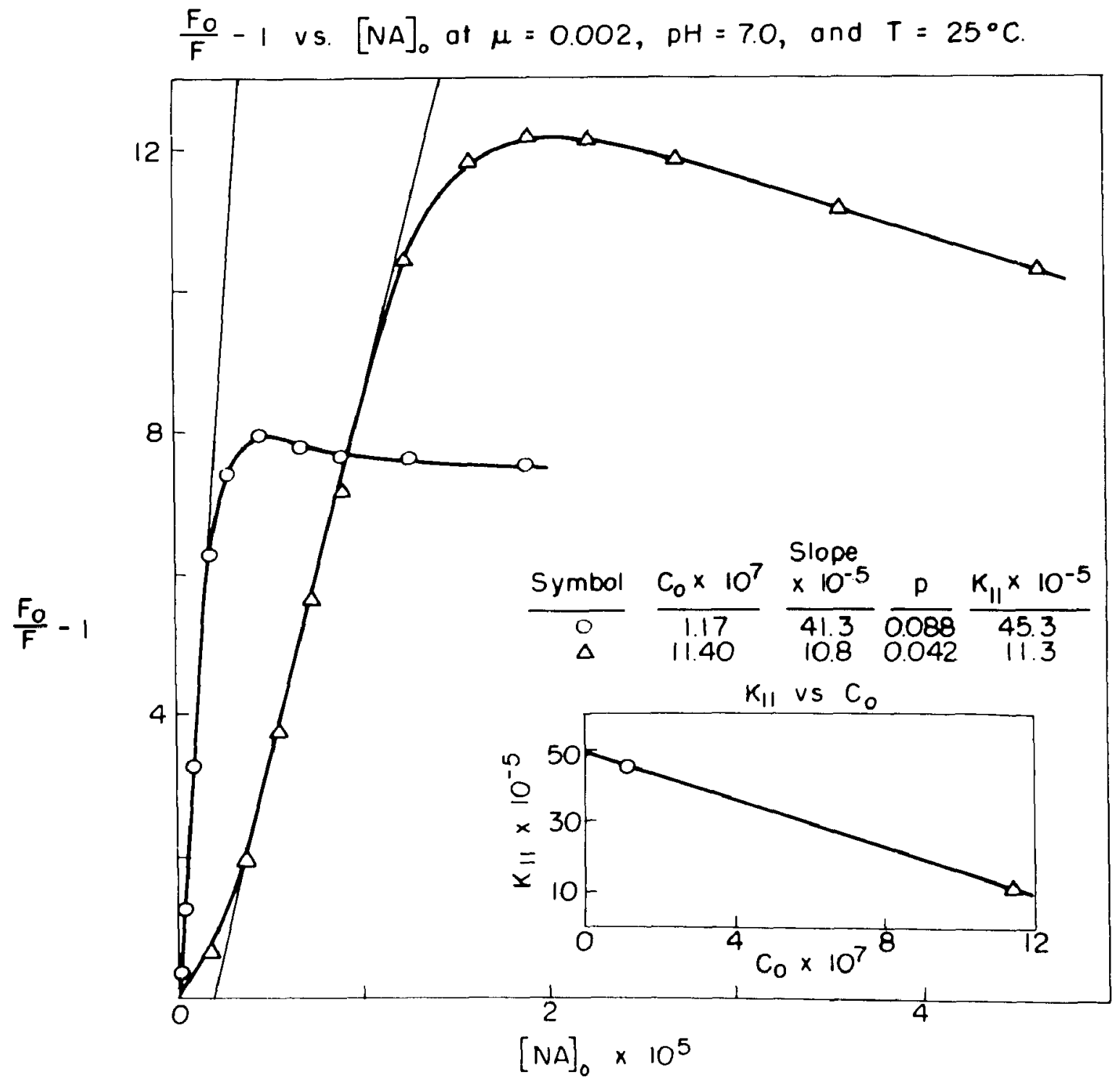

FIGURE IA 
quenching curve obtained when the amount of binding is high, in this case for two dye concentrations at $\mu=$ 0.002 , pH 7 , and $25^{\circ} \mathrm{C}$. There is a curved portion of continually increasing slope at low [NA] preceding the linear portion, and the curve goes through a maximum at higher [NA]。 and then slowly levels of $f_{0}$

In order to obtain $k_{l}$ from the quenching data by the slope method sugesested at the end if section III. H., the following procedure was adopted: The initial slopes, of curves like those in Fichure 13, were easily drawn, but for curves of the type in Figure 14, not the initial slopes, but the slopes of the linear portions, measured as indicated in the figure, were used. The slopes were taken in this manner both bocause the reskits for ki were in ruch better agreement with those obtained by other methods than if the initial slopes were used, and because it wes suspected that the initial curvature is due, at least partly, to the aiscrepancy between [ivA] and [NA]。 when binding is consicierable. The maxima in some of the auenching curves indicate immediately that $p$ is not constant with concentration for the [MA-acriflavine system. It was decided to choose, in each case, a value of $p$ which would hold fairly well in the concentration ranee corresuonding to the linear portion of the quenching curve: ${ }{ }_{0} / \mathrm{F}$ was plotted against $1 /[\mathrm{NA}]_{0}$ and the rising portion of the curve was axtrapolated to $1 /[\mathrm{NA}]_{0}=0$ as indicated by 
equation [20]. The values of $\mathrm{F} / \mathrm{F}$ falling below the extrapolated curve at low values of $1 /$ [NA] o were disregarded. Since $p$ estimated in this manner is, in every case, less than about 0.1 , the value of the slope divided by $(1-p)$ at any particular dye concentration, called $\mathrm{K}_{11}$, is very insensitive to the value chosen for $p$. The graph of $K_{1 l}$ versus $c_{0}$ is slightly curved, as is seen in the insert in Figure 13, but, for the cases where quenching curves were run at only two dye concentrations, a linear extrapolation to $c_{0}=0$ was made. Despite this approximation and the others mentioned, the results for $k_{I}$, included in lable $I$, are in agreement with the values obtained from partition analysis.

Once it was estahlished that fairly reliable first equilibrium constants could be obtained by this relatively simple and rapid quenching-slope method, it was decided to obtain quenching curves under conditions other than those studied by partition aralysis in order to learn something more about the interaction. A further approximation was made in these cases: values for $\mathrm{K}_{11}$ were detemined at orly one acriflavi ce concentration, anci the values at $c_{0}=0$ were estimated, very roughly, by choosing a slope for $K_{I l}$ versus $c_{0}$. The choice was based upon consideration of the slopes obtained in cases when quenching was studied at two or more dye concentrations. The values for $k_{1}$ obtained in this way, tocether with the thermo- 
dynamic constants calculated from them, are listed in Table II.

Since, as we have seen, $p$ is not constant with concentration for the Div-acriflavine system, it was not found possible to apply the method derived in section III. F. for the calculation of $c$ according to equation [19]. Figure 15 shows the results for $r / c$ versus $r$ obtained for the two cases of ingures 13 and 14 on the basis of the values of $p$ chosen in the application of the quenchingslope method. The calculated points are superimposed upon the curves calculated on the two-constant assumption, and it is evident that no single value of $p$ would make the points fall on the curve at $\mu=0.002$. At $\mu=0.1$, on the other hand, where the variation of $p$ is not so reat at the concentrations studied, the points follow the curve rather closely over a sizable region and indicate the order of magnitude of $k_{1}$ at least.

I'icure 16 represents the results for $k_{1}$ summarized in Tables I and II. It is gratifying that the results, indicated by the onen symbols, which a re based on quenching data at a sirgle dye concentration and calculated using very rough approximations, form a smooth curve with the values determined carefully by both partition analysis and fluorescence quenching. As is immediately evident, $k_{l}$ decreases markedly with increasing ionic strength at low ionic strength, the dependence becoming less at higher 
$\frac{r}{c}$ vs. $r$ from fluorescence quenching dato (points)

Curves calculated for partition analysis data according to the two-constant method (Figs 384 )
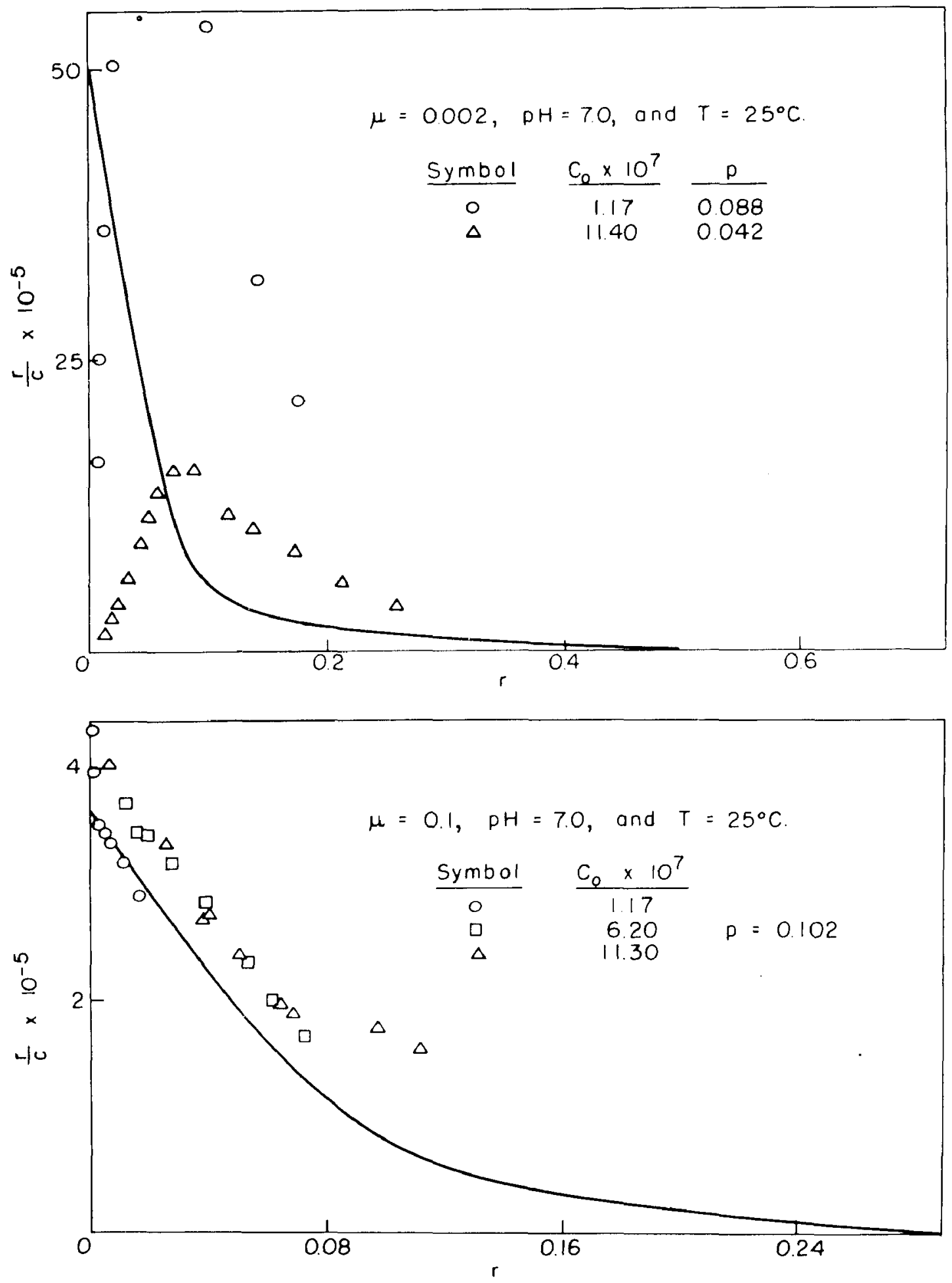

FIGURE 15 
Log $k_{\text {IAVVS. }} \mu$ (ordinote scale at right)

and $k_{\text {Iav }}$ vs. $\mu$ (ordinate scale at left)

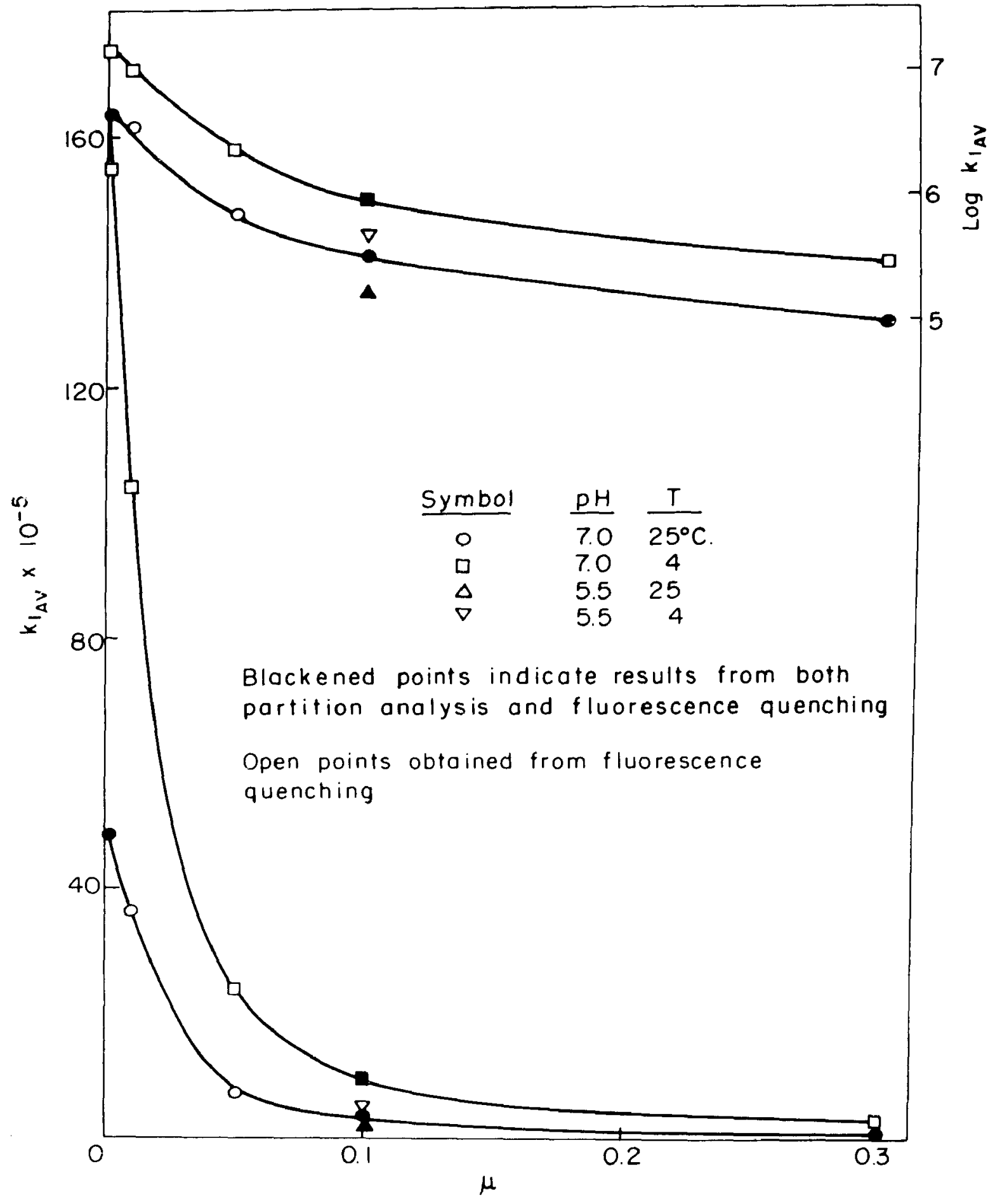

FIGURE 16 
TABLE I

Summary of Constants for the Interaction of DivA

with Acriflavine Obtained from Partition Analysis

and from Fluorescence quenching Experiments

$\left.\stackrel{\mu}{\mathrm{pH}} \mathrm{T}_{\mathrm{O} .}\right)$

$k_{1} \times 10^{-5}$

$\mathrm{k}_{1} \times 10^{-5}$

$k_{1} \times 10^{-5}$

$k_{1} \times 10^{-5}$

$k_{12 \mathrm{v}} \times 10^{-5}$

$-\Delta F_{1}^{\circ}$

$-\Delta \mathrm{H}_{1} \mathrm{O}$

$-\Delta S_{1}^{0}$

$\mathrm{K}_{1} \times 10^{-0}$

$\mathrm{K}_{2 \times 10^{-5}}$

n?

$\mathrm{n}$

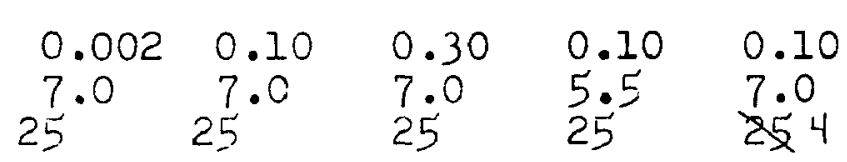

Partition Analysis :

Two-Constant ile thod

Partition Analysis:

Nethod of Scatchard

Partition Analysis:

ine thod of Steiner

Quenching - Slope liethod

$\begin{array}{lllll}50.0 & 3.63 & 1.20 & 1.93 & 9.55 \\ \ldots & 3.48 & 0.99 & 1.84 & 9.43 \\ 49.3 & 3.35 & 1.03 & 1.78 & 9.39\end{array}$

$\begin{array}{lllll}19.0 & 2.90 & 0.92 & 1.96 & 9.22\end{array}$

$\begin{array}{lllll}49.0 & 3.3 & 1.1 & 1.9 & 9.4\end{array}$

(kcal./mole)

(kcal /mole)

(cal./\%ole)

$\begin{array}{lllll}9.1 & 7.5 & 0.8 & 7.2 & 7.6 \\ & 3.1 & & & \\ 1.9 & & & \end{array}$

$\begin{array}{lllll}66.8 & 3.89 & 2.82 & 2.53 & 11.7 \\ 4.76 & 1.31 & 1.83 & 1.75 & 3.35 \\ 0.07 & 0.09 & 0.03 & 0.00 & 0.08 \\ 0.43 & 0.20 & 0.18 & 0.20 & 0.21 \\ 0.50 & 0.285 & 0.208 & 0.262 & 0.285\end{array}$




\section{Summary of Constants}

for the Interaction of DNA with Acriflavine

Obtained from Fluorescence Quenching Experiments

\begin{tabular}{|c|c|c|c|c|c|c|}
\hline$\mu$ & $\mathrm{OEF}$ & $\mathrm{T}\left({ }^{\circ} \mathrm{C}.\right)$ & $\pi_{1 x^{1}}-5$ & $\begin{array}{c}-\Delta F_{1}{ }^{\circ} \\
\mathrm{kcal} / \mathrm{mole}\end{array}$ & $\begin{array}{c}-\Delta \mathrm{H}_{1}{ }^{\circ} \\
\mathrm{kcal} / \mathrm{mole}\end{array}$ & 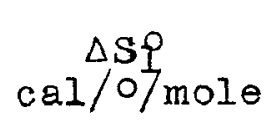 \\
\hline 0.002 & 7.0 & 25 & $1 \frac{49^{*}}{60}$ & $\frac{9.1}{9.1}$ & 8.9 & +0.7 \\
\hline 0.01 & 7.0 & 25 & $\begin{array}{r}30 \\
100\end{array}$ & $\begin{array}{l}8.9 \\
8.9\end{array}$ & 8.2 & +2.3 \\
\hline 0.05 & 7.0 & 25 & $2 L^{7 \cdot 0}$ & $\begin{array}{l}8.0 \\
8.1\end{array}$ & 9.5 & $-4 \cdot 9$ \\
\hline 0.10 & 7.0 & 2.5 & $\frac{3.3}{9.4}$ & $\frac{7.5}{7.6}$ & 8.1 & -1.9 \\
\hline 0.30 & 7.0 & 25 & $\frac{1 \cdot 1}{2 \cdot 8}$ & $\frac{6.8}{0.9}$ & 8.1 & $-4 \cdot 2$ \\
\hline 0.10 & 5.5 & 25 & $\frac{1.9}{1.9}$ & $\frac{7.2}{7.2}$ & 7.8 & -2.1 \\
\hline
\end{tabular}

*The underlined values appear in Table $I$ and are average values from both fluorescence querching and partition analysis experiments. 
ionic strengths. The value of $k_{1}$ at $\mathrm{pH} 5.5$ is lower than - that at $\mathrm{pH}$ 7. The thermodynamic constants $\Delta \mathrm{F}_{1}{ }^{0},{ }^{\circ} \Delta \mathrm{H}_{1}{ }^{\circ}$, and $\Delta \mathrm{s}_{1}{ }^{\circ}$ for the formation of the first DNA-acriflavine complex, calculated from the averaged values of $k_{l}$, are listed in Table $I$, and values based upon the approximate quenching results for $k_{1}$ are given in Table II. It is seen that $\Delta \mathrm{H}_{1}{ }^{\circ}$ is negative in all cases, and that $\Delta \mathrm{S}_{1}{ }^{\circ}$ is approximately zero. 
VI. Discussion

Evidence in both partition analysis and

fluorescence quenching experiments indicates that the interaction between the DNA and acriflavine samples studied is reversible and that equilibrium is attained rapidly on mixing the two in solution. The distinct curvature in all the graphs of $\mathrm{r} / \mathrm{c}$ versus $r$ (Figures 3 through 7 ) shows that the interaction involves more than one intrinsic association constant; that is, that there are dieferences among the binding sites on the DirA macromolecule with resect to their affinity for the acrifla'ine cation. It was not considered that electrostatic interadions among the binding sites play a large role, first, because the dye cations replace inormic cations at the sites, and, second, becauge the electrostatic correction was inadequate to account for the curves obtained by Cavalieri and Angelo: (59) for the binding of rosaniline by DiA. Although the data in the present study, as in the case investicated by cavalieri and Anzelo; (59), inay be fitled satisiactorily with a theoretical curve calculated on the

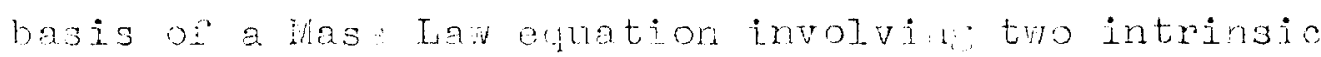
equilibrium constants, it does not necessarily follow, as Karush (1I) has pointed out, that only two types of sites exist. Rather, it may probably be inferred that the sites fall into at least two groups, each of which may be represented by an intrinsic constant, but that differences. $\circ$ 
in affinity may exist within these groups. That the situation is indeed not quite as simple as appears on first sight is indicated by the small but distinct disparity between the calculated curves and the experimental points in the region where the slope is changing rapidly ( is chosen for the intercept on the $\mathrm{r} / \mathrm{c}$ axis, $\mathrm{k}_{1}$. Thus, the values of $K_{1}$ and $K_{2}, n_{1}$ and $n_{2}$ should not be interpreted too literally, but they do serve to indicate that a small number of sites with high intrinsic afrinity exists and that a considerably larger number of sites have affinities a great deal lower. It is of interest, in this connection, that the heterogeneity of the sites on DNA which combex acriflavine is not described by the continuous distrioutions of binding energies considered by $\operatorname{sins}(79,30)$

As we have noted, the three methods, all based on the ilass Law treatment of multinle equilibria (section IIl. A.), which were employed for the calculation of $\mathrm{k}_{\mathrm{I}}$, commonly used as a basis of comparison in cases where the one-constant agsumption does not arply, give results which are in satisfactory agreement. Horeover, no noticeable trend appears in the deviations of the values of $k_{1}$ calculated by any one of the methods from the average values, and the deviations are very probably attributable to uncertainties in extrapolating the data to $c=0$. These 
uncertainties, for the experiments reported here, were a good deal smaller than the differences betwe the equilibrium constants $k_{1}$ for different environmental conditions, but, if greater accuracy were required, partition analyses could be carried out at somewhat lower dye concentrations than were measured in this investigation if a larger cell and bigger slits were employed for fluorescence measurements in the dilute range. N-hexanol seems very well suited for the study of the DNA-gcriflavine system by partition analysis: There is no indication that it interferes in the interaction, since equilibrium dialysis experiments confirm the partition analysis results, and since the independent fluorescence quenching method yielog essentially the same results for $k_{1}$. In addition, the variation of partition coefficient with acriplavine concentration is in the proper direction to facilitate measurement at low equilibrium concentrations of the dye. The partition coeficients misht be incroased by the addition of some suitable compound to the organic phase, which, however, would not affect the Diva or its interaci: on with acriflavine. The modificaiion developed here of the method used by Oster (07) to calculate an equilibrium constant for the DA-acriflavine assoclation from fluorescence quenching ${ }^{\circ}$ data takes into account the multiple equilibria 
involved in the binding and permits the determination of values for $k_{l}$ which agree with the partition analysis results. It is indicated, therefore, that the quenchingslope procedure provides a relatively rapid and reliable method for the determination of $k_{1}$, not only for the Diva-acriflavine complexing, but also, perhaps, for other interacting systems involving multiple equilibria where fluorescence quenching occurs to an appreciable extent and where a limiting slope at infinitely low quencher concentration can be determined.

It has been mentioned that the method suggested for the calculation or $c$ and, hence, $r$ from quenching data (equation [19]) cannot be anplied to the DiA-acriflavine system except, with proper caution, to roveal the order of magnitude of the binding under conditions such that the binding is not too great. 'The princioal reason for the failure of the method appears to be the variation in $p$ with the relative concentrations of the interactants, the value of $p$ increasing as the concentration of dye relative to the concentration of Did decreases. Ilhis variation is not evident from the quenching curves reported by Uster (67), partly, perhaps, because of differences in the samples of DNA and acriflavine studied, and partiy because Oster's work was carried out at a diye concentration an order of magnitude higher than the hishest concentration used in the present study. If it may be assumed 
that the quantum yield of fluorescence of the free dye remains constant in the presence of DNA, while the yield for the bound molecules depends upon the strength of binding at the sites, then the fact that $p$ is not constant would tend to confirm that the binding sites are heterogeneous with respect to their affinities for acriflavine, and the indicated variation in $p$ would mean that the fluorescence quenching due to interaction at the most active binding sites, those taken up first, is less than that due to binding at sites of lower intrinsic affinity. In view of the hypothesis, mentioned by Bowen (95), that fluorescence quenching is usually accompanied by strong van der vals forces betwe n interacting molecules, it might be sugosted, tontatively, that eloctrostatic forces are relatively more important in the binding at the very active sites. This is in conformity with the view expressed by Cavalieri and Anselas (59) that the more active sites involve secondary phosphate proups, while the ones of lower affinity involve primary groups. At hieh concentrations of dye relative to the DwA concentration, there are indications of' some phenomenon which causes quenching of the dye in adition to the quenching due to interaction with DiA; that is, no value of $p$, not even

(95) E. J. Bowen, uuart. Kev. I, I (1947). 
$p=0$, will yield a value of $r$ calculated according to equation [19] low enough to agree with the partition analysis results in the range of high dye concentration. Although this apparent excess quenching was not investigated further, the explanation might be suggested that aggregation of acriflavine molecules and the attendant selif-quenching occurs in the presence of the alighing forces of the charged Div macromolecule at lower dye concentrations than when DNA is aissent.

The results for $k_{1}$ presented in Tables $I$ and II and in Figure 16 show that the value for the first equilibrium constant is high under any of the conditions studied. For example, the value at $\mu=0.1$, pH 7 , nd $25^{\circ} \mathrm{C}, \mathrm{k}_{1}=$ $3.3 \times 10^{5}$, nay be compared with $2 k_{1}$ of approximately $2.2 \times 10^{3}$ for the binding of rosaniline by DIA under almost the same experinental conditions calculated from the data of Cavalieri and Angelos (59), using the same concentration units as wero employed in this report. Binding constants for other DWA interactions are sumnarized in the paper of Allenby and Collier (úl), and these, too, are considerably lower than those founc for the iystem tudied here, but it should be remembered that comparisons must be made with caution in view of the considerable variation in the LAA preparations used in ginding studies. Since, as is the case in most binding studies of this type, the values reported for $n$ are estimates 
only, based upon the uncertain extrapolation to $\mathrm{r} / \mathrm{c}=0$, it would be of little value to make a detailed comparison with the values given by other workers. It suffices to say that the value of 0.5 for $n$ at $\mu=0.002$, $\mathrm{pH} 7$, and $25^{\circ} \mathrm{C}$. Is in the neighborhood of the results obtained by Cavalier1, et al. (60) for the two dyes whose binding to DNA they studied in the absence of added salt, and by shack, et al. (4.2), for the binding of sodium ions. The eflect on $k_{1}$ of decreasing the $\mathrm{pH}$ from 7 to

5.5 is opposite to that found by Cavalieri and Angelos (59) for the binding of rosaniline. Very probably, the decrease in binding affinity with decraasing pH in the acriflavine-DNA case is in large part due to the increased competition of hydroren ions for the bindins sites. on the other hand, since rosaniline is not a quaternary salt, the shift in equilibrium in favor of the ionized hydrochloride at the lower pf would account for the increased binding, observed.

Thie very marked dependence of $k_{1}$ upon ionic strength indicates, of course, that the interaction between D A and acriflavine is essontially electrostatic in nature. It is evident, however, as uster (ú7) pointed out, that secondary forces play a very large part in the interaction. First, as we have noted, quenching of fluorescence upon interaction indicates strong van der waals bonding between the quencher and the fluorescent compound (95), and the 
rather large negative values found for $\Delta \mathrm{H}_{1}{ }^{\circ}$ are in accord with this hypothesis. Then, we may infer from the qualitative results with several organic cations, and from the other information on DNA complexing available (section II. c.), that binding by DNA is favored for molecules which ofier oportunities for secondary interactions; for example molecules with Iong hydrocarbon chains, as in the case of the alkyl pyridinium salts, or with several aromatic rings (ou), especially if these aro coplenar.

In contrast with the results of Cavalieri and Angelos (59) on rosaniline binding to Div and with the majority of findings in quantitative studies of protein complexing that there are large positive entropy changes on interaction in these casos, the entropy chanie, $\Delta s^{\circ}$, for the formetion of the first Lid-Acriflavine complex is found to be zero, within experimental error, according to the partition analysis rosults presented here. From his investigation of the tempereture dependence of cluorescence quenching, Oster (07), too, concluded that the entropy change is zero. It appears, then, that borpeaching structural chanies do not ocom when acriflevine interacts with DUA, as they are not believed to occur on nucleic acia-protein interaction (51).

For this reason, and, also, because equilibrium is reached very rapidly in the Dil-acriflavine system, it would seem that a proposed structural configuration for the 
DNA macromolecule should place the charged phosphate groups so that they would be readily accessible for electrostatic interaction without $?$ great deal of configurational change. Several DNA structures suggested (section II. B.), the structure of Crick and watson $(40)$ included, satisf requirement. A structure similar to the one proposed by Crick and watson, in addition, allows that the planar hydrocarbon portion of a molecule such as acriflavine slip between successive paraliel planes occupied by the purine and pyrimicine bases, the quaternary nitrogen of the molecule oriented tward the INA phosphate croup, thus permitting strong van der wals bonding in addition to the electrostatic interaction without requiring much change in the conpiantion of the rin nolecule. In this connection, it migrit je sug ested that a licht scatterine investigation of the DNA-acriflavine interaction would, perhaps, yield information on the molecular weicht, shape, and other properties of the complex, as compared to those of unreacted DHA, which would aid in the interpretation of binding data in terms of molecular structure. It is to be hoved that bindine studios involving molecules tailored so as to reveal steric factors, and others employing DNA preparations which have been modified chemically or enzymatically, will contribute in revealing details of the macromolecular configuration of DNA as it exists under various environmental conditions. 


\section{Summary}

1. The interaction between purified acriflavine and the high molecular weight sample of DNA prepared was found to be reversible in the concentration range where soluble complexes are formed.

2. Determinations of the amount of binding were made at several values of ionic strength, pit, and temperature over a wide range of free acriflavine concentrations by the method of partition analysis, using n-hexanol as the organic solvent. Results from several equilibrium dialysis experiments are in agreement with those obtained from partition analysis.

3. The data from partition analysis shows that the binding sites on DwA are heterogeneous with respect to their intrinsic affinities for acriflavine, and theoretical binding curves calculated on the basis that two groups of sites exist, each characterized by a single intrinsic: association constant, fit the binding date satisfactorily. 4. Three, methods, all based on the hass Law treatment of multiple equilibria, were employed to calculate $k_{1}$, the equilibrium constant for the formetion of the first InAacriflavine complex, from the partition analysis data. For each set of experimental conditions, the values of $k_{1}$ calculated according to the three metrods agree within the limits of the uncertainty in extrapolatine to zero free acriflavine concentration. 
5. The maximum number of sites availble to the acriflavine molecule per DNA phosphate group is estimated to be 0.5 at $\mu=0.002$ and $\mathrm{pH} 7$.

6. Measurements of the quenching of the fluorescence of acriflavine by DNA under different experimental conditions were used to calculate values for $k_{1}$. A modification of a treatment by Oster (ó7) of f'luorescence quenching was developed which takes into account the multiple equilibria concept for complexing; by a molecule with a number of independent binding sites. Application of this quenchingslope method yields values for $k_{1}$ in agreement with the independent partition analysis results. 7. The values for $k_{1}$ obtained by the two experimental techniques under the different experjmental conditions investieated are: at $\mathrm{pH} 7$ and $25^{\circ} \mathrm{C}, \mathrm{k}_{1}=49 \times 10^{5}$ at $\mu$ $=0.002,3.3 \times 10^{5}$ at $\mu=0.10$, and $1.1 \times 10^{5}$ at $\mu=$ 0.30 ; at pri 5.5, $\mu=0.10$, and $25^{\circ} \mathrm{C}, \mathrm{k}_{1}=1.9 \times 10^{5}$; and at $4 \mathrm{O}_{\mathrm{C}}, \mu=0.10$, and $\mathrm{pH}^{2}, \mathrm{k}_{1}=9.4 \times 10^{5}$.

8. kl decreases somewhat with a decrease in pi from 7 to 5.5, probably because of increased competition of hydrocen ions for the binding sites.

9. The decrease in $k_{1}$ with increasing ionic strength, which is very marked at low ionic strength, testifies to the essentially electrostatic nature of the DNA-acriflavine interaction. 
10. The evidence, from this work and from literature sources, indicates that secondary binding forces play an important role. Nolecules which interact strongly with polymerized DNA usually of fer opportunities for extensive van der Waals bonding. In addition, fluorescence quenching, such as occurs on the interaction of Diva with acridines, is believed to occur when van der vals interactions between the fluorescent and quenching molecules are strong. The relatively large negative value of $\Delta \mathrm{H}_{1}{ }^{\circ}$ found for the DNA-acriflavine system, about - d kcal./mole, is indicative of van der wals binding. 11. $\Delta s_{1} 0$ is zero within experimental error, indicating that the macromolecular configuration of DivA does not change significantly upon interaction with acriflavine. 12. The findings reported here are generally consistent with a macromolecular structure for Di A like that proposed by Crick and watson $(\lfloor, 0)$. 


\section{APPENDIX}

\section{- TABLE III}

Fluorescence - Extinction Data

\section{Organic Layer}

\begin{tabular}{|c|c|c|c|c|c|}
\hline$E_{470}$ & Forg. & Range & $E_{470}$ & Forg. & Range \\
\hline $\begin{array}{l}.00368 \\
.00382 \\
.00401 \\
.00602 \\
.00654 \\
.00802 \\
.00981 \\
.0105 \\
.0115 \\
.0120 \\
.0160 \\
.0180 \\
.0207 \\
.0371 \\
.0382 \\
.0401\end{array}$ & $\begin{array}{l}19.3 \\
20.9 \\
21.7 \\
31.4 \\
34.6 \\
41.1 \\
19.2 \\
51.7 \\
24.0 \\
54.7 \\
25.3 \\
59.0 \\
27.3 \\
59.3 \\
27.5 \\
77.3 \\
35.8 \\
89.0 \\
41.1 \\
46.1 \\
78.8 \\
17.1 \\
82.8 \\
18.1 \\
81.3\end{array}$ & $\begin{array}{l}.0001 \\
.0001 \\
.0001 \\
.0001 \\
.0001 \\
.0001 \\
.0002 \\
.0001 \\
.0002 \\
.0001 \\
.0002 \\
.0001 \\
.0002 \\
.0001 \\
.0002 \\
.0001 \\
.0002 \\
.0001 \\
.0002 \\
.0002 \\
.0002 \\
.001 \\
.0002 \\
.001 \\
.0002\end{array}$ & $\begin{array}{l}.055 \\
.0601 \\
.0763 \\
.0779 \\
.0981 \\
.101 \\
.106\end{array}$ & $\begin{array}{l}17.6 \\
24.2 \\
27.0 \\
34.4 \\
33.3 \\
43.1 \\
43.2 \\
45.2\end{array}$ & $\begin{array}{l}.001 \\
.001 \\
.001 \\
.001 \\
.001 \\
.001 \\
.001 \\
.001\end{array}$ \\
\hline
\end{tabular}


TABLE III (continued)

Aqueous Layer

\begin{tabular}{|c|c|c|c|c|c|}
\hline $\mathrm{E}_{452}$ & $F_{2 q}$ & Range & $\mathrm{E}_{452}$ & $F_{a g}$. & Range \\
\hline \multicolumn{3}{|c|}{$\mu=0.002, p^{\mathrm{HI}} ?$} & \multicolumn{3}{|c|}{$\mu=0.1, \mathrm{p}^{\mathrm{H}} \quad 5.5$} \\
\hline $\begin{array}{l}.00205 \\
.00409 \\
.00614 \\
.00818 \\
.0123 \\
.0164 \\
.0170 \\
.0409 \\
.0579 \\
.0851 \\
.102\end{array}$ & $\begin{array}{l}14.3 \\
29.5 \\
42.6 \\
19.7 \\
55.4 \\
25.6 \\
83.0 \\
38.2 \\
52.1 \\
55.9 \\
26.8 \\
37.9 \\
50.0 \\
62.1\end{array}$ & $\begin{array}{l}.0001 \\
.0001 \\
.0001 \\
.0002 \\
.0001 \\
.0002 \\
.0001 \\
.0002 \\
.0002 \\
.0002 \\
.001 \\
.001 \\
.001 \\
.001\end{array}$ & $\begin{array}{l}.00198 \\
.00396 \\
.00594 \\
.00792 \\
.0119 \\
.0158 \\
.0198 \\
.0396 \\
.0594 \\
.0891 \\
.100\end{array}$ & $\begin{array}{l}16.6 \\
31.9 \\
47.5 \\
21.8 \\
61.0 \\
28.0 \\
40.9 \\
53.0 \\
63.5 \\
27.2 \\
38.0 \\
52.8 \\
59.5\end{array}$ & $\begin{array}{l}.0001 \\
.0001 \\
.0001 \\
.0002 \\
.0001 \\
.0002 \\
.0002 \\
.0002 \\
.0002 \\
.001 \\
.001 \\
.001 \\
.001\end{array}$ \\
\hline \multicolumn{6}{|c|}{$\mu=0.1, \& 0.3, p^{H} \quad 7$} \\
\hline $\begin{array}{l}.00203 \\
.00393 \\
.00655 \\
.00765 \\
.00917 \\
.0121 \\
.0203 \\
.0262 \\
.0655 \\
.0765 \\
.0917 \\
.121\end{array}$ & $\begin{array}{l}18.1 \\
36.1 \\
57.5 \\
26.4 \\
65.1 \\
29.9 \\
79.0 \\
36.2 \\
46.8 \\
78.0 \\
17.0 \\
20.6 \\
48.1 \\
55.2 \\
65.0 \\
80.7\end{array}$ & $\begin{array}{l}.0001 \\
.0001 \\
.0001 \\
.0002 \\
.0001 \\
.0002 \\
.0001 \\
.0002 \\
.0002 \\
.0002 \\
.001 \\
.001 \\
.001 \\
.001 \\
.001 \\
.001\end{array}$ & $i$ & $\cdot$ & \\
\hline
\end{tabular}


111.

TABLE IV

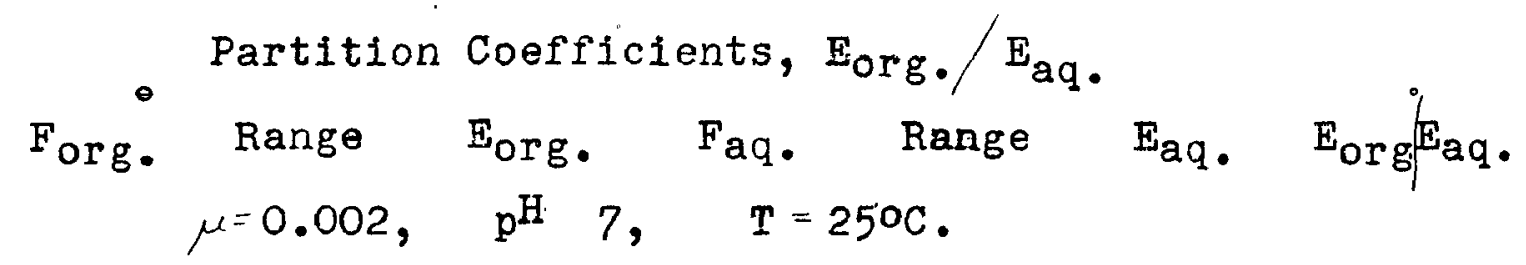

\begin{tabular}{|c|c|c|c|c|c|c|}
\hline 1. $\quad 58.6$ & .0001 & .0115 & 7.7 & .0001 & .0011 & 10.7 \\
\hline $\begin{array}{ll}\text { 2. } & 50.7 \\
3 . & 78.5\end{array}$ & $\begin{array}{l}.0002 \\
.0002\end{array}$ & $\begin{array}{l}.0232 \\
.0377\end{array}$ & $\begin{array}{l}16.9 \\
37.6\end{array}$ & $\begin{array}{l}.0001 \\
.0001\end{array}$ & $\begin{array}{l}.0024 \\
.00539\end{array}$ & $\begin{array}{l}9.80 \\
6.94\end{array}$ \\
\hline 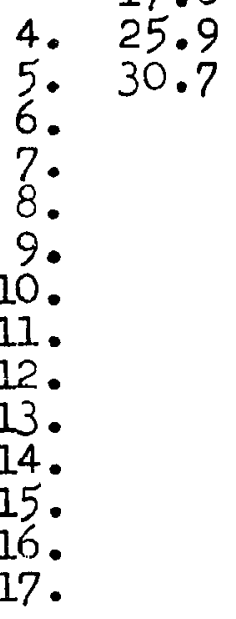 & .001 & $\begin{array}{l}.0574 \\
.0688 \\
.0915 \\
.103 \\
.119 \\
.144 \\
.187 \\
.228 \\
.285 \\
.317 \\
.385 \\
.437 \\
.494 \\
.549\end{array}$ & $\begin{array}{l}69.8 \\
40.8 \\
14.8 \\
20.3 \\
27.0 \\
39.0\end{array}$ & $\begin{array}{l}.0001 \\
.0002 \\
.001 \\
.001 \\
.001 \\
.001\end{array}$ & $\begin{array}{l}.0103 \\
.0127 \\
.0222 \\
.0307 \\
.0410 \\
.0600 \\
.108 \\
.187 \\
.340 \\
.482 \\
.721 \\
1.009 \\
1.16 \\
1.46\end{array}$ & $\begin{array}{r}5.69 \\
5.42 \\
4.12 \\
3.34 \\
2.90 \\
2.40 \\
1.73 \\
1.22 \\
.838 \\
.658 \\
.534 \\
.433 \\
.426 \\
.376\end{array}$ \\
\hline
\end{tabular}

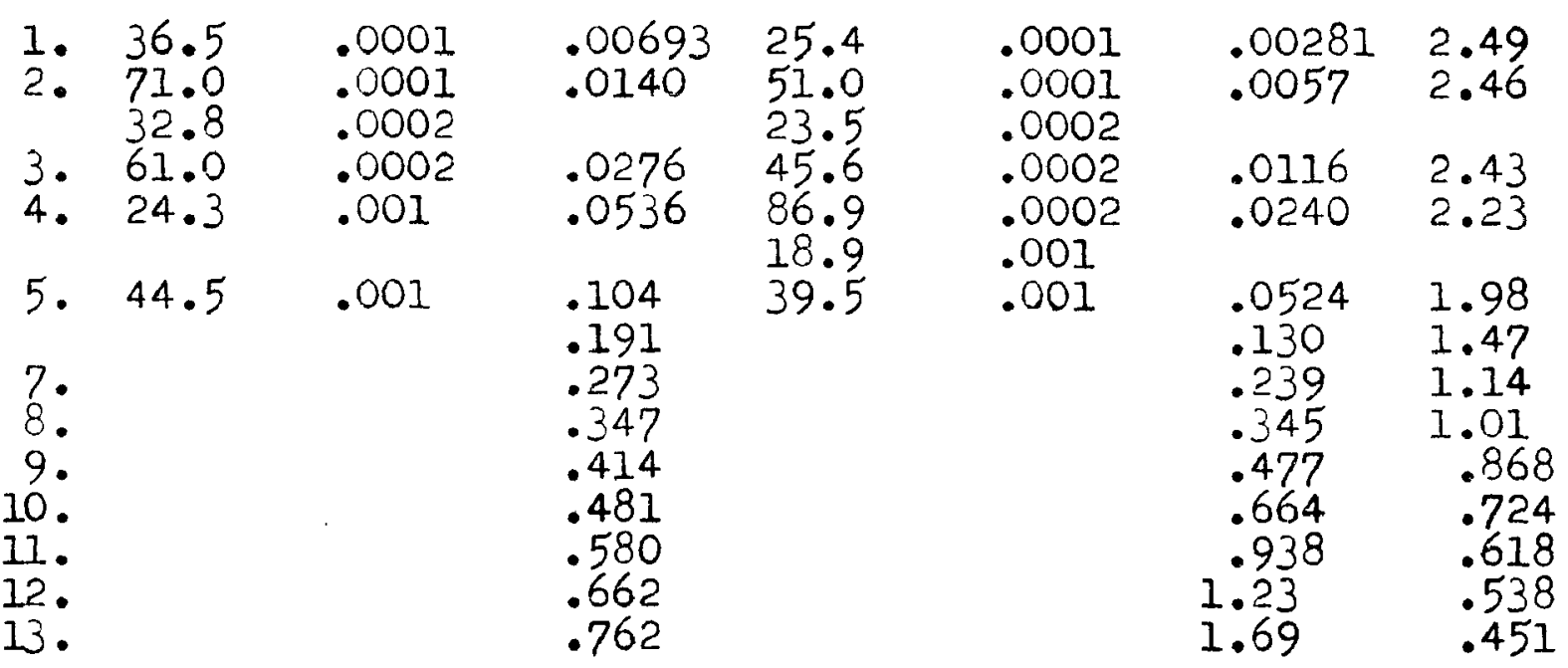


112.

TABLE IV (continued)

Forg.

Range

Eorg. $F_{a q}$. Range $E_{a q}^{\circ}$ E $E_{\text {org }} E_{a q}$. $\mu=0.3, \quad \mathrm{pH} \quad 7, \quad \mathrm{~T}=25 \mathrm{O}^{\circ} \mathrm{C}$.

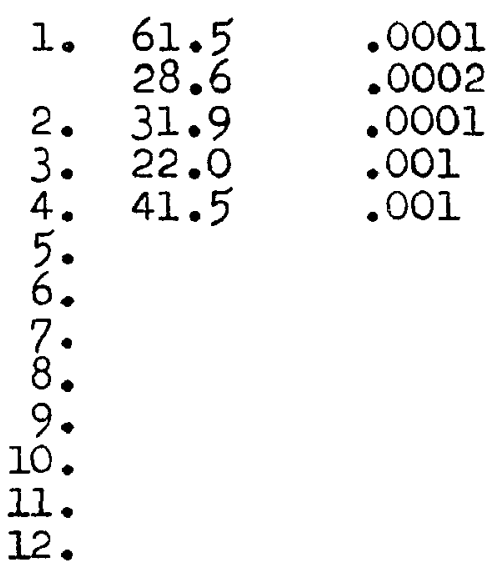

1. 64.7

30.0

2. 55.6

3. 23.0

4. 43.3

5.

6.

8.

10.

11.

12 .
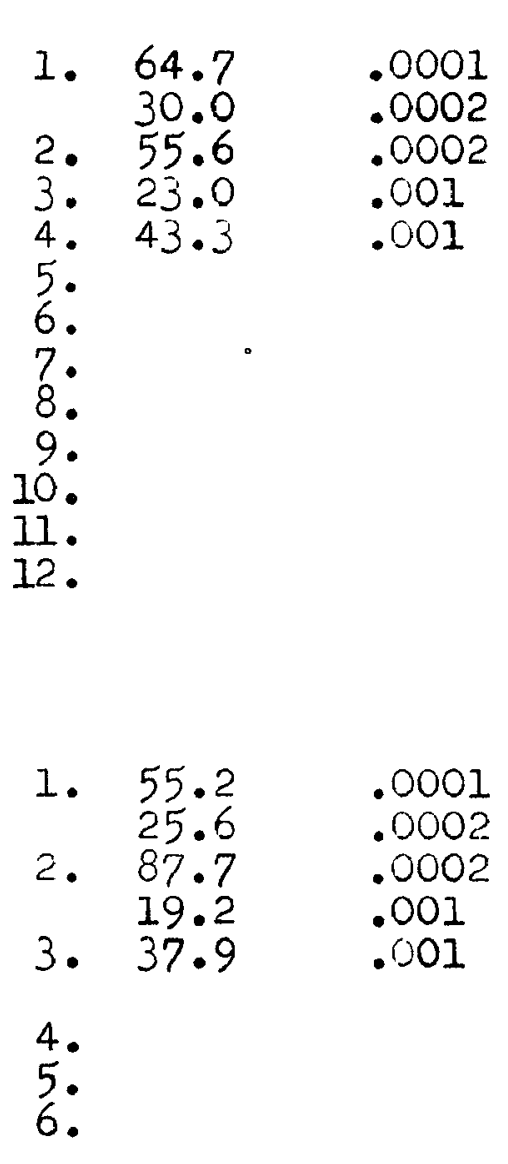

$\mu=0.1$

.0121 .000602

.0483

.0959

.190

.271

.370

-. 442

.550

.648

.781

.890

\section{$55 \cdot 3$}

55.3
25.4
28.0

28.0

21.0
41.5

.0001
.0002
.0001
.001
.001

$\begin{array}{ll}.00616 & 1.96 \\ .00307 & 1.96 \\ .0271 & 1.78 \\ .0551 & 1.74 \\ .131 & 1.45 \\ .200 & 1.36 \\ .322 & 1.15 \\ .404 & 1.09 \\ .603 & .912 \\ .765 & .847 \\ 1.103 & .708 \\ 1.33 & .692\end{array}$

pH $5.5 \quad \mathrm{~T}=250^{\circ} \mathrm{C}$.

$\begin{array}{llll}41.2 & .0001 & .005212 .44\end{array}$

$18.9 \quad .0002$

$37.2 \quad .0002$

$15.9 \quad .001$

$32.5 \quad .001$

$.0107 \quad 2.39$

.0256

.0506

.1007

.202

.298

.399

.501

.599

.741

.856

59.5

.001

$.0227 \quad 2.23$

.04832 .08

$.101 \quad 2.00$

$.171 \quad 1.74$

$.261 \quad 1.53$

$.370 \quad 1.35$

.4951 .21

.7131 .04

$\begin{array}{ll}.924 & .926 \\ 1.25 & .822\end{array}$

$$
\mu=0.1, \quad \mathrm{p}^{\mathrm{H}} \quad 7, \quad \mathrm{~T}=25^{\circ} \mathrm{C} .
$$

.0001

.0107

$21.7 \quad .0001$

.002374 .51

$\begin{array}{lllll}.0423 & 38.4 & .0002 & .00970 & 4.36\end{array}$

.0002

.001

.0884

84.7

18.4

.0002

.02223 .98

.182

42.8

.001

.001

.0573
.129
.225

3.18

2.33
1.77 
TABLE IV (continued)

\begin{tabular}{|c|c|c|c|c|c|c|}
\hline$F_{\text {org }}$. & Range & $\mathrm{E}_{\text {org }}$. & $F_{a q}$. & Range & $\mathrm{E}_{\mathrm{aq}}$. & $E_{o r g} E_{a q}$ \\
\hline $\begin{array}{l}7 . \\
8: \\
9 \\
10 \\
11 \\
12 .\end{array}$ & & $\begin{array}{r}.501 \\
.630 \\
.719 \\
.837 \\
.919 \\
1.038\end{array}$ & & & $\begin{array}{l}.358 \\
.566 \\
.736 \\
1.028 \\
1.25 \\
1.65\end{array}$ & $\begin{array}{l}1.40 \\
1.11 \\
.977 \\
.814 \\
.735 \\
.629\end{array}$ \\
\hline
\end{tabular}


Partition Analysis: $\mu=0.002, \mathrm{p}^{\mathrm{H}} 7, \mathrm{~T}=25^{\circ} \mathrm{C},,[\mathrm{NA}]_{\mathrm{o}}=.005 \%$

$$
\begin{gathered}
k_{\text {aq. }}=1720 \\
r=.147\left[E_{o}-.735 \quad E_{\text {org. }}-E_{\text {aq. }} \cdot\right] \\
\frac{r}{c}=\left(4.52 \times 10^{4}\right) \frac{\hat{t}_{\text {aq. }}}{\mathrm{E}_{\text {aq }}}
\end{gathered}
$$

$\begin{array}{llllll}\text { Eo }_{\text {O }} & \text { Forg. } & \text { Range } & \text { E }_{\text {org. }} & \mathbf{r} & \frac{\mathbf{r}}{c} \times 10^{-5} \\ .228 & 28.5 & .0001 & .0055 & .0327 & 31.1 \\ .317 & 52.7 & .0001 & .0102 & .0451 & 21.6 \\ .400 & 78.1 & .0001 & .0157 & .0565 & 16.4 \\ .467 & 47.2 & .0002 & .0204 & .0659 & 13.9 \\ .544 & 65.1 & .0002 & .0300 & .0759 & 9.57 \\ .641 & 83.7 & .0002 & .0400 & .0888 & 7.38 \\ .715 & 23.8 & .001 & .0524 & .0979 & 5.24 \\ .975 & 27.8 & .001 & .0617 & .135 & 5.32 \\ 1.30 & 36.9 & .001 & .0840 & .178 & 3.97 \\ 1.69 & & & .125 & .228 & 2.28 \\ 2.37 & & & .197 & .307 & 1.10\end{array}$


TABLE VI

Partition Analysis: $\mu=0.1, \mathrm{p}^{\mathrm{H}} 7, \mathrm{~T}=250 \mathrm{C},[\mathrm{NA}]_{0}=.005 \%$

$$
\begin{gathered}
\mathrm{k}_{\mathrm{aq} .}=1810 \\
\mathrm{r}=.139\left[\mathrm{E}_{\mathrm{o}}-.774 \text { Eorg. }-\mathrm{E}_{\mathrm{aq} .}\right] \\
\mathrm{r} / \mathrm{c}=(4.75 \times 104) \cdot \mathrm{r} / \mathrm{E}_{\mathrm{aq} .} .
\end{gathered}
$$

$\begin{array}{llllll}E_{O} & F_{\text {org. }} & \text { Range } & E_{\text {org. }} & r & r / c \times 10-5 \\ .806 & 22.5 & .0001 & .0043 & .0112 & 3.24 \\ .170 & 52.0 & .0001 & .0101 & .0220 & 2.67 \\ .215 & 64.1 & .0001 & .0126 & .0278 & 2.68 \\ .260 & 36.7 & .0002 & .0158 & .0335 & 2.54 \\ .302 & 44.5 & .0002 & .0194 & .0388 & 2.38 \\ .375 & 59.2 & .0002 & .0274 & .0477 & 2.03 \\ .505 & 87.4 & .0002 & .0421 & .0631 & 1.67 \\ .675 & 30.1 & .001 & .0673 & .0824 & 1.32 \\ .865 & & & .0967 & .103 & .996 \\ .970 & & & .126 & .112 & .757 \\ 1.20 & & & .167 & .134 & .608 \\ 1.40 & & & .225 & .147 & .416 \\ 1.695 & & & .292 & .168 & .306 \\ 2.15 & & & .399 & .193 & .202 \\ 3.025 & & & .585 & .224 & .111 \\ 5.00 & & & .958 & .250 & .048\end{array}$




\section{TABLE VII}

Partition Analysis: $\mu=0.3, \mathrm{pH}^{\mathrm{H}} 7, \mathrm{~T}=250^{\circ} \mathrm{C},[\mathrm{NA}]_{0}=.005 \%$ $\mathrm{k}_{\mathrm{aq} \cdot}=1810$ $r=.139\left[E_{0}-.774\right.$ Erg. $\left.-E_{a q .}\right]$ $\mathrm{r} / \mathrm{c}=\left(4.75 \times 10^{4}\right) \cdot \mathrm{r} / \mathrm{E}_{\mathrm{aq}}$.

$\begin{array}{llllll}\text { Eo }_{\text {o }} & \text { Forg. } & \text { Rang } & \text { E }_{\text {org }} & \text { r } & \mathrm{r} / \mathrm{c} \times 10^{-5} \\ .047 & 26.8 & .0001 & .00503 & .0057 & 1.066 \\ .080 & 50.8 & .0001 & .00975 & .0094 & .897 \\ .154 & 45.4 & .0002 & .0199 & .0178 & .821 \\ .311 & 20.0 & .001 & .0439 & .0352 & .700 \\ .456 & 33.6 & .001 & .0758 & .0492 & .538 \\ .720 & & .127 & .0755 & .455 \\ .945 & & & .193 & .0923 & .332 \\ .970 & & & .194 & .0955 & .341 \\ 1.495 & & & .357 & .127 & .199 \\ 1.515 & & & .383 & .123 & .175 \\ 2.70 & & & .728 & .167 & .085 \\ 3.66 & & & .979 & .177 & .052 \\ 3.71 & & & .971 & .187 & .055\end{array}$


TABLE VIII

Partition Analysis: $\mu=0.1, \quad \mathrm{p}^{\mathrm{H}} \quad 5.5, \quad \mathrm{~T}=25^{\circ} \mathrm{C}, \quad[\mathrm{NA}]_{0}=.005 \%$

$$
\begin{aligned}
& \mathrm{k}_{\mathrm{aq} .}=1640 \\
& \mathbf{r}=.154\left[\mathrm{E}_{\mathrm{O}}-.701 \mathrm{E}_{\mathrm{org} .}-\mathrm{E}_{\mathrm{aq} \cdot}\right] \\
& \mathbf{r} / \mathrm{c}=\left(4.31 \times 10^{4}\right) \cdot \mathrm{r} / \mathrm{E}_{\mathrm{aq} .}
\end{aligned}
$$

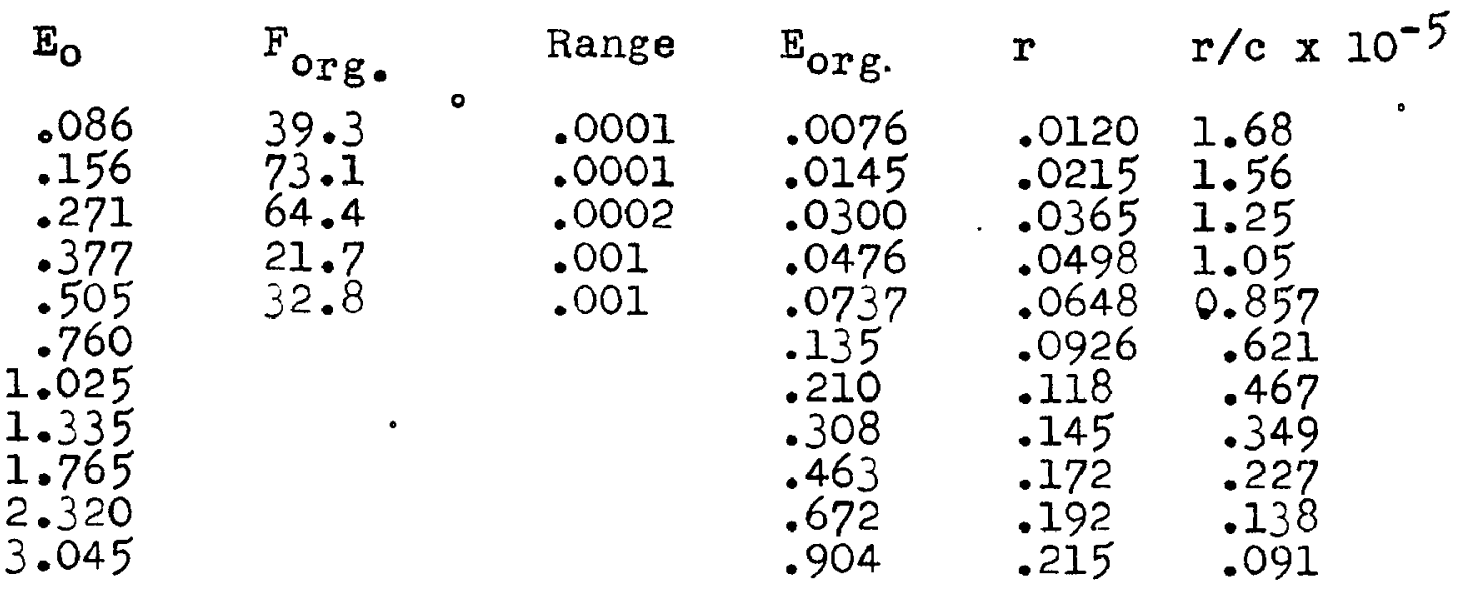


TABLE IX

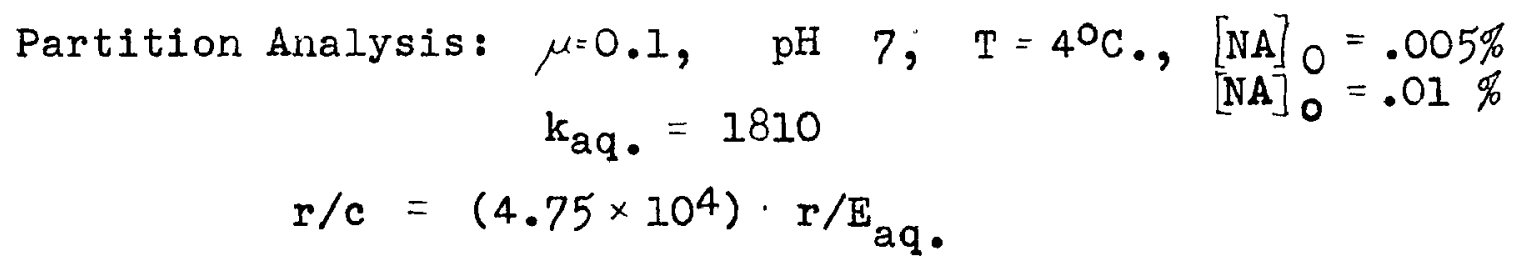

\begin{tabular}{|c|c|c|c|c|c|}
\hline \multirow[t]{2}{*}{$E_{0}$} & Forg. & Range & $E_{\text {org }}$ & $r$ & $\mathrm{r} / \mathrm{c} \times 10^{-5}$ \\
\hline & {$[\mathrm{NA}]_{\mathrm{O}}$} & & $r=.139\left[E_{0}\right.$ & -.774 & $\left.E_{\text {org. }}-E_{a q} \cdot\right]$ \\
\hline \multirow[t]{2}{*}{$\begin{array}{l}.085 \\
.168 \\
.315 \\
.460 \\
.630 \\
.785 \\
1.065 \\
1.365 \\
1.615 \\
2.025 \\
2.850 \\
4.815\end{array}$} & $\begin{array}{l}17.2 \\
36.5 \\
38.3 \\
66.7 \\
24.6 \\
35.3\end{array}$ & $\begin{array}{l}.0001 \\
.0001 \\
.0002 \\
.0002 \\
.001 \\
.001\end{array}$ & $\begin{array}{l}.00320 \\
.00700 \\
.0167 \\
.0312 \\
.0543 \\
.0800 \\
.145 \\
.230 \\
.315 \\
.456 \\
.704 \\
1.113\end{array}$ & $\begin{array}{l}.0114 \\
.0223 \\
.0404 \\
.0596 \\
.0799 \\
.0977 \\
.127 \\
.154 \\
.171 \\
.192 \\
.222 \\
.268\end{array}$ & $\begin{array}{l}8.02 \\
7.11 \\
5.43 \\
4.07 \\
2.98 \\
2.34 \\
1.45 \\
.891 \\
.579 \\
.309 \\
.149 \\
.063\end{array}$ \\
\hline & {$[\mathrm{NA}]_{0}$} & \%, $r=$ & $=.0695\left[\mathrm{E}_{\mathrm{O}}\right.$ & $.774 \mathrm{E}_{\mathrm{O}}$ & $\operatorname{org} \cdot-\mathrm{E}_{\mathrm{aq} \cdot]}$ \\
\hline $\begin{array}{l}1.365 \\
1.615 \\
2.025 \\
2.850 \\
4.815\end{array}$ & $\begin{array}{l}29.2 \\
39.2\end{array}$ & $\begin{array}{l}.001 \\
.001\end{array}$ & $\begin{array}{l}.0652 \\
.0900 \\
.155 \\
.325 \\
.782\end{array}$ & $\begin{array}{l}.0902 \\
.106 \\
.129 \\
.170 \\
.231\end{array}$ & $\begin{array}{r}2.73 \\
2.09 \\
1.35 \\
.544 \\
.125\end{array}$ \\
\hline
\end{tabular}


TABLE $X$

Fluorescence Quenching Data

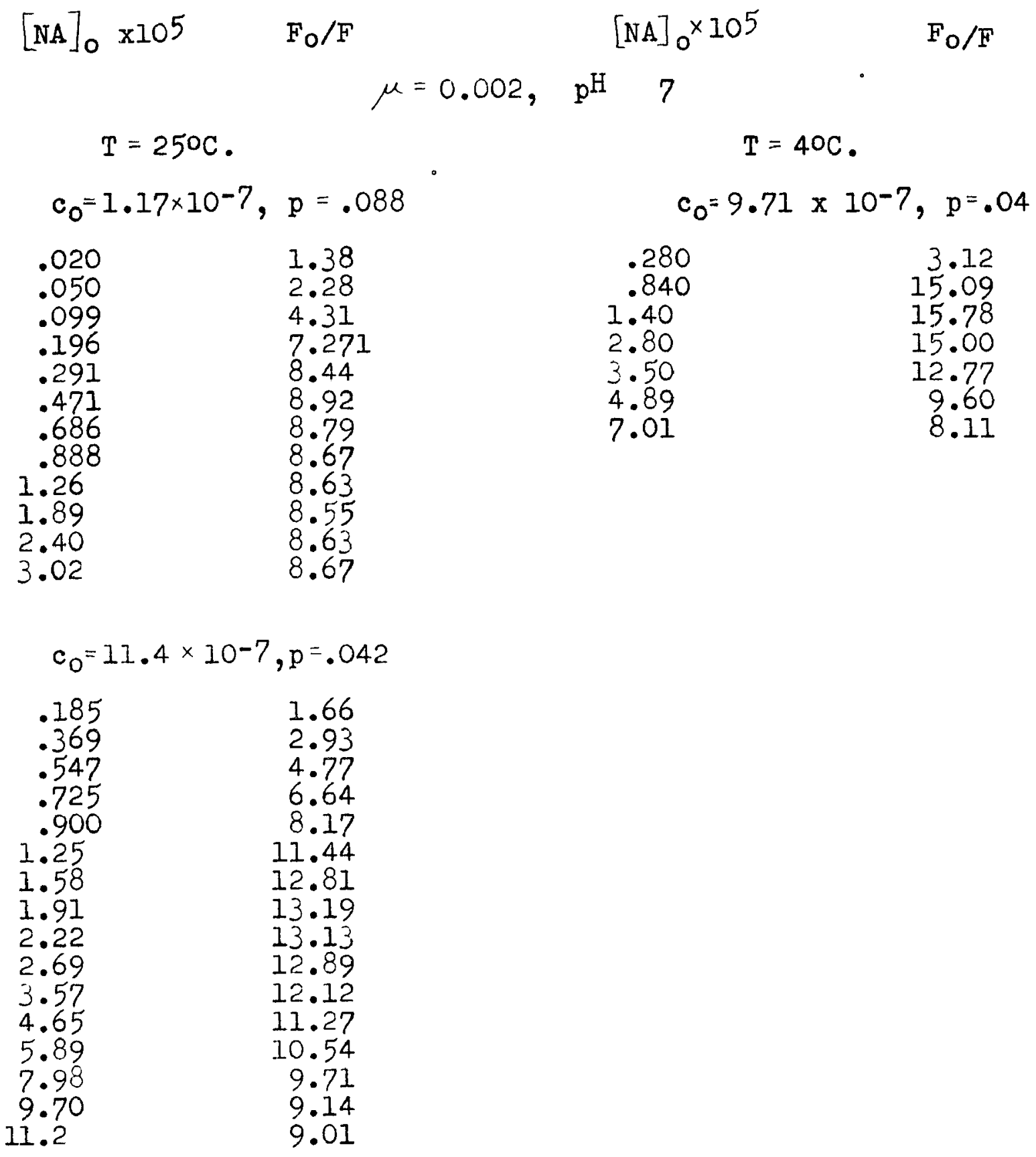


TABLE X (continued)
[NA $]_{0} \times 105$
$\mathrm{F}_{\mathrm{O}} / \mathrm{F}$
[NA] $\times 105$
$F_{0} / F$ $\mu=0.01, \quad \mathrm{p}^{\mathrm{H}} \quad 7$

$$
\begin{gathered}
T=250 \mathrm{C} . \\
C_{0}=11.4 \times 10-7, p=.051
\end{gathered}
$$$$
\begin{array}{r}
.185 \\
.369 \\
.547 \\
.725 \\
.900
\end{array}
$$
1.24
1.58
1.91
2.22
2.54
2.99
3.57
4.38
5.89
7.98
9.79
11.2

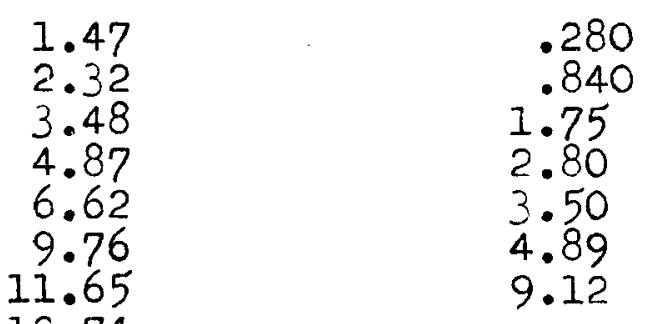
12.74
12.97
13.18
13.04
12.76
12.30
11.61
10.89
10.56
10.30

$$
c_{0}=9.71 \times 10^{-}-\mathrm{G}, \mathrm{p}=.045
$$

$$
\begin{array}{r}
2.00 \\
11.64 \\
14.06 \\
12.11 \\
10.98 \\
9.68
\end{array}
$$

$$
\mu=0.05, \mathrm{p}^{\mathrm{H}} \quad 7
$$

$$
\begin{gathered}
\mathrm{T}=25^{\circ} \mathrm{C} . \\
\mathrm{C}_{\mathrm{o}}=11.4^{\mathrm{T}} 10^{-7}, \mathrm{p}=.088
\end{gathered}
$$

$$
\begin{aligned}
& T=40 \mathrm{C} \\
& c_{0}=11.4 \times 10^{-7}, p=.075
\end{aligned}
$$

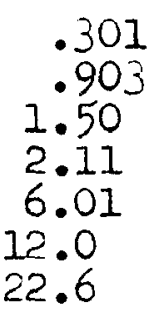

$$
\begin{aligned}
& 1.49 \\
& 2.80 \\
& 4.13 \\
& 5.43 \\
& 8.86 \\
& 8.62 \\
& 8.50
\end{aligned}
$$

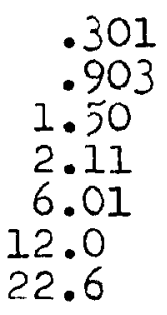
1.76
5.70
8.25
8.55
9.06
8.19
7.89 
TABLE X (continued)

$$
\begin{aligned}
& {[\mathrm{NA}]_{0} \times 10^{-5} \quad \mathrm{~F}_{0} / \mathrm{F} \quad[\mathrm{NA}]_{0} \times 10^{-5} \quad \mathrm{~F}_{\mathrm{O}} / \mathbf{F}} \\
& \mu=0.1, \mathrm{p}^{\mathrm{H}} \quad 7 \\
& \mathrm{~T}=25^{\circ} \mathrm{C} . \\
& c_{0}=1.17 \times 10^{-7}, p=.102 \\
& c_{0}=1.17 \times 10^{-7}, p=.111 \\
& .369 \\
& .731 \\
& 1.45 \\
& 2.17 \\
& 3.49 \\
& 9.31 \\
& 14.0 \\
& 18.1 \\
& 22.3 \\
& 1.86 \\
& 3.91 \\
& \begin{array}{l}
3.91 \\
4.79
\end{array} \\
& 5.87 \\
& 7.96 \\
& 8.57 \\
& 8.89 \\
& 8.94 \\
& c_{0}=6.20 \times 10^{-7}, p=.102 \\
& \begin{array}{l}
.201 \\
.502 \\
.643
\end{array} \\
& .994 \\
& 1.96 \\
& 2.91 \\
& \begin{array}{l}
4.71 \\
8.88
\end{array} \\
& 12.6 \\
& 18.9 \\
& 24.5 \\
& 30.2 \\
& \begin{array}{c}
2.19 \\
3.78 \\
4.46
\end{array} \\
& 5.29 \\
& 6.41 \\
& 6.92 \\
& 7.43 \\
& 7.99 \\
& 8.27 \\
& 8.30 \\
& 8.20 \\
& 8.02
\end{aligned}
$$

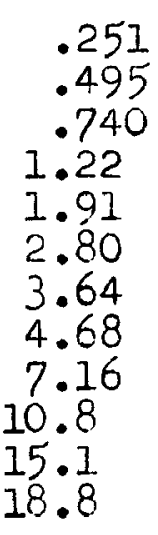

$\begin{array}{ll}c_{0}=11.3 \times 10^{-7}, & p=.102 \\ .366 & 1.49 \\ 1.10 & 2.52 \\ 1.83 & 3.70 \\ 2.56 & 4.63 \\ 4.02 & 6.09 \\ 9.15 & 7.95 \\ 36.6 & 8.34 \\ 73.1 & 8.34\end{array}$


TABLE X (contjnued)

$$
\begin{aligned}
& {[\mathrm{NA}]_{0} \times 10^{-5} \quad \mathrm{~F}_{\mathrm{O}} / \mathrm{F} \quad[\mathrm{NA}]_{0} \times 10^{-5} \quad \mathrm{~F}_{\mathrm{O}} / \mathrm{F}} \\
& \mu=0.3, \mathrm{p}^{\mathrm{H}} \quad 7 \\
& \mathrm{~T}=25^{\circ} \mathrm{C} . \\
& T=4^{\circ} \mathrm{C} \text {. } \\
& c_{0}=1.17 \times 10^{-7}, p=.102 \\
& c_{0}=11.4 \times 10^{-7}, p=.123
\end{aligned}
$$

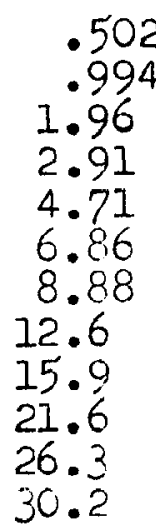

$$
\mu=0.1, \mathrm{pH} 5.5
$$

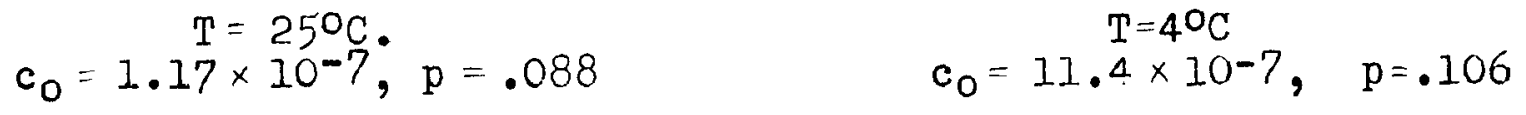

$\begin{array}{rrrr}.201 & 1.43 & .601 & 1.94 \\ .502 & 2.04 & 1.28 & 3.98 \\ .994 & 2.91 & 1.88 & 5.02 \\ 1.96 & 4.13 & 2.48 & 5.87 \\ 2.91 & 4.91 & 6.01 & 6.97 \\ 4.71 & 5.98 & 12.8 & 7.21 \\ 6.86 & 6.76 & 24.8 & 7.04 \\ 8.88 & 7.54 & & \\ 12.6 & 8.20 & & \\ 18.9 & 8.91 & & \\ 24.0 & 9.16 & & \\ 30.2 & 9.38 & & \end{array}$


TABLE X (continued)
$[\mathrm{NA}]_{0} \times 10^{-5}$
$\mathrm{F}_{0} / \mathrm{F}$
$[\mathrm{NA}]_{0} \times 10^{-5}$
$F_{0} / F$
$\mu=0.1, \quad \mathrm{p}^{\mathrm{H}} \quad 5.5$
$c_{0}=1.17=250 \mathrm{C}=7, p=.088$
$\mathrm{T}=4^{\circ} \mathrm{C}$.
$c_{0}=11.4 \times 10^{-7}, \dot{p}=.106$
.601
1.54
1.28
2.40
1.88
2.48
6.01
12.8
30.1
56.5
3.11
3.70
5.76
7.13
7.60
7.54 


\section{AUTOBIOGRAPHY}

I, Harriet Gerletz Heilweil, was born September 8, 1928 in Brooklyn, New York, where I received my primary education. I attended Hunter college High School, 19421948, and then Hunter College, from 1945 to 1948 , when I was granted the degree Bachelor of Arts. In 1948, I began my graduate studies at The Ohio State University, serving as Graduate Teaching Assistant in the period from 1948 to 1950. I was granted an Abbott Laboratories Fellowship for the year 1951-1952 and received the degree Master of science in 1951. During the year 1952-1953, I was an Ohio State University Chemistry Department Fellow. I worked as Research Assistant under a grant from the Unj.ted States Public Health Service in 1950 and 1951 and, again, from 1953 to the present, during, which time I completed the requirements for the degree Doctor of Philosophy. 